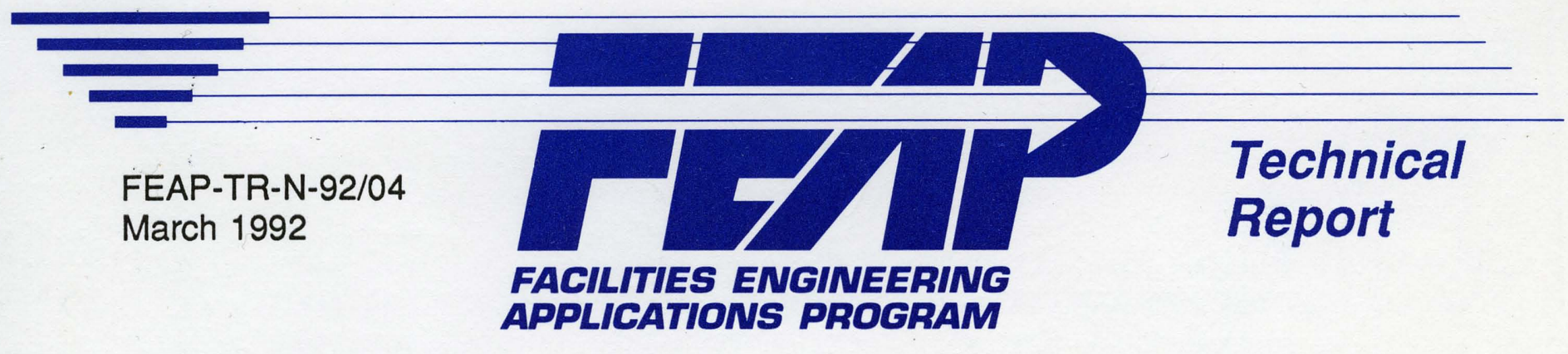

\title{
Application of Carbon Dioxide Treatment To Manage Scale in Building Potable Water Systems
}

by

Richard J. Scholze, Prakash M. Temkar, Ken Rainwater, and John Harwood

U.S. Army Construction Engineering Research Laboratory

Champaign, IL 61824-4005

Approved for Public Release; Distribution is Unlimited.

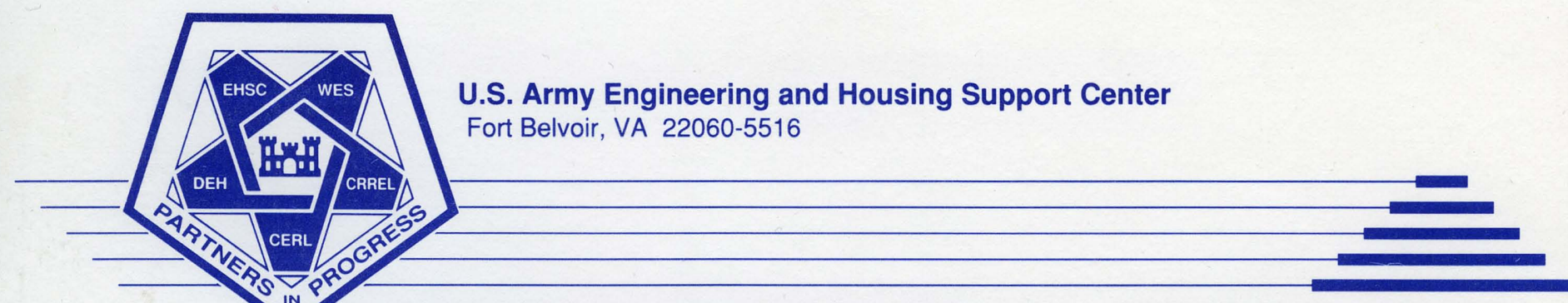

Innovative Ideas for the Operation, Maintenance, \& Repair of Army Facilities 
The contents of this report are not to be used for advertising, publication, or promotional purposes. Citation of trade names does not constitute an official endorsement or approval of the use of such commercial products. The findings of this report are not to be construed as an official Department of the Army position, unless so designated by other authorized documents. 


\section{USER EVALUATION OF REPORT}

\section{REFERENCE: USACERL Technical Report N-92/04, Application of Carbon Dioxide Treatment to Manage Scale in Building Potable Water Systems}

Please take a few minutes to answer the questions below, tear out this sheet, and return it to USACERL. As user of this report, your customer comments will provide USACERL with information essential for improving future reports.

1. Does this report satisfy a need? (Comment on purpose, related project, or other area of interest for which report will be used.)

2. How, specifically, is the report being used? (Information source, design data or procedure, management procedure, source of ideas, etc.)

3. Has the information in this report led to any quantitative savings as far as manhours/contract dollars saved, operating costs avoided, efficiencies achieved, etc.? If so, please elaborate.

4. What is your evaluation of this report in the following areas?

a. Presentation:

b. Completeness:

c. Easy to Understand:

d. Easy to Implement:

e. Adequate Reference Material:

f. Relates to Area of Interest:

g. Did the report meet your expectations?

h. Does the report raise unanswered questions? 
i. General Comments. (Indicate what you think should be changed to make this report and future reports of this type more responsive to your needs, more usable, improve readability, etc.)

5. If you would like to be contacted by the personnel who prepared this report to raise specific questions or discuss the topic, please fill in the following information.

Name:

Telephone Number:

Organization Address:

6. Please mail the completed form to:

Department of the Army CONSTRUCTION ENGINEERING RESEARCH LABORATORY ATTN: CECER-IMT

P.O. Box 9005

Champaign, IL 61826-9005 
Public reporting burden for this collection of information is estimated to average 1 hour per response, including the time for reviewing instructions, searching existing data sources, gathering and maintaining the data needed, and completing and reviewing the collection of information. Send comments regarding this burden estimate or any other aspect of this collection of information, including suggestions for reducing this burden, to Washington Headquarters Services, Directorate for information Operations and Reports, 1215 Jefferson Davis Highway, Suite 1204, Arlington, VA 22202-4302, and to the Office of Management and Budget, Paperwork Reduction Project (0704-0188), Washington, DC 20503. \begin{tabular}{|l|l|l}
\hline 1. AGENCY USE ONLY (Leave Blank) & $\begin{array}{c}\text { 2. REPORT DATE } \\
\text { March } 1992\end{array}$ & $\begin{array}{c}\text { 3. REPORT TYPE AND DATES COVERED } \\
\text { Final }\end{array}$
\end{tabular}

4. TITLE AND SUBTITLE

Application of Carbon Dioxide Treatment to Manage Scale in Building

Potable Water Systems

6. AUTHOR(S)

Richard J. Scholze, Prakash M. Temkar, Ken Rainwater, and John Harwood

7. PERFORMING ORGANIZATION NAME(S) AND ADDRESS(ES)

U.S. Army Construction Engineering Research Laboratory (USACERL)

PO Box 9005

Champaign, IL 61826-9005

9. SPONSORING/MONITORING AGENCY NAME(S) AND ADDRESS(ES)

U.S. Army Engineering and Housing Support Center

ATTN: CEHSC-FU

Fort Belvoir, VA 22060

11. SUPPLEMENTARY NOTES

Copies are available from the National Technical Information Service, 5285 Port Royal Road,

Springfield, VA 22161

12a. DISTRIBUTION/AVAILABILITY STATEMENT

12b. DISTRIBUTION CODE

Approved for public release; distribution is unlimited.

13. ABSTRACT (Maximum 200 words)

The U.S. Army Construction Engineering Research Laboratory (USACERL) has developed a carbon dioxide treatment system to remove scale from potable water systems safely and effectively. This report describes laboratory experiments to optimize the system and presents the results of field demonstration at three sites. Carbon dioxide treatment will also be demonstrated in a dormitory at a university campus; preliminary laboratory work for that project is described.

Information is provided to help installation Directorates of Engineering and Housing (DEHs) test their water supplies and determine the potential for scaling. In addition, generic guidance is presented to assist the DEH in installing, operating, and monitoring a carbon dioxide treatment system.

\begin{tabular}{|c|c|c|c|}
\hline \multirow{2}{*}{$\begin{array}{l}\text { 14. SUBJECT TERMS } \\
\text { drinking water } \\
\text { carbon dioxide treatment }\end{array}$} & \multirow{2}{*}{\multicolumn{2}{|c|}{$\begin{array}{l}\text { scale removal } \\
\text { water treatment }\end{array}$}} & $\begin{array}{l}\text { 15. NUMBER OF PAGES } \\
60 \\
\end{array}$ \\
\hline & & & 16. PRICE CODE \\
\hline $\begin{array}{l}\text { 17. SECURITY CLASSIFICATION } \\
\text { OF REPORT } \\
\text { Unclassified }\end{array}$ & $\begin{array}{l}\text { 18. SECURITY CLASSIFICATION } \\
\text { OF THIS PAGE } \\
\text { Unclassified }\end{array}$ & $\begin{array}{l}\text { 19. SECURITY CLASSIFICATION } \\
\text { OF ABSTRACT } \\
\text { Unclassified }\end{array}$ & $\begin{array}{l}\text { 0. LIMITATION OF ABSTRACT } \\
\text { SAR }\end{array}$ \\
\hline
\end{tabular}

NSN 7540-01-280-5500

Standard Form 298 (Rev. 2-89) Preecribed by ANSI Std 239-18 208-102 
This work was performed for the U.S. Army Engineering and Housing Support Center (USAEHSC) under the FY88 Facilities Engineering Applications Program (FEAP) project "Rehabilitation of $\mathrm{CaCO}_{3}$ Scaled Pipe by $\mathrm{CO}_{2}$ Treatment." The USAEHSC technical monitors were B. Wasserman, CEHSC-FU, and Malcolm McLeod, CEHSC.

The study was conducted by the Environmental Division (EN) of the U.S. Army Construction Engineering Research Laboratory (USACERL). Dr. Edward W. Novak is Acting Chief, EN.

Thanks is expressed to the many individuals and installations who contributed to this project: at Karlsruhe MCA, B. Zuiss, D. Gibbs, and T. Smiley; at Dugway Proving Ground, D. Koffel; at Fort Ord, B. McComas and H. Fields; at Texas Tech, L. Urban; at USACERL, T. Robinson; and especially C. Neff of the Illinois State Water Survey. Thanks also is expressed to V. VanBlaricum of USACERL's Engineering and Materials Division for review and performing the life cycle cost analysis.

COL Daniel Waldo, Jr., is Commander and Director of USACERL, and Dr. L.R. Shaffer is Technical Director. 
1 INTRODUCTION $\ldots \ldots \ldots \ldots \ldots \ldots \ldots \ldots \ldots \ldots \ldots \ldots \ldots \ldots \ldots \ldots \ldots$

$\begin{array}{ll}\text { Background } & 7\end{array}$

\begin{tabular}{ll} 
Objective & 7 \\
\hline
\end{tabular}

\begin{tabular}{ll} 
Approach & 8 \\
\hline
\end{tabular}

$\begin{array}{lr}\text { Scope } & 8\end{array}$

$\begin{array}{lr}\text { Mode of Technology Transfer } & 8\end{array}$

2 EVALUATING SCALING CHARACTERISTICS OF WATER .......... 9

Technical Background $\quad 9$

$\begin{array}{lr}\text { Causes of Scale } & 10\end{array}$

Basic Carbonate Chemistry $\quad 10$

Treatment Practices $\quad 11$

Saturation Indexes $\quad 11$

3 CALCIUM CARBONATE SCALE DISSOLUTION IN WATER STABILIZED BY

CARBON DIOXIDE TREATMENT: MODEL APPLICATION $\ldots \ldots \ldots \ldots \ldots$

$\begin{array}{lr}\text { Model Development } & 12\end{array}$

$\begin{array}{ll}\text { Model Application } & 13\end{array}$

4 CARBON DIOXIDE CONTROL SYSTEM FOR SCALE

REMOVAL IN POTABLE WATER SYSTEMS $\ldots \ldots \ldots \ldots \ldots \ldots \ldots \ldots \ldots \ldots$

$\begin{array}{ll}\text { Operating Principle } & 14\end{array}$

System Components $\quad 14$

$\begin{array}{ll}\text { Summary } & 16\end{array}$

5 FIELD DEMONSTRATION OF CARBON DIOXIDE TECHNOLOGY ....... 19

$\begin{array}{ll}\text { Fort Ord } & 19\end{array}$

Dugway Proving Ground $\quad 23$

$\begin{array}{ll}\text { Karlsruhe MCA } & 28\end{array}$

Summary of Field Tests $\quad$ - 29

6 LABORATORY EVALUATION OF CARBON DIOXIDE IN VERY

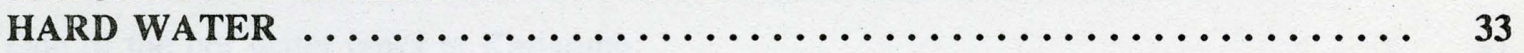

Overview $\quad 33$

$\begin{array}{lr}\text { Study Objectives } & 33\end{array}$

Laboratory Experiments $\quad 33$

Modeling Equilibrium Water Quality $\quad 40$

Installation in Doak Hall $\quad 42$

7 FURTHER LABORATORY EVALUATION $\ldots \ldots \ldots \ldots \ldots \ldots \ldots \ldots \ldots \ldots$

8 INSTALLATION, MONITORING, AND SAFETY $\ldots \ldots \ldots \ldots \ldots \ldots \ldots \ldots \ldots$

Installation and Monitoring $\quad \mathbf{5 2}$

$\begin{array}{ll}\text { Safety } & 52\end{array}$ 
CONTENTS (Cont'd)

9 CONCLUSIONS AND RECOMMENDATIONS METRIC CONVERSION TABLE REFERENCES

APPENDIX: Parts Used in the Dosage Control Panel DISTRIBUTION 


\section{FIGURES}

Number

Page

1 Example of scaled pipe (copper)

2 Schematic of the carbon dioxide treatment system

3 Dosage control panel

4 Electrical connections for dosage control panel

5 Reset timer settings for a 100-gal batch volume

6 Reset timer settings for 200-gal batch volume

$7 \quad$ Injection port

8 Fort Ord scaled heat exchanger

9 Fort Ord scaled sprayer in dishwasher

10 Fort Ord heat exchanger receiving $\mathrm{CO}_{2}$ treatment

11 Dugway Proving Ground scaled heat exchanger before treatment

12 Closeup of the scaled heat exchanger

13 Hot water storage tanks at Dugway Proving Ground

14 Electricontact water meter

15 Carbon dioxide control panel

16 Carbon dioxide tank and regulator setup

17 Heat exchanger after carbon dioxide treatment

18 Schematic of Karlsruhe system

19 One of the hot water tanks at Karlsruhe

20 Carbon dioxide injection system and water bypass

21 Test piece installation at Karlsruhe

22 Scaled pipe samples from Drane Hall

23 Pipe manifold apparatus used in laboratory experiments

24 Effect of carbon dioxide addition on aragonite dissolution 


\section{FIGURES (Cont'd)}

Nunber

Page

25 Effect of carbon dioxide addition on aragonite and dolomite dissolution

26 Scaled pipe samples from Doak Hall

27. Floor plans of the upper residential floors in Doak Hall

28 Device for monitoring scale removal and corrosion

29 Effect of ph 5.5 on metal concentrations

30 Effect of ph 8.5 on metal concentrations

31 Effect of temperature on calcium concentration

32 Effect of temperature on alkalinity concentration

49

33 Effect of temperature on copper concentration

50

34 Effect of $\mathrm{CO}_{2}$ on copper concentration, $25^{\circ} \mathrm{C}$.

50

35 Effect of $\mathrm{CO}_{2}$ on copper concentration, $60^{\circ} \mathrm{C}$.

\section{TABLES}

1 Fort Ord Water Characteristics

2 Monitoring Data From Fort Ord

3 Dugway Proving Ground Water Sample Analysis

4. Average Water Quality in Lubbock Wells, 1944

5 Water Quality of Lubbock Water Supply, June 1989

6 Water Quality Measured in Pipe Manifold Experiments (mg/L)

7 Results of Scale Removal Experiments

$8 \quad$ Results of Corrosion Tests

9 Mineral Equilibrium Analyses for (Old) 1944 and (New) 1989 Water Supplies, at $68{ }^{\circ} \mathrm{C}$ 


\section{APPLICATION OF CARBON DIOXIDE TREATMENT TO MANAGE SCALE IN BUILDING POTABLE WATER SYSTEMS}

\section{INTRODUCTION}

\section{Background}

For Army installations having water sources with high levels of hardness, formation of calcium carbonate scale in hot water lines can cause serious problems. Increased head loss reduces the hydraulic efficiency of hot water delivery piping, and even moderate scale greatly reduces the heating efficiency of tubing in heat exchangers. Extensive deposition can lead to complete failure of the piping systems. Removal and replacement of blocked piping can be very expensive, especially in buildings with limited access to the piping. Chemical treatments with acids have been successful in removing scale in place, but these techniques require extensive downtime and present safety hazards.

The U.S. Army Construction Engineering Research Laboratory (USACERL) has investigated injection of carbon dioxide as an alternative chemical treatment in laboratory and field experiments. ${ }^{1}$ The technique has been shown to be effective in calcium carbonate scale removal and prevention, although care is necessary to prevent pipe corrosion once the scale is completely eliminated. Carbon dioxide is much easier and safer to handle than acidic additives, and the scale removal process requires no system downtime.

Continued research at USACERL examined precipitation/dissolution phenomena of calcium carbonate and carbon dioxide. ${ }^{2}$ That work evaluated scaling indexes and resulted in a computer program (available from USACERL) to optimize application of the carbon dioxide treatment system.

During FY88, the carbon dioxide treatment and control technology was demonstrated as part of the Facilities Engineering Applications Program (FEAP). The successful results indicate that all Army facilities could use carbon dioxide treatment as a safe, effective, low-cost alternative to other methods of scale removal.

\section{Objective}

The objective of this study was to:

1. Present the results of recent laboratory testing and evaluation of the process concepts.

2. Develop analytical modeling techniques for predicting scale dissolution phenomena.

3. Provide procedures that will allow installations to monitor their water supplies to determine the potential for scaling.

4. Describe a general approach as guidance for installations to install, operate, and monitor a carbon dioxide treatment system.

\footnotetext{
${ }^{1}$ T.M. Prakash et al., Carbon Dioxide Treatment for Scale Removal and Control in Potable Water Systems, Technical Report N-87/16/ADA184346 (U.S. Army Construction Engineering Research Laboratory [USACERL], 1987).

${ }^{2}$ P. Temkar, J. Harwood, and R.J. Scholze, Calcium Carbonate Scale Dissolution in Water Stabilized by Carbon Dioxide Treatment, Technical Report N-90/01/ADA218502 (USACERL, 1989).
} 
5. Demonstrate the effectiveness of carbon dioxide treatment for scale dissolution in potable water systems under real world conditions at Army installations.

\section{Approach}

The literature and previous USACERL work were summarized along with the results of recent laboratory testing and evaluation. An analytical modeling approach was developed. For the field demonstration, three sites were selected and the carbon dioxide treatment system was placed in service. The systems were monitored and data were collected for the duration of the test.

\section{Scope}

This report provides information necessary to understand, apply, and evaluate the use of carbon dioxide treatment for prevention and removal of calcium carbonate scale in building water distribution systems. Lessons learned from the field demonstration cover the period 1987 through 1989.

\section{Mode of Technology Transfer}

The carbon dioxide treatment technology has been transferred to the field through the FEAP demonstration. In addition, it is recommended that the information in this report be used to update Technical Manual (TM) 5-813-3, Water Supply, Water Treatment, TM 5-810-5, Plumbing, and O\&M TM5660, Maintenance and Operation of Water Supply, Treatment, and Distribution Systems. 
Guidance has been developed to enable Army installation Directorates of Engineering and Housing (DEHs) to monitor the scaling characteristics of their potable water supply. These procedures will help DEHs determine the potential for a scaling problem in their water treatment and distribution systems.

\section{Technical Background}

Scale formation (Figure 1) in potable water treatment and distribution systems usually is the direct result of a hard water supply. Hard water is common throughout many areas of the United States, Europe, and Asia where Army installations are located. The results of untreated or improperly treated hard water include clogged water distribution lines in buildings (especially hot water lines), increased operating expenses due to inefficiencies, excessive downtime and maintenance, and shortened life expectancies for many system components. Scaling is most prevalent in domestic hot water (DHW) heat exchangers, storage tanks, and plumbing systems of buildings. The most common type of scale in drinking water systems is composed of calcium carbonate.

Most scaling problems do not exhibit readily observable symptoms; for this reason, scaling is not detected until it disrupts system operation. In addition, when a disruption does signal a scaling problem, remedial actions taken to correct it sometimes worsen the situation. Thus, water treatment plant operators and personnel responsible for maintenance of building plumbing systems need a clear understanding of the options available for evaluating scale potential. Waters that show a high potential for scaling can be treated to prevent damage to systems.

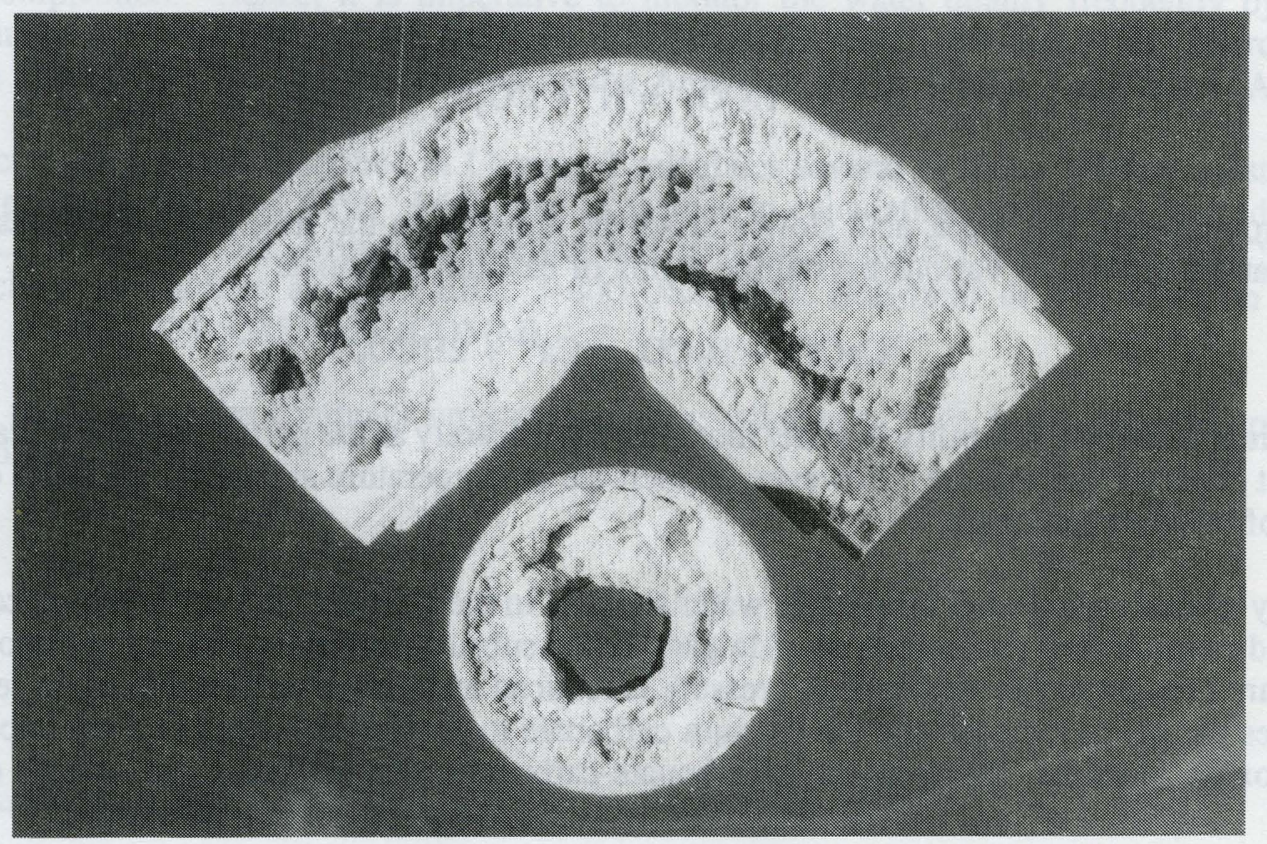

Figure 1. Example of scaled pipe (copper). 


\section{Causes of Scale}

Causes and mechanisms of scale formation are discussed in detail elsewhere; ${ }^{3}$ a brief summary follows. Compounds carried by water as soluble constituents (e.g., calcium carbonate, calcium sulfate, barium sulfate, and silica) may precipitate and form scale as a result of changes within the system, such as pressure drops, temperature variations, flow rate alterations, incompatibility, contamination, $\mathrm{pH}$, fluctuations in water quality, and other phenomena. Water quality can change for several reasons, including seasonal variation in water source, blending of two or more water sources to increase water production, and modification of the water treatment processes. All of these changes can occur almost anywhere water is used or handled such as in heat exchangers, water pipes, and cooling towers.

Mechanisms of scale deposition have been studied extensively in an effort to understand and quantify the process so that remedial and preventive treatments can be developed. At present, there is no universal method for predicting the formation of calcium carbonate scale in a given situation due to the numerous factors that can contribute to the process. However, it is possible to predict the tendency of water to deposit scale by understanding basic carbonate chemistry.

\section{Basic Carbonate Chemistry}

The chemical composition of water is the most important factor in determining if scale will form in a system. Natural waters used for potable or industrial water production always contain a certain amount of dissolved minerals and gases, some of which are undesirable. Carbon dioxide gas plays a vital role in calcium carbonate formation. Water readily absorbs carbon dioxide from both the atmosphere and soil, where the carbon dioxide is formed by microbiological metabolism. Carbon dioxide dissolves in water to form carbonic acid in the following reaction:

$$
\mathrm{CO}_{2}+\mathrm{H}_{2} \mathrm{O}=\mathrm{H}_{2} \mathrm{CO}_{3}
$$

The acid further ionizes as follows:

$$
\begin{aligned}
& \mathrm{H}_{2} \mathrm{CO}_{3}=\mathrm{H}^{+}+\mathrm{HCO}_{3}^{-} \\
& \mathrm{HCO}_{3}^{-}=\mathrm{H}^{+}+\mathrm{CO}_{3}{ }^{2-}
\end{aligned}
$$

In groundwater, this weak acid slowly dissolves minerals in the soil, including limestone, calcite aragonite, and marble - all various crystalline forms of calcium carbonate:

$$
\mathrm{CaCO}_{3}+\mathrm{H}_{2} \mathrm{CO}_{3}=\mathrm{Ca}^{2+}+2 \mathrm{HCO}_{3}^{-}
$$

Calcium carbonate solubility in water increases significantly as the partial pressure of carbon dioxide increases at constant temperature. However, an increase in temperature at constant pressure decreases the solubility of calcium carbonate.

Many groundwaters used for potable water supplies in the United States contain high concentrations of dissolved calcium ions and carbon dioxide gas. When subsurface waters containing dissolved calcium carbonate are brought to the atmosphere, pressure is reduced and excess carbon dioxide is released. Thi event causes the $\mathrm{pH}$ to increase and the calcium carbonate to precipitate. Loss of even trace amounts of carbon dioxide disturbs the water's bicarbonate-carbonate equilibrium. In many cases, water

\footnotetext{
${ }^{3}$ T. Prakash et al.
} 
sources-especially groundwater with high dissolved solids content-are untreated before delivery to consumers. These waters have a greater potential for scale formation than do treated waters.

\section{Treatment Practices}

In the potable water industry, a treatment objective is to stabilize the finished (treated) water so that it is neither scaling nor corrosive to pipes and appurtenances in the distribution system. This "stability" usually is defined in terms of calcium carbonate concentration and most often is assessed using saturation indexes.

Stabilization treatment mainly involves careful adjustment of the alkalinity, calcium hardness, and $\mathrm{pH}$ of the finished water. The stabilized water is slightly scaling, that is, it will deposit and maintain a thin layer of calcium carbonate on the inside surface of water distribution system pipes. This scale layer is actually beneficial because it prevents direct contact between the water and pipe material, thus reducing corrosion.

After a treated water leaves the plant, it can be subjected to environmental conditions that destabilize the carbonate equilibrium. For example, the change in temperature inside heat exchangers can cause water to precipitate calcium carbonate and form scale on the heat exchanger surface.

\section{Saturation Indexes}

The water industry uses calcium carbonate saturation indexes to predict if a particular water is scale-forming. These indexes determine if a water is undersaturated, saturated, or oversaturated with respect to calcium carbonate, thus indicating the water's capacity for calcium carbonate deposition or dissolution. These indexes are expressed in terms of commonly measured characteristics of water quality. Several indexes of calcium carbonate saturation have been proposed, including the Langelier Index (LI), the Ryznar Index (RI), and the Calcium Carbonate Precipitation Potential (CCPP). In using these indexes, it is important to note that the tendency of water to form scale can vary with changes in the water's chemical composition. Hence, it is imperative to monitor the water quality frequently by calculating saturation indexes. These indexes are reviewed in detail elsewhere. ${ }^{4}$ Another useful source of help in using these indexes is a handbook published by the American Water Works Association (AWWA). ${ }^{5}$

The computer model described in Chapter 3 calculates several of these indexes, most importantly the Langelier Index and the CCPP. Additional assistance in calculating the indexes is readily available from USACERL or the U.S. Army Engineering and Housing Support Center (USAEHSC). Points of Contact include the authors at USACERL, 1-800-USACERL (toll-free) or Mr. Malcolm McLeod of USAEHSC at (703) 355-3588/3208 (COMM).

Input required for the computer program includes: alkalinity, $\mathrm{Ca}^{+2}, \mathrm{Mg}^{+2}, \mathrm{pH}$, and optimally total dissolved solids (TDS).

\footnotetext{
${ }^{4}$ P. Temkar et al. ${ }^{5}$ Corrosion Control by Deposition of $\mathrm{CaCO}_{3}$ Films-A Handbook of Practical Application and Instruction (American Water
Works Association [AWWA], 1978).
} 
sources-especially groundwater with high dissolved solids content-are untreated before delivery to consumers. These waters have a greater potential for scale formation than do treated waters.

\section{Treatment Practices}

In the potable water industry, a treatment objective is to stabilize the finished (treated) water so that it is neither scaling nor corrosive to pipes and appurtenances in the distribution system. This "stability" usually is defined in terms of calcium carbonate concentration and most often is assessed using saturation indexes.

Stabilization treatment mainly involves careful adjustment of the alkalinity, calcium hardness, and $\mathrm{pH}$ of the finished water. The stabilized water is slightly scaling, that is, it will deposit and maintain a thin layer of calcium carbonate on the inside surface of water distribution system pipes. This scale layer is actually beneficial because it prevents direct contact between the water and pipe material, thus reducing corrosion.

After a treated water leaves the plant, it can be subjected to environmental conditions that destabilize the carbonate equilibrium. For example, the change in temperature inside heat exchangers can cause water to precipitate calcium carbonate and form scale on the heat exchanger surface.

\section{Saturation Indexes}

The water industry uses calcium carbonate saturation indexes to predict if a particular water is scale-forming. These indexes determine if a water is undersaturated, saturated, or oversaturated with respect to calcium carbonate, thus indicating the water's capacity for calcium carbonate deposition or dissolution. These indexes are expressed in terms of commonly measured characteristics of water quality. Several indexes of calcium carbonate saturation have been proposed, including the Langelier Index (LI), the Ryznar Index (RI), and the Calcium Carbonate Precipitation Potential (CCPP). In using these indexes, it is important to note that the tendency of water to form scale can vary with changes in the water's chemical composition. Hence, it is imperative to monitor the water quality frequently by calculating saturation indexes. These indexes are reviewed in detail elsewhere. ${ }^{4}$ Another useful source of help in using these indexes is a handbook published by the American Water Works Association (AWWA). ${ }^{5}$

The computer model described in Chapter 3 calculates several of these indexes, most importantly the Langelier Index and the CCPP. Additional assistance in calculating the indexes is readily available from USACERL or the U.S. Army Engineering and Housing Support Center (USAEHSC). Points of Contact include the authors at USACERL, 1-800-USACERL (toll-free) or Mr. Malcolm McLeod of USAEHSC at (703) 355-3588/3208 (COMM).

Input required for the computer program includes: alkalinity, $\mathrm{Ca}^{+2}, \mathrm{Mg}^{+2}, \mathrm{pH}$, and optimally total dissolved solids (TDS).

\footnotetext{
${ }^{4}$ P. Temkar et al.

${ }^{5}$ Corrosion Control by Deposition of $\mathrm{CaCO}_{3}$ Films-A Handbook of Practical Application and Instruction (American Water Works Association [AWWA], 1978).
} 


\section{CALCIUM CARBONATE SCALE DISSOLUTION IN WATER STABILIZED BY CARBON DIOXIDE TREATMENT: MODEL APPLICATION}

As part of the overall research examining the use of carbon dioxide treatment for calcium carbonate scale removal and prevention, a computer model was developed to predict the calcium carbonate dissolution characteristics of water stabilized by carbon dioxide treatment. USACERL Technical Report $\mathrm{N}-90 / 01$ describes the development of this theoretical model to predict the effects of carbon dioxide treatment on calcium carbonate scale dissolution in potable waters. That report reviews the various indexes that define the water's ability to dissolve or deposit calcium carbonate. It also examines solution kinetics of calcium carbonate in an attempt to define the rate at which calcium carbonate is dissolved or deposited from a particular water under specific environmental conditions.

Information was needed on the characteristics of scale dissolution to optimize the treatment system because overdoses of carbon dioxide can eventually damage pipes. A theoretical model was formulated and used in developing a computer program for assessing a water's propensity to become undersaturated, saturated, or oversaturated with respect to carbon dioxide, and to determine its capacity for calcium carbonate deposition or dissolution.

\section{Model Development}

Several theoretical models were identified for characterizing calcium carbonate dissolution. Following evaluation of these models, a theoretical model was developed and used to create a computer program in BASIC language to predict the effects of carbon dioxide treatment on potable waters, i.e., the calcium carbonate dissolution characteristics of waters stabilized by carbon dioxide treatment.

The CCPP was concluded to be the index best suited to describe calcium carbonate precipitation and dissolution, showing whether the water is oversaturated, undersaturated, or saturated over the entire range of $\mathrm{pH}$ values. The CCPP has been defined by Merrill and Sanks ${ }^{6}$ to denote the quantity of calcium carbonate that can theoretically be precipitated from oversaturated waters or dissolved by undersaturated waters.

A computer program called "CO2TRT PLOT" was developed from an appropriate theoretical model $^{7}$ to predict a water's dissolution properties under carbon dioxide treatment. Details of development and use are available in USACERL Technical Report N-90/01. The computer program is listed in that report or is available on diskette by contacting USACERL.

The program is written in BASIC language to run on IBM-compatible computers. The program is compiled on a single-sided, double-density, 5.25-in. floppy diskette formatted by MS-DOS. It includes a program to facilitate writing the data input file and a flexible output file that can be read by the graphics or data base management program of the user's choice. Complete instructions, documentation and examples are available with USACERL Technical Report N-90/01.

6 D.T. Merrill and R.L. Sanks, "Corrosion Control by Deposition of Calcium Carbonate Films: A Practical Approach to Plant Operators," Journal of the American Water Works Association (JAWWA), Vol 70, No. 1 (1978).

7 J.R. Rossum and D.T. Merrill, "An Evaluation of the Calcium Carbonate Saturation Indexes," Journal of the American Water Works Association, Vol 75, No. 2 (1983). 


\section{Model Application}

The program computes interim (nonequilibrium) pH, CCPP, and LI over an incremented range of temperatures or carbon dioxide treatment concentrations. The program also computes magnesium hydroxide precipitation potential (MHPP), equilibrium concentrations of alkalinity, $\mathrm{Ca}^{+2}$ and $\mathrm{Mg}^{+2}$, and $\mathrm{pH}$ of treated or untreated waters. Besides carbon dioxide treatment, the program will predict the outcome of treatment with calcium, magnesium, acid, caustic, lime, soda ash, and bicarbonate.

This automated prediction model can be used to optimize the design of carbon dioxide treatment regimens for individual distribution systems. A sample of the water to be treated can be subjected to the computer program to determine the proper dosage based on the water's propensity for becoming undersaturated, saturated, or oversaturated with respect to carbon dioxide and its capacity for calcium carbonate deposition/dissolution.

Program testing and results showed that the program can successfully determine and sustain predetermined $\mathrm{pH}$ levels. The computer model also correctly predicted the effect of temperature on the scaling potential of the various waters tested. 

IN POTABLE WATER SYSTEMS

This chapter describes a carbon dioxide application technique for scale removal and control in potable water systems (domestic hot water heat exchangers, storage, and plumbing) at Army installations. A system is described for proportionate application and control of carbon dioxide dosage in potable water systems using equipment designed to respond to actual water usage.

The required equipment is readily available and relatively inexpensive. However, the treatment program needs to be monitored carefully to control the damaging effects of excessive carbon dioxide dosage. USACERL has developed an optimized system for carbon dioxide application.

\section{Operating Principle}

Carbon dioxide treatment should be applied proportionately by equipment designed to respond to actual water usage when the treated water quality does not vary significantly. Figure 2 summarizes the carbon dioxide treatment system. A water meter equipped with an electricontact switch is installed in the supply piping; this switch activates a timer on the carbon dioxide injection system based on a constant volume of water as determined by the contact interval. The carbon dioxide injection system, activated by the electricontact meter, then injects a constant volume of gas; the gas volume is controlled by the timer mechanism, which keeps the solenoid valve open for a specified time interval. The flow rate of carbon dioxide gas can be fine-tuned by a two-stage pressure regulator and flow-rate meter. This system does not apply carbon dioxide during nonuse periods, which means the water chemistry will be nearly stable under normal operating conditions.

\section{System Components}

Based on the operating principle described above, a carbon dioxide treatment control system was designed for general use in a typical potable water system for a building. The control mechanism consists of four subsystems:

- Carbon dioxide supply system

- Dosage control panel

- Water meter

- Injection port.

\section{Carbon Dioxide Supply System}

The carbon dioxide supply is from a standard commercial-grade carbon dioxide tank. Several tanks can be placed in parallel if heavy use of the system is anticipated. The carbon dioxide tanks should be fitted with a two-stage regulator, the first stage indicating the tank pressure and the second stage showing delivery pressure. The delivery pressure should be at least 15 psi higher than the water pressure at the point where carbon dioxide is injected. Normally, a delivery pressure gauge with a higher limit of 200 psi is adequate. The flow rate of carbon dioxide from the tanks should be measured by a flow-rate meter. A device to prevent backflow should be installed inline so that water does not enter the system due to back pressure. The gas tubing used was copper. Sewage lock fittings for 1/2-in." tubing were also used.

\footnotetext{
- Metric conversion table appears on page 54.
} 

IN POTABLE WATER SYSTEMS

This chapter describes a carbon dioxide application technique for scale removal and control in potable water systems (domestic hot water heat exchangers, storage, and plumbing) at Army installations. A system is described for proportionate application and control of carbon dioxide dosage in potable water systems using equipment designed to respond to actual water usage.

The required equipment is readily available and relatively inexpensive. However, the treatment program needs to be monitored carefully to control the damaging effects of excessive carbon dioxide dosage. USACERL has developed an optimized system for carbon dioxide application.

\section{Operating Principle}

Carbon dioxide treatment should be applied proportionately by equipment designed to respond to actual water usage when the treated water quality does not vary significantly. Figure 2 summarizes the carbon dioxide treatment system. A water meter equipped with an electricontact switch is installed in the supply piping; this switch activates a timer on the carbon dioxide injection system based on a constant volume of water as determined by the contact interval. The carbon dioxide injection system, activated by the electricontact meter, then injects a constant volume of gas; the gas volume is controlled by the timer mechanism, which keeps the solenoid valve open for a specified time interval. The flow rate of carbon dioxide gas can be fine-tuned by a two-stage pressure regulator and flow-rate meter. This system does not apply carbon dioxide during nonuse periods, which means the water chemistry will be nearly stable under normal operating conditions.

\section{System Components}

Based on the operating principle described above, a carbon dioxide treatment control system was designed for general use in a typical potable water system for a building. The control mechanism consists of four subsystems:

- Carbon dioxide supply system

- Dosage control panel

- Water meter

- Injection port.

\section{Carbon Dioxide Supply System}

The carbon dioxide supply is from a standard commercial-grade carbon dioxide tank. Several tanks can be placed in parallel if heavy use of the system is anticipated. The carbon dioxide tanks should be fitted with a two-stage regulator, the first stage indicating the tank pressure and the second stage showing delivery pressure. The delivery pressure should be at least 15 psi higher than the water pressure at the point where carbon dioxide is injected. Normally, a delivery pressure gauge with a higher limit of 200 psi is adequate. The flow rate of carbon dioxide from the tanks should be measured by a flow-rate meter. A device to prevent backflow should be installed inline so that water does not enter the system due to back pressure. The gas tubing used was copper. Sewage lock fittings for 1/2-in." tubing were also used.

\footnotetext{
- Metric conversion table appears on page 54.
} 


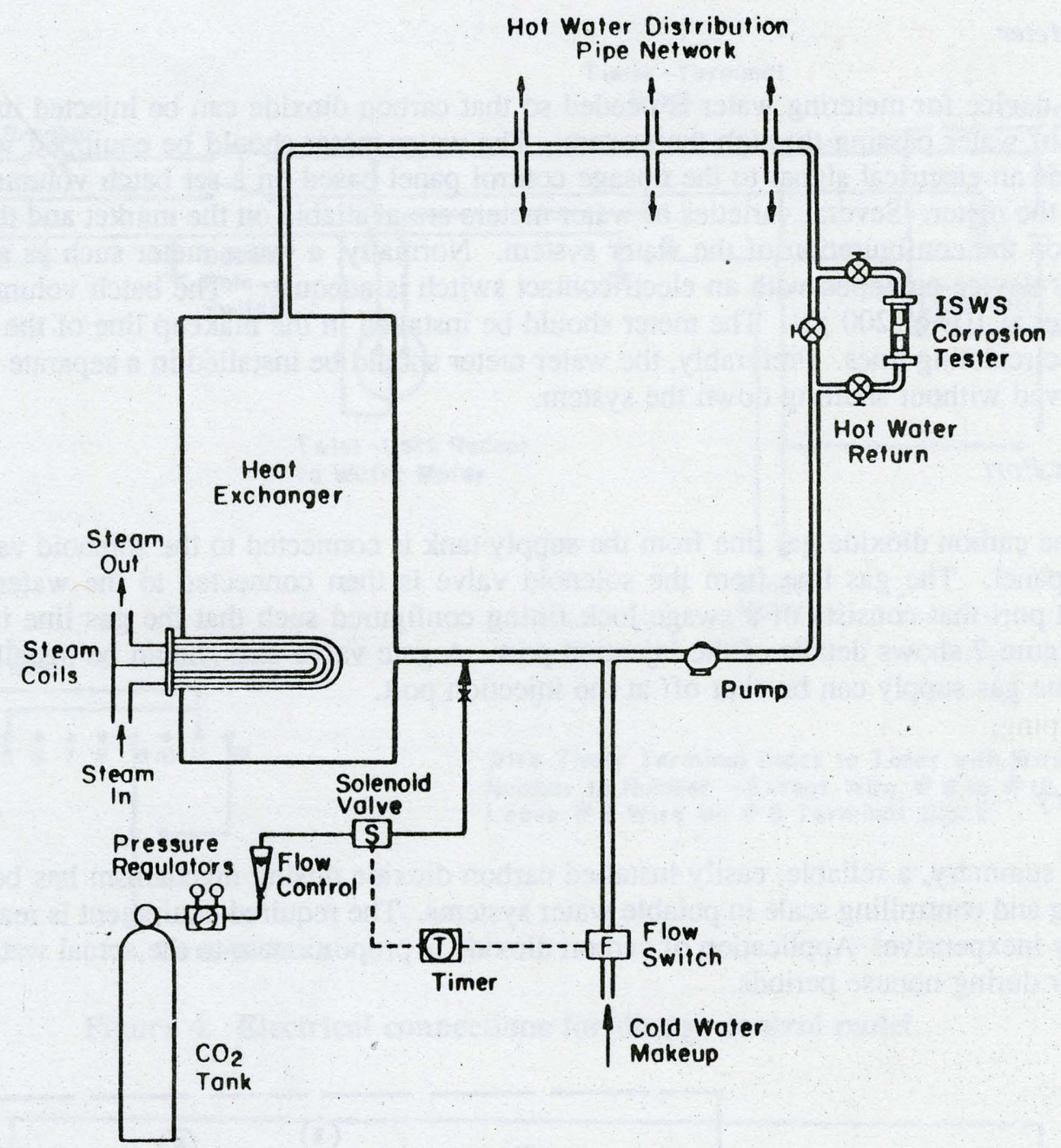

Figure 2. Schematic of carbon dioxide treatment system.

\section{Dosage Control Panel}

A carbon dioxide dosage control panel was designed and assembled for ease of operation and portability. This panel consists of: automatic reset timer, minute timer, contact relay switch, circuit breaker, main switch, and solenoid valve with parts mounted on a plywood panel.

The layout of components shown in Figure 3 and the electrical connections mapped in Figure 4 will allow the DEH to assemble a dosage control panel. Details of components used in the control panel are listed in the Appendix. From the dosage control panel, the carbon dioxide dosage applied to the water system can be controlled by adjusting the time on the automatic reset timer.

Figures 5 and 6 show the dosage applied as a function of time set on the automatic reset timer and carbon dioxide gas flow rate (which can be adjusted separately in the carbon dioxide supply system) for batch volumes of 100 and $200 \mathrm{gal}$, respectively. That is, for every 100 or 200 gal of water passing through the line, a given amount of gas is injected. 


\section{Water Meter}

A device for metering water is needed so that carbon dioxide can be injected in proportion to the amount of water passing through the system. The water meter should be equipped with a microswitch that sends an electrical signal to the dosage control panel based on a set batch volume of water passing through the meter. Several varieties of water meters are available on the market and the one chosen will depend on the configuration of the water system. Normally, a water meter such as a Badger disk or a propeller device equipped with an electricontact switch is adequate. The batch volume on these meters can be set at 100 or 200 gal. The meter should be installed in the makeup line of the water system, not in the recirculating lines. Preferably, the water meter should be installed in a separate loop so that it can be removed without shutting down the system.

\section{Injection Port}

The carbon dioxide gas line from the supply tank is connected to the solenoid valve on the dosage control panel. The gas line from the solenoid valve is then connected to the water system using an injection port that consists of a swage lock fitting configured such that the gas line is inside the water pipe. Figure 7 shows details of the injection port. A gate valve also should be installed in the gas line so that the gas supply can be shut off at the injection port.

\section{Summary}

In summary, a reliable, easily installed carbon dioxide dosing mechanism has been developed for removing and controlling scale in potable water systems. The required equipment is readily available and relatively inexpensive. Application of carbon dioxide is proportionate to the actual water usage and does not occur during nonuse periods.

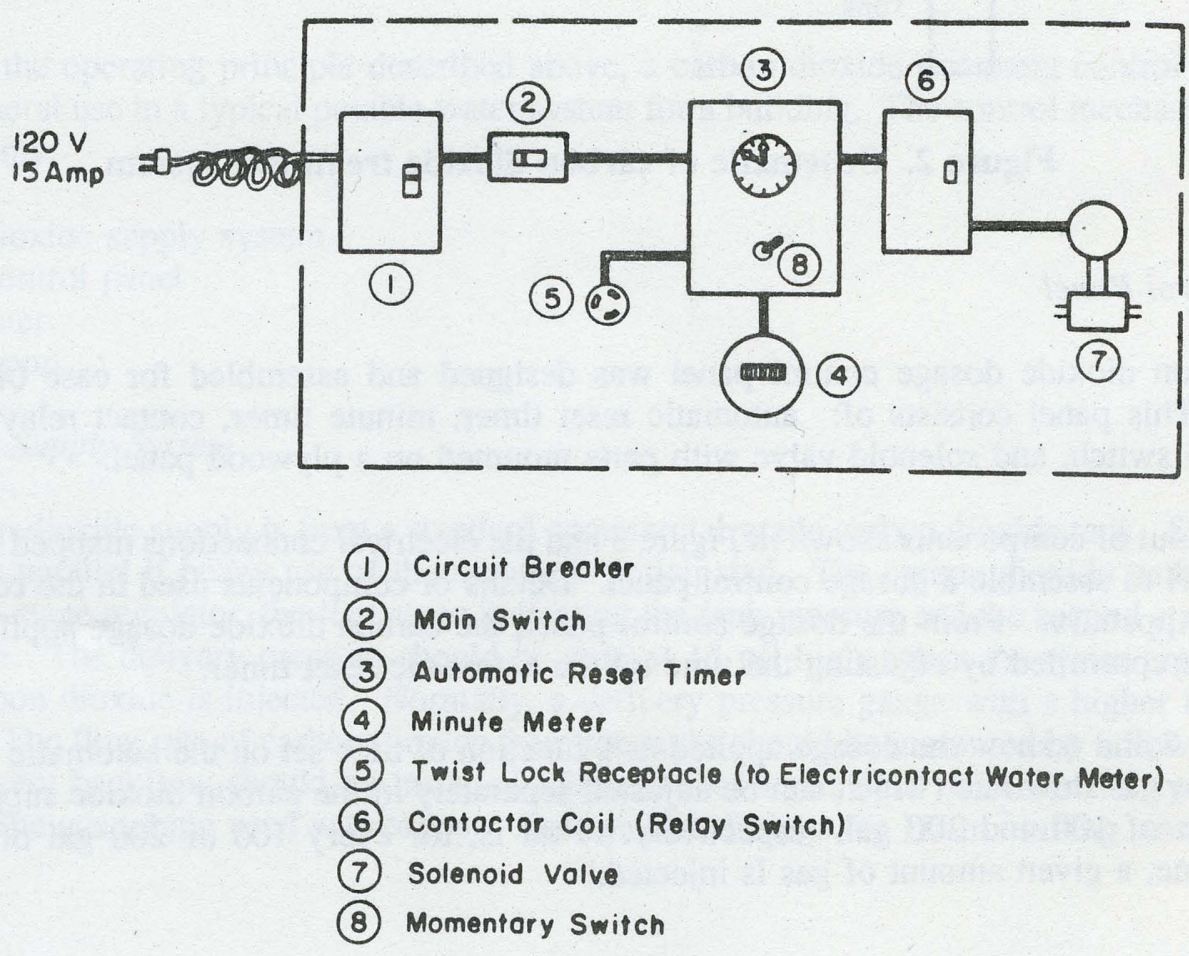

Figure 3. Dosage control panel. 

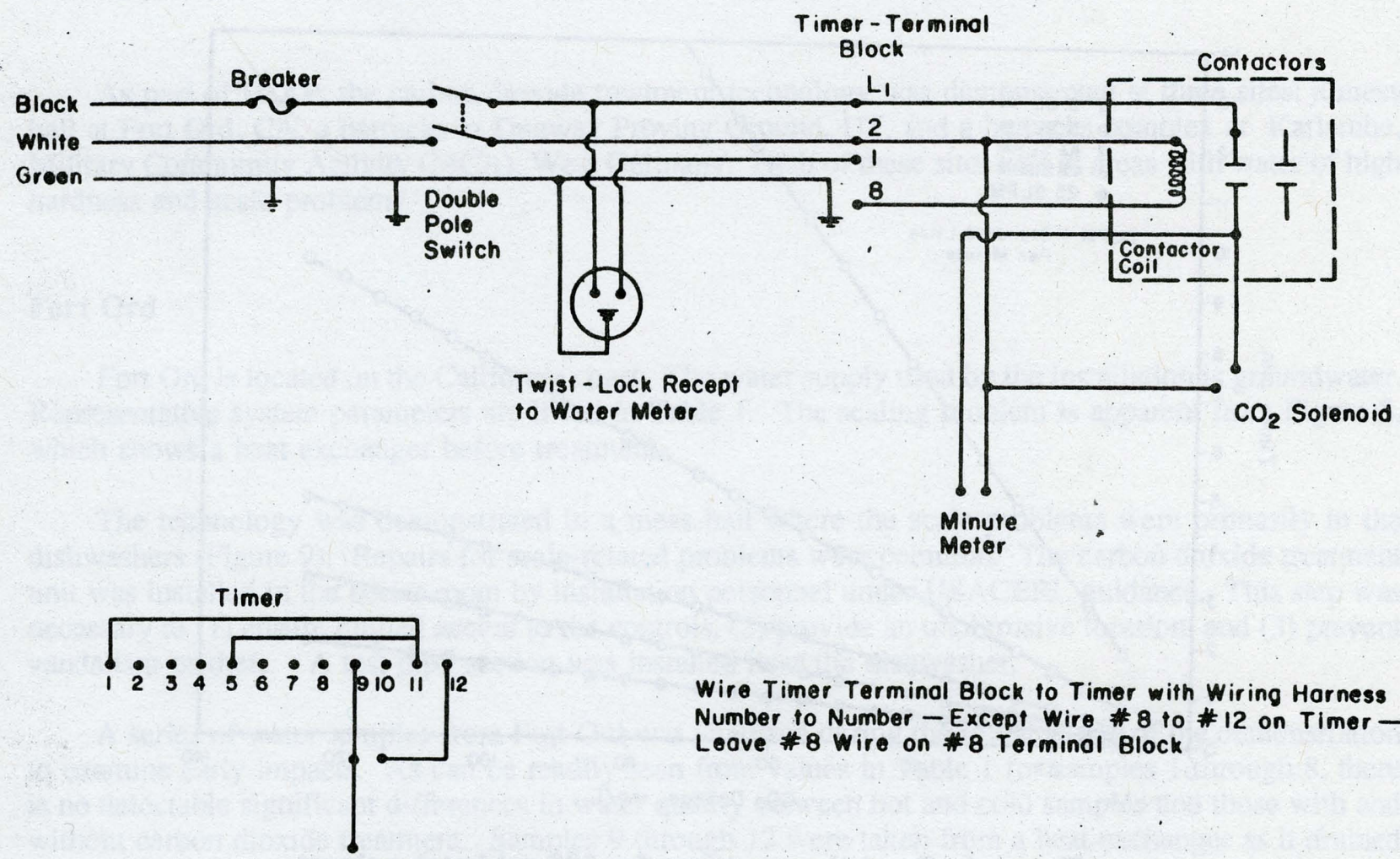

Wire Timer Terminal Block to Timer with Wiring Harness Number to Number - Except Wire \#8 to \#12 on Timer Leave \#8 Wire on \#8 Terminal Block

Figure 4. Electrical connections for dosage control panel.

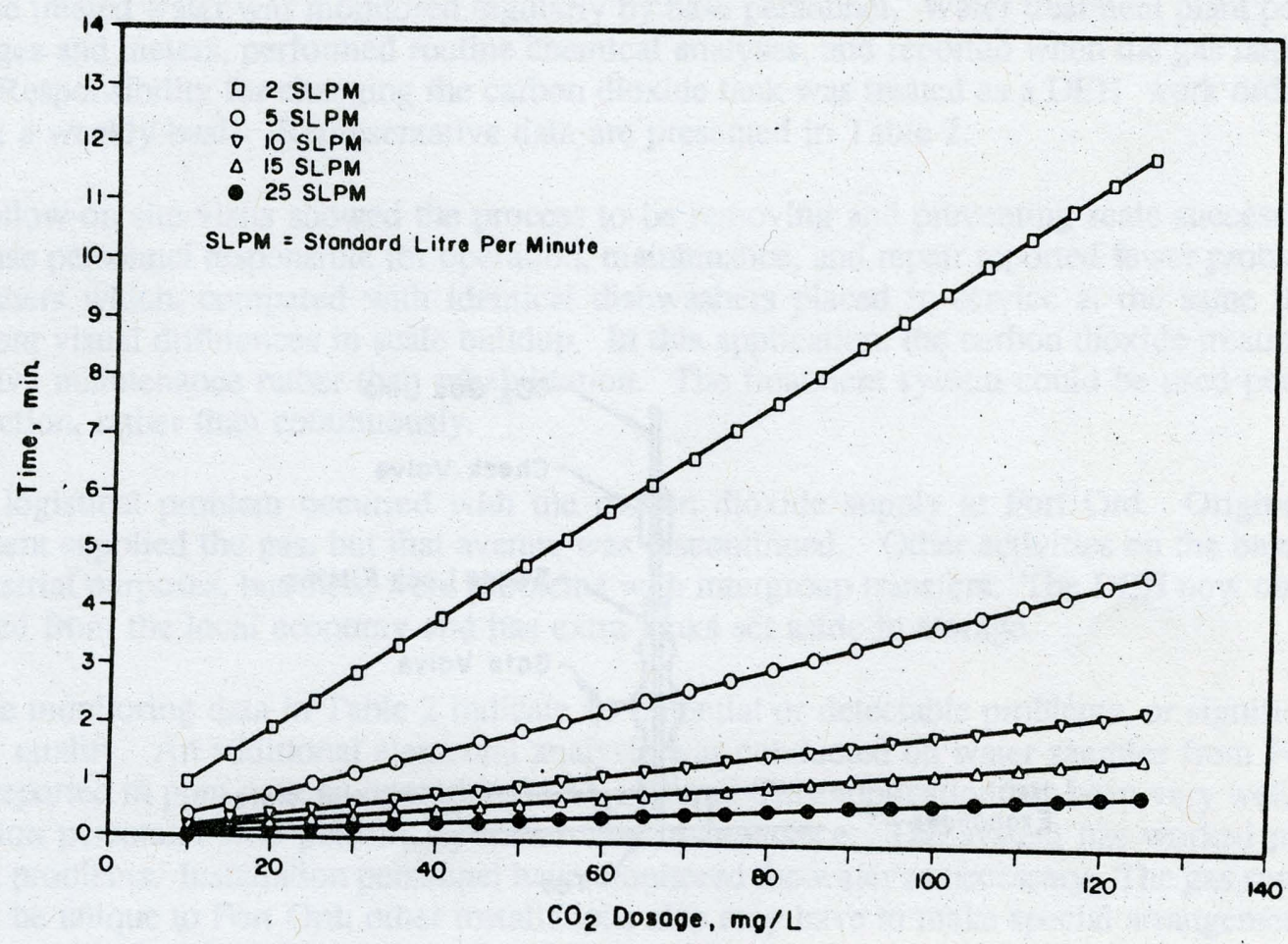

Figure 5. Reset timer settings for a 100-gal batch volume. 


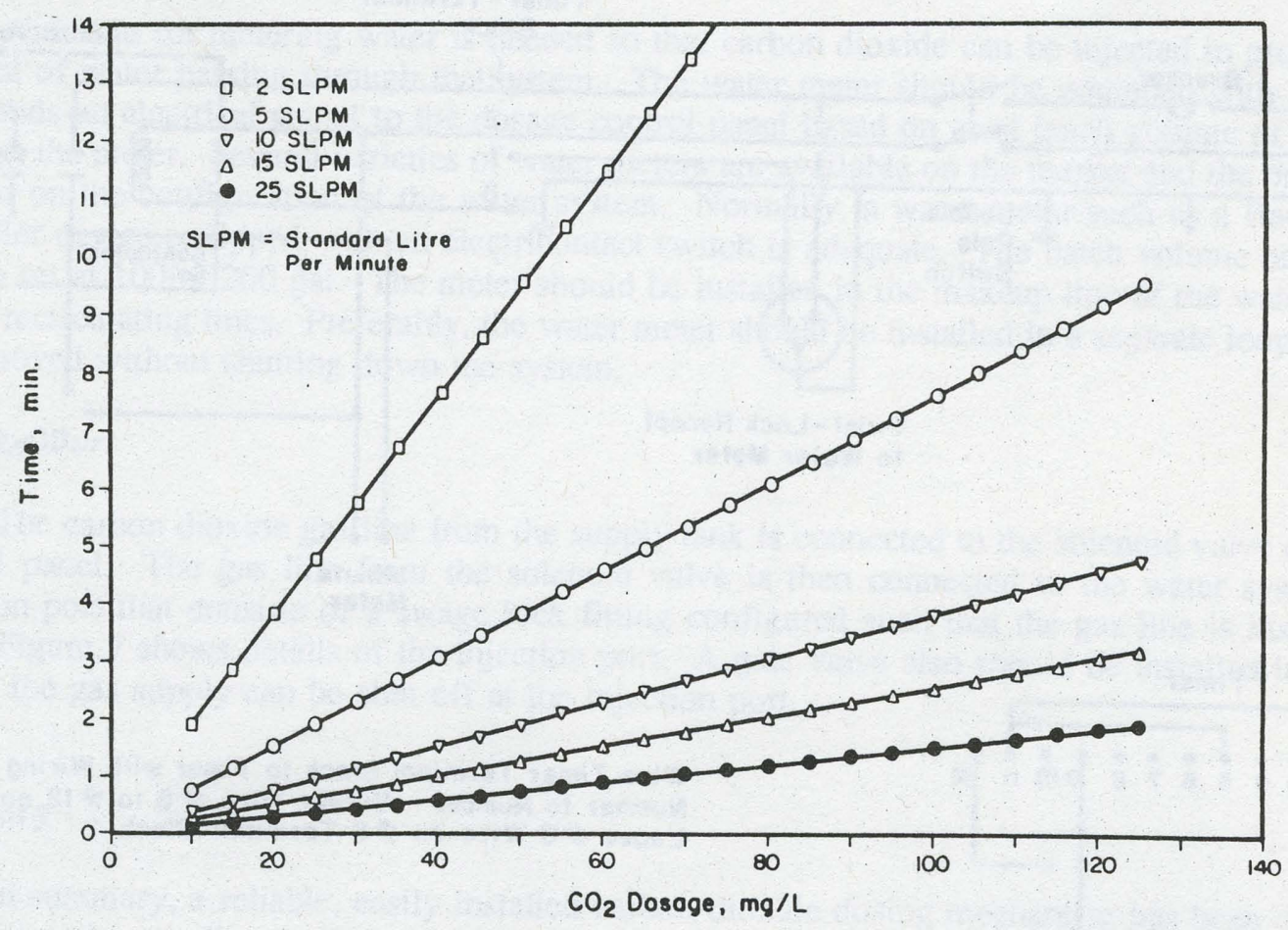

Figure 6. Reset timer settings for 200-gal batch volume.

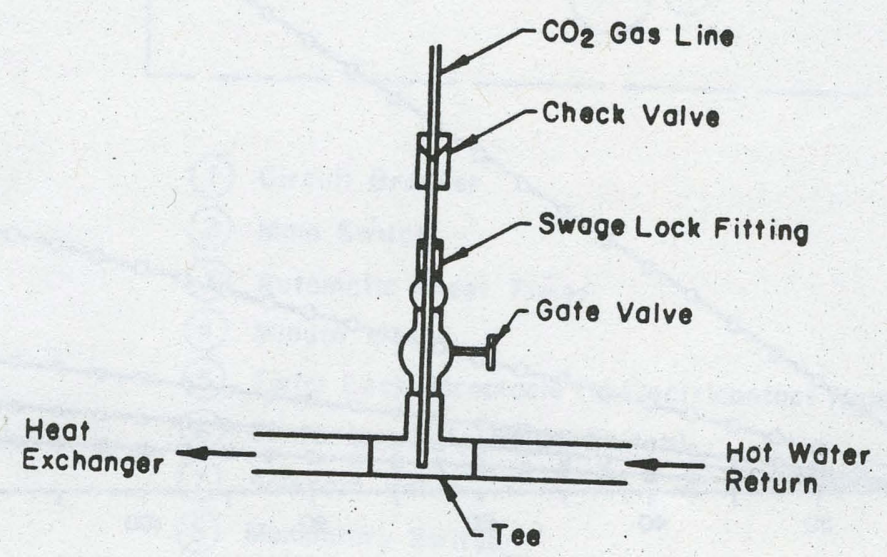

Figure 7. Injection port. 


\section{FIELD DEMONSTRATION OF CARBON DIOXIDE TECHNOLOGY}

As part of FEAP, the carbon dioxide treatment technology was demonstrated at three sites: a mess hall at Fort Ord, CA, a barracks at Dugway Proving Ground, UT, and a barracks complex at Karlsruhe, Military Community Activity (MCA), West Germany. Each of these sites was in areas with water of high hardness and scale problems.

\section{Fort Ord}

Fort Ord is located on the California coast. The water supply used by the installation is groundwater. Representative system parameters are listed in Table 1. The scaling problem is apparent from Figure 8, which shows a heat exchanger before treatment.

The technology was demonstrated in a mess hall where the scale problems were primarily in the dishwashers (Figure 9). Repairs for scale-related problems were common. The carbon dioxide treatment unit was installed in the boiler room by installation personnel under USACERL guidance. This step was necessary to (1) ensure limited access to the controls, (2) provide an unobtrusive location, and (3) prevent vandalism or theft. A test pipe section was installed near the dishwasher.

A series of water samples from Fort Ord was analyzed during the initial stages of the demonstration to examine early impacts. As can be readily seen from values in Table 1 for samples 1 through 8 , there is no detectable significant differences in water quality between hot and cold samples and those with and without carbon dioxide treatment. Samples 9 through 12 were taken from a heat exchanger as it drained to establish "before" and "after" profiles. Increased levels of iron and copper are likely corrosion products. An analysis of the deposit on the heat exchanger showed about 98 percent $\mathrm{CaCO}_{3}$; the deposit from the bottom of the tank was 78 percent $\mathrm{CaCO}_{3}$ and 12 percent $\mathrm{Fe}_{2} \mathrm{O}_{3}$, with the remainder primarily sediment.

The treated water was monitored regularly by base personnel. Water treatment plant personnel read the gauges and meters, performed routine chemical analyses, and reported when the gas tank levels were down. Responsibility for changing the carbon dioxide tank was treated as a DEH work order. Readings were on a weekly basis. Representative data are presented in Table 2.

Follow-on site visits showed the process to be removing and preventing scale successfully (Figure 10). Base personnel responsible for operation, maintenance, and repair reported fewer problems with the dishwashers which, compared with identical dishwashers placed in service at the same time, showed significant visual differences in scale buildup. In this application, the carbon dioxide treatment provides preventive maintenance rather than rehabilitation. The treatment system could be used periodically for this function, rather than continuously.

A logistical problem occurred with the carbon dioxide supply at Fort Ord. Originally, the fire department supplied the gas, but that avenue was discontinued. Other activities on the base use the gas for industrial purposes, but there were problems with intergroup transfers. The DEH now obtains the gas as needed from the local economy and has extra tanks set aside in storage.

The monitoring data in Table 2 indicate no potential or detectable problems, or significant changes in water quality. An additional elemental analysis was conducted on water samples from Fort Ord with results reported in $\mathrm{ppm}$ with an operational $\mathrm{CO}_{2}$ system. This application has been very well received by installation personnel who perform operation and maintenance. The system has worked properly with minimal problems. Installation personnel have monitored the water as necessary. The gas supply problem may not be unique to Fort Ord; other installations also may have to make special arrangements to ensure a ready supply of carbon dioxide. 
Table 1

Fort Ord Water Characteristics

\begin{tabular}{|c|c|c|c|c|c|c|c|c|c|c|}
\hline \multirow{2}{*}{$\begin{array}{l}\text { Sample } \\
\text { Number* }\end{array}$} & \multicolumn{9}{|c|}{ Concentration (mg/L) } & \multirow[b]{2}{*}{ Description } \\
\hline & Fe & $\mathrm{Cu}$ & $\mathrm{Zn}$ & $\mathrm{Ca}$ & $\mathbf{M g}$ & $\mathbf{N a}$ & SO4 & $\mathrm{Cl}$ & TDS & \\
\hline 001 & - & - & - & - & - & - & 137 & 44 & 412 & Cold water from kitchen sink, $1 / 22$ \\
\hline 002 & 0.00 & 0.12 & 0.02 & 59.6 & 19.5 & 47.3 & - & - & - & Cold water from kitchen sink, $1 / 22$, acidified \\
\hline 003 & - & - & - & - & - & - & 125 & 39 & 373 & Hot water $\left(58^{\circ} \mathrm{C}\right)$ from kitchen sink, $1 / 22, \mathrm{CO} 2$ system on \\
\hline 004 & 0.12 & 0.21 & 0.03 & 58.5 & 18.4 & 46.0 & - & - & - & Hot water from kitchen sink, $1 / 22, \mathrm{O} 2$ system on, acidified \\
\hline 005 & - & - & - & - & - & - & 130 & 42 & 389 & Cold water from kitchen sink, $1 / 25$ \\
\hline 006 & 0.10 & 0.09 & 0.02 & 57.5 & 18.1 & 44.0 & - & - & - & Cold water from kitchen sink, $1 / 25$, acidified \\
\hline 007 & - & - & - & - & - & - & 134 & 44. & 400 & Hot water $\left(58^{\circ} \mathrm{C}\right)$ from kitchen sink, $1 / 25, \mathrm{CO} 2$ system on \\
\hline 008 & 0.10 & 0.23 & 0.03 & 53.8 & 16.5 & 40.2 & - & - & - & $\begin{array}{l}\text { Hot water }\left(58^{\circ} \mathrm{C}\right) \text { from kitchen sink, } 1 / 25, \mathrm{CO} 2 \text { system on, } \\
\text { acidified }\end{array}$ \\
\hline 009 & 2.64 & 0.86 & 0.04 & 55.9 & 17.6 & 45.0 & - & - & - & Water draining from heat exchanger tank, initial, $1 / 26$ \\
\hline 010 & 0.97 & 0.35 & 0.03 & 59.6 & 18.7 & 46.8 & - & - & - & Water draining from heat exchanger tank, end, 1/26 \\
\hline 011 & 0.45 & 0.29 & 0.01 & 59.6 & 18.1 & 46.8 & - & - & - & Water draining from heat exchanger tank, middle, $1 / 26$ \\
\hline 012 & 5.10 & 2.09 & 0.10 & 60.1 & 19.0 & 46.7 & - & - & - & Water draining from heat exchanger tank, middle, $1 / 26$ \\
\hline
\end{tabular}

*Samples 1 - 8 taken from bldg. 4468, samples 9 - 12 taken from bldg. 4798, on 22, 25, or 26 January 1988. 


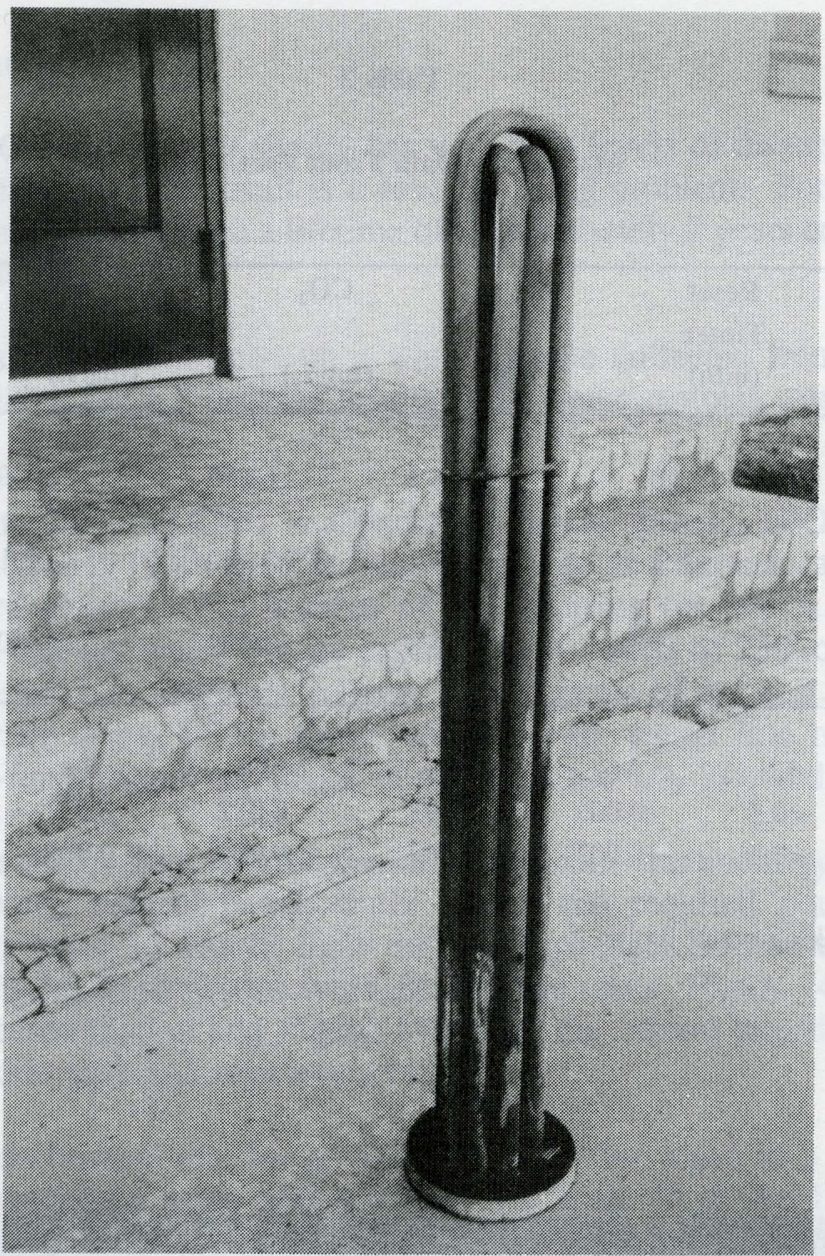

Figure 8. Fort Ord scaled heat exchanger.

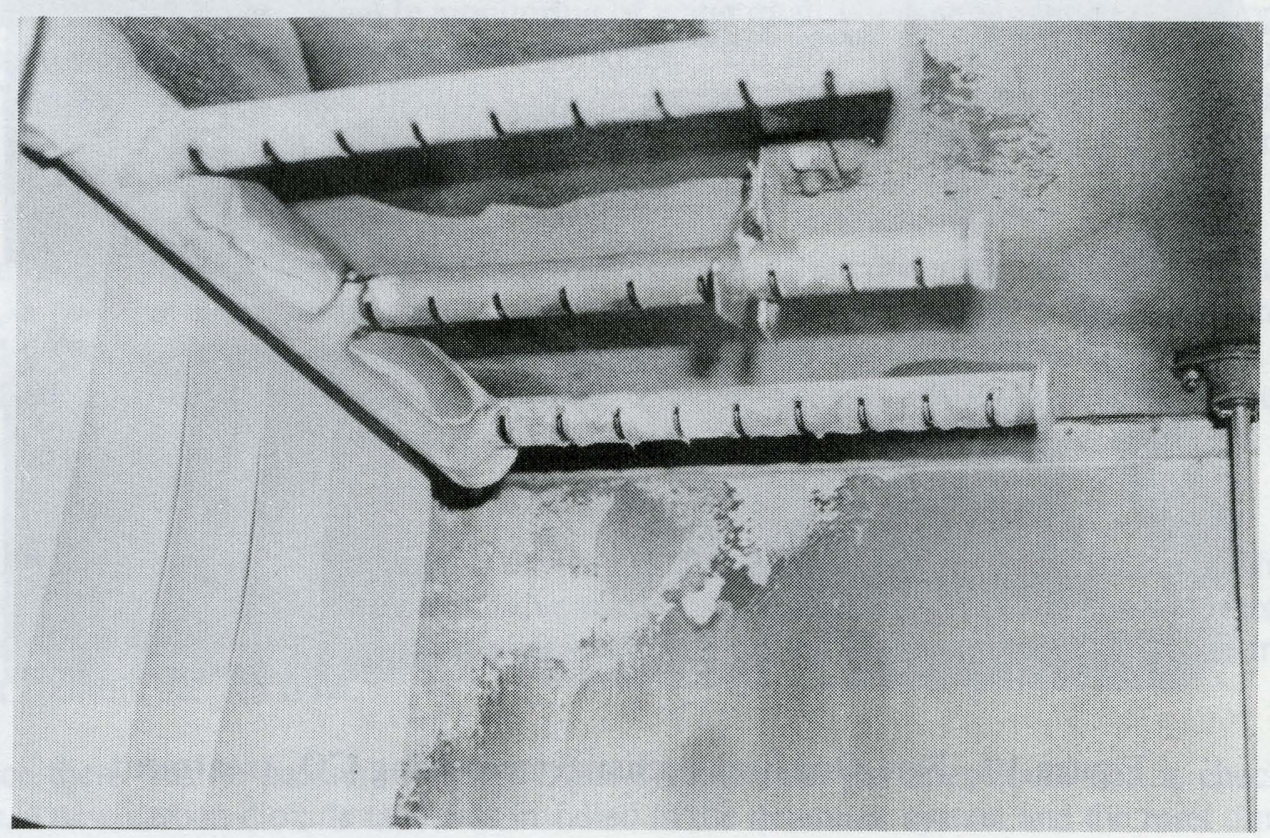

Figure 9. Fort Ord scaled sprayer in dishwasher. 
Table 2

Monitoring Data From Fort Ord*

\begin{tabular}{|c|c|c|c|c|c|c|c|c|}
\hline Dates & $\begin{array}{c}\mathrm{CO}_{2} \text { Flow } \\
\text { Meter } \\
\text { Reading }\end{array}$ & & & pH & $\begin{array}{c}\mathrm{CO}_{2} \\
(\mathrm{mg} / \mathrm{L})\end{array}$ & $\begin{array}{c}\mathrm{Cu} \\
(\mathrm{mg} / \mathrm{L})\end{array}$ & $\begin{array}{c}\mathrm{Fe} \\
(\mathrm{mg} / \mathrm{L})\end{array}$ & \\
\hline $1 / 88-3 / 88$ & 2.5 & & 10 & $5.8-6.4$ & $11-130$ & $0.1-0.2$ & \multicolumn{2}{|c|}{$<0.1$} \\
\hline $5 / 88-6 / 88$ & 2.5 & & 7 & 5.9 & $70-100$ & 0.1 & \multicolumn{2}{|c|}{$<0.1$} \\
\hline $12 / 88-8 / 89$ & $1.0-1.4$ & & 7 & $5.6-6.3$ & $10-330$ & $0.1-0.2$ & \multicolumn{2}{|c|}{$<0.1-0.4$} \\
\hline & AS & FE & $\mathrm{Mn}$ & $\mathrm{Cu}$ & $\mathrm{Cr}$ & $\mathrm{Ba}$ & $\mathrm{Cd}$ & $\mathrm{Pb}$ \\
\hline Hot & $<0.1$ & $<0.5$ & $<0.003$ & 0.093 & 0.012 & 0.031 & $<0.005$ & $<0.05$ \\
\hline Cold & $<0.1$ & $<0.5$ & $<0.003$ & 0.049 & 0.013 & 0.029 & $<0.005$ & $<0.05$ \\
\hline
\end{tabular}

* All results were within drinking water limits.

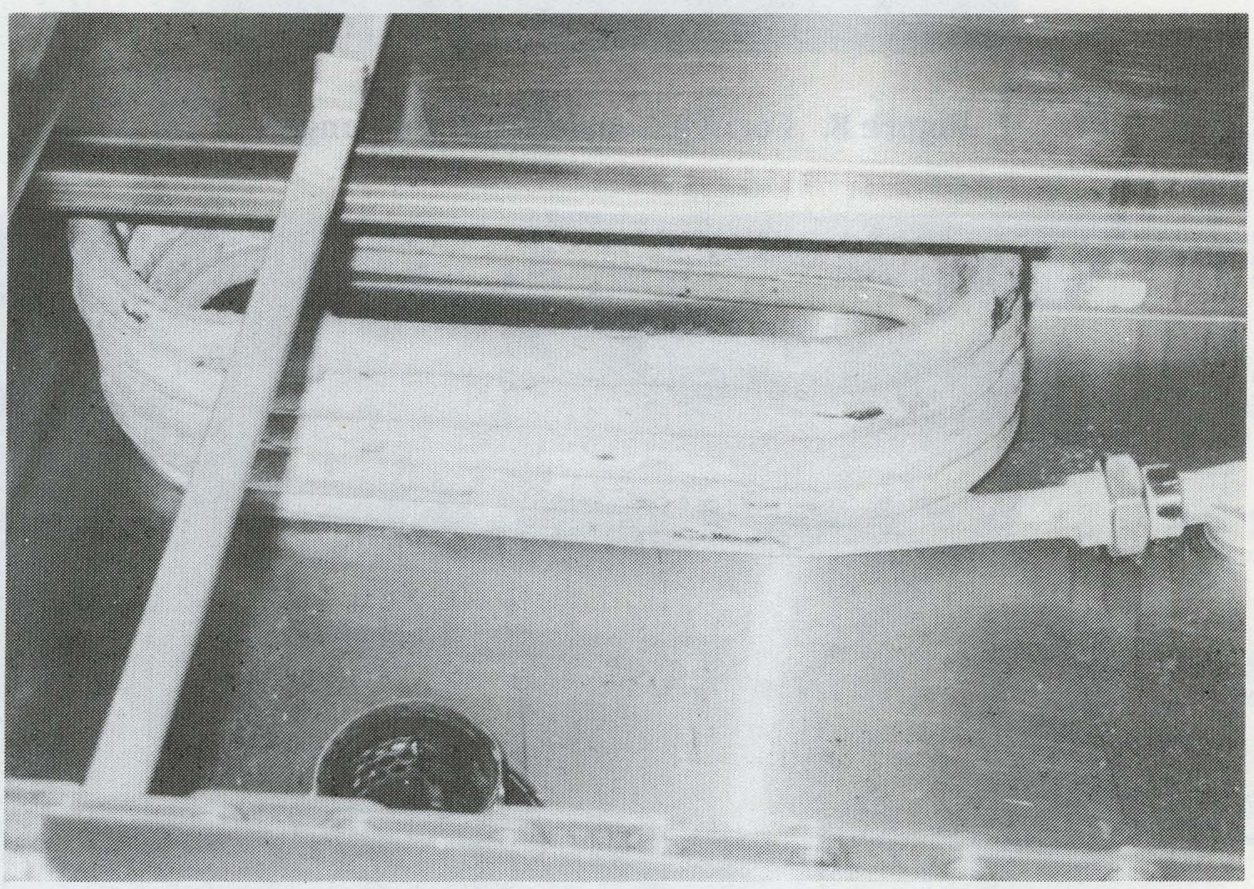

Figure 10. Fort Ord heat exchanger receiving $\mathrm{CO}_{2}$ treatment. 


\section{Dugway Proving Ground}

Dugway Proving Ground's water supply has very high levels of dissolved solids. No treatment is used other than chlorination and the result is a severe scaling problem. For example, heating elements in family housing hot water heaters have a lifetime of approximately 2 years compared with 10 to 15 years for more typical installations.

Laboratory analysis was performed on a water sample collected from Dugway Proving Ground (DPG) on 31 August 1987. Table 3 lists the results. The water samples were taken from building 5220 at hot and cold taps.

The application site, building 5220, is a Bachelor Officer Quarters (BOQ) for the installation. The probable date of construction is 1950-55. The building is used as a barracks and there is no mess facility; however kitchenettes are present. The number of people using the site is typically 20 to 24 and the number of rooms is 24 . The hot water storage capacity is two tanks of 250 to 300 gal each. Inlet, outlet, and return line pipes are all 2 -in. diameter copper. Components of the heat exchanger system include: heating coils of copper or brass, 1/2-in. tubes, and a 3/4-in. steam line of black iron pipe. Other components are wall-to-flush valves and angle stops which are $1 / 2,3 / 4$, and 1 in.

DPG was the first application site for the carbon dioxide treatment system beginning August 28 , 1987. The carbon dioxide control panel, water meter, and required plumbing were performed by installation personnel. Figures 11 and 12 show the heat exchanger before treatment in cross section and closeup, respectively. Figure 13 shows the hot water storage tanks. Figure 14 presents the electricontact water meter setup at the installation and Figure 15 shows the carbon dioxide control panel. Figure 16 features the carbon dioxide tank and regulator setup.

The carbon dioxide dosage was set so as to stabilize the water to a $\mathrm{pH}$ of 7.5 , which prevents deposition of calcium carbonate scale and dissolves the scale from the heat exchanger surface. A monitoring routine was established and was to be performed by contractors (DPG uses a contracted DEH workforce).

USACERL visited DPG to inspect the carbon dioxide treatment system's performance for controlling scale in the heat exchanger. Weekly monitoring of water quality for metals (iron, zinc, copper), hardness, and $\mathrm{pH}$ had been conducted by water plant personnel (actually data was collected two to three times per week). The water quality data showed that the proper dosage had been applied to maintain pH 7.5, although the carbon dioxide values were generally less than $10 \mathrm{mg} / \mathrm{L}$. The metals were well within acceptable safety limits-less than $0.1 \mathrm{ppm}$.

The installation monitor reported that the system had functioned properly until September 25 . At this time, a problem with the treatment system occurred when the pressure in the carbon dioxide tank decreased from 900 psi to 25 psi within 2 weeks. This rate of depletion was not anticipated since the tank contained about $40 \mathrm{lb}$ of gas which should have lasted more than 1 year at the set treatment rate ( 25 to $30 \mathrm{mg} / \mathrm{L}$ ). The most probable reason for sudden loss of pressure was leakage in the gas lines used for injection into the water system.

USACERL analyzed the operating data up to that time to check for a possible malfunction in the carbon dioxide control panel. The cumulative timer and the cumulative volume of water treated revealed that the reset timer was operating exactly as set. No physical defect could be observed in the solenoid valve that controls the gas flow.

Since there was no pressure left in the gas cylinder, the gas lines could not be checked for leaks. Therefore, a new carbon dioxide tank was installed in the treatment system and the reset timer was turned on manually. All joints in the gas line were checked for leaks using soap water. Small leaks were found at swagelock connections at the backflow check valve, solenoid valve, and pressure regulator. 
Table 3

Dugway Proving Ground Water Sample Analysis*

\begin{tabular}{|c|c|c|}
\hline Parameter & $\begin{array}{l}\text { Cold } \\
\text { Water }\end{array}$ & $\begin{array}{l}\text { Hot } \\
\text { Water }\end{array}$ \\
\hline M Alkalinity (as $\mathrm{CaCO}_{3}$ ) & 152.00 & 154.00 \\
\hline Hardness (as $\mathrm{CaCO}_{3}$ ) & 216.00 & 214.00 \\
\hline Calcium (as $\mathrm{Ca}$ ) & 44.00 & 36.10 \\
\hline Magnesium (as $\mathrm{Mg}$ ) & 26.30 & 30.50 \\
\hline Sulfate $\left(\right.$ as $\left.\mathrm{SO}_{4}\right)$ & 40.00 & 39.00 \\
\hline Chloride (as $\mathrm{Cl}$ ) & 225.00 & 200.00 \\
\hline Iron (as $\mathrm{Fe}$ ) & 0.05 & 0.05 \\
\hline Sodium (as $\mathrm{Na}$ ) & 123.00 & 122.00 \\
\hline Total dissolved solids & 649.00 & 617.00 \\
\hline Silica (as $\mathrm{SiO}_{2}$ ) & 50.50 & 50.70 \\
\hline $\mathrm{pH}$ (field) & 7.67 & 7.70 \\
\hline
\end{tabular}

* Carbon dioxide addition in progress. 


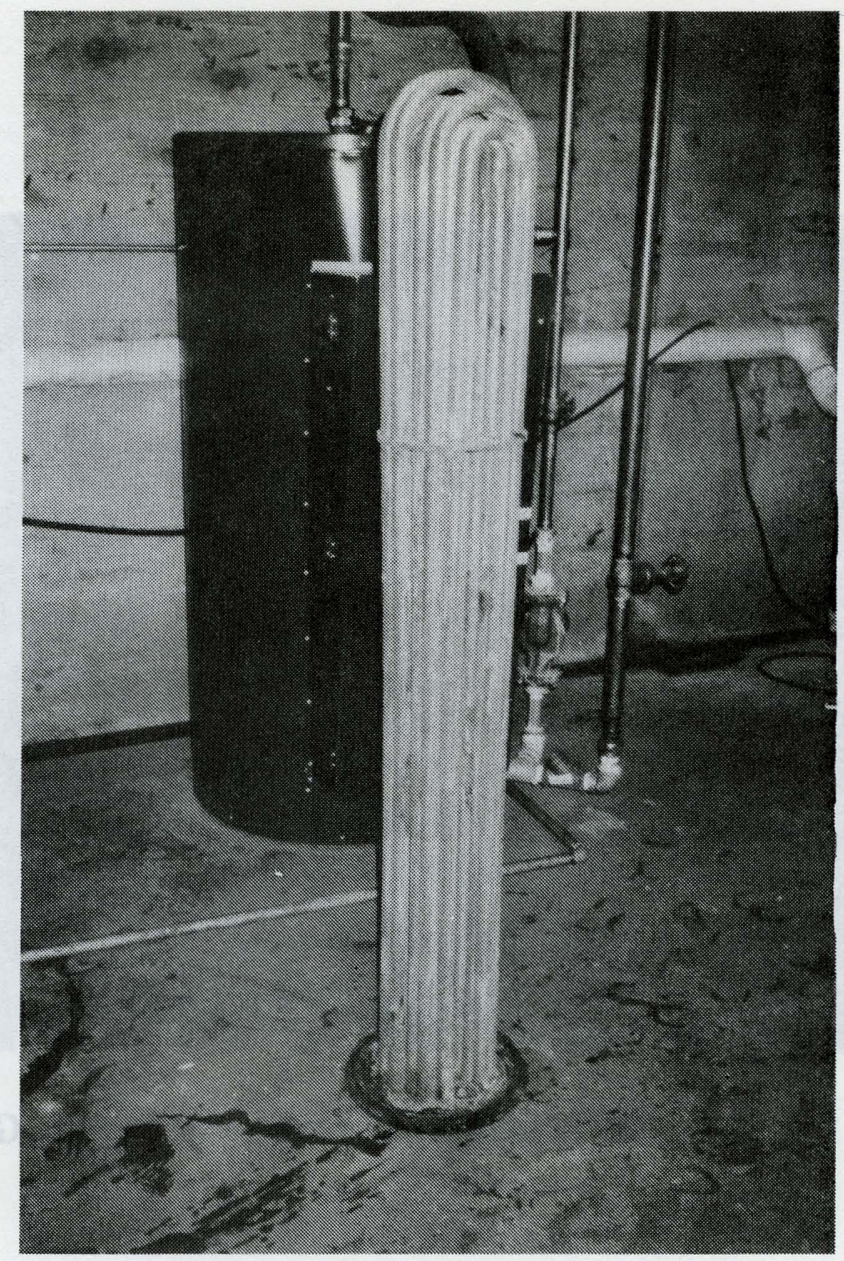

Figure 11. Dugway Proving Ground scaled heat exchanger before treatment.

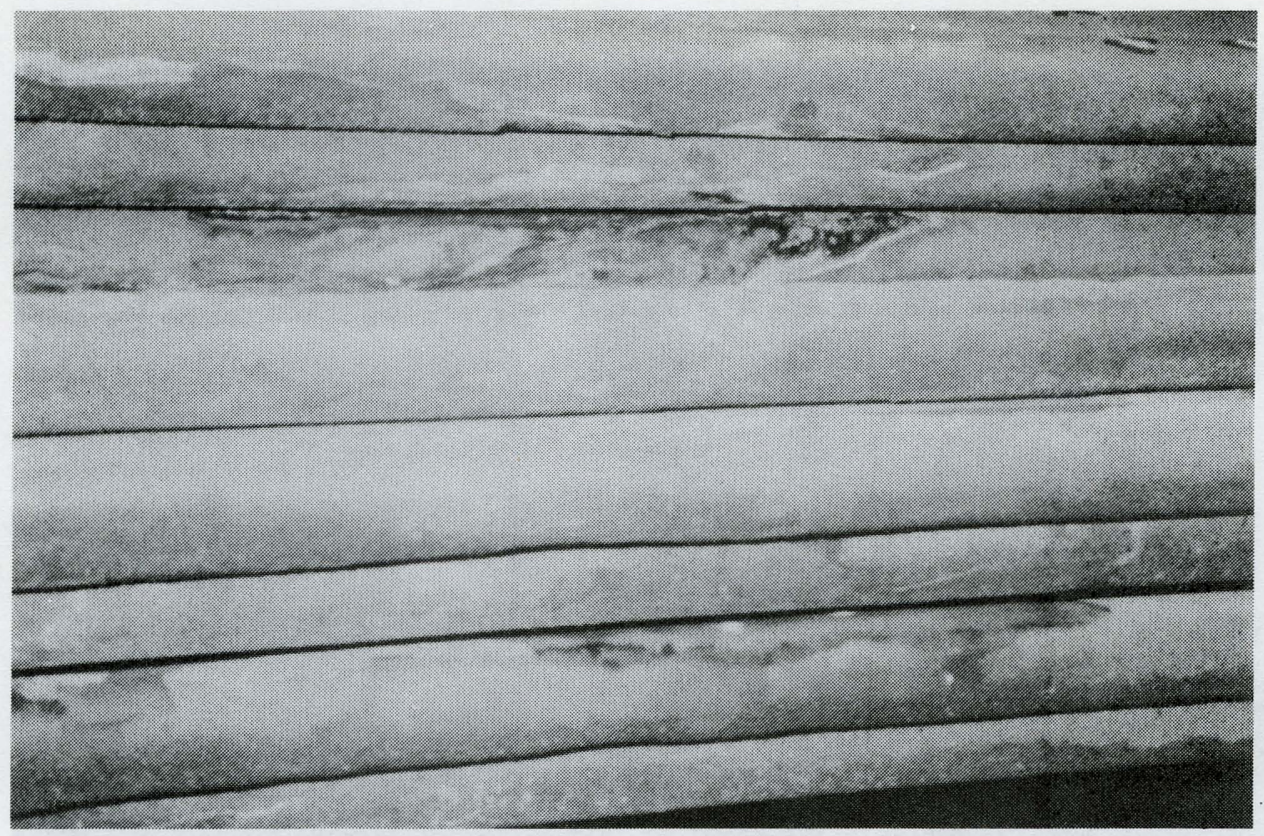

Figure 12. Closeup of the scaled heat exchanger. 


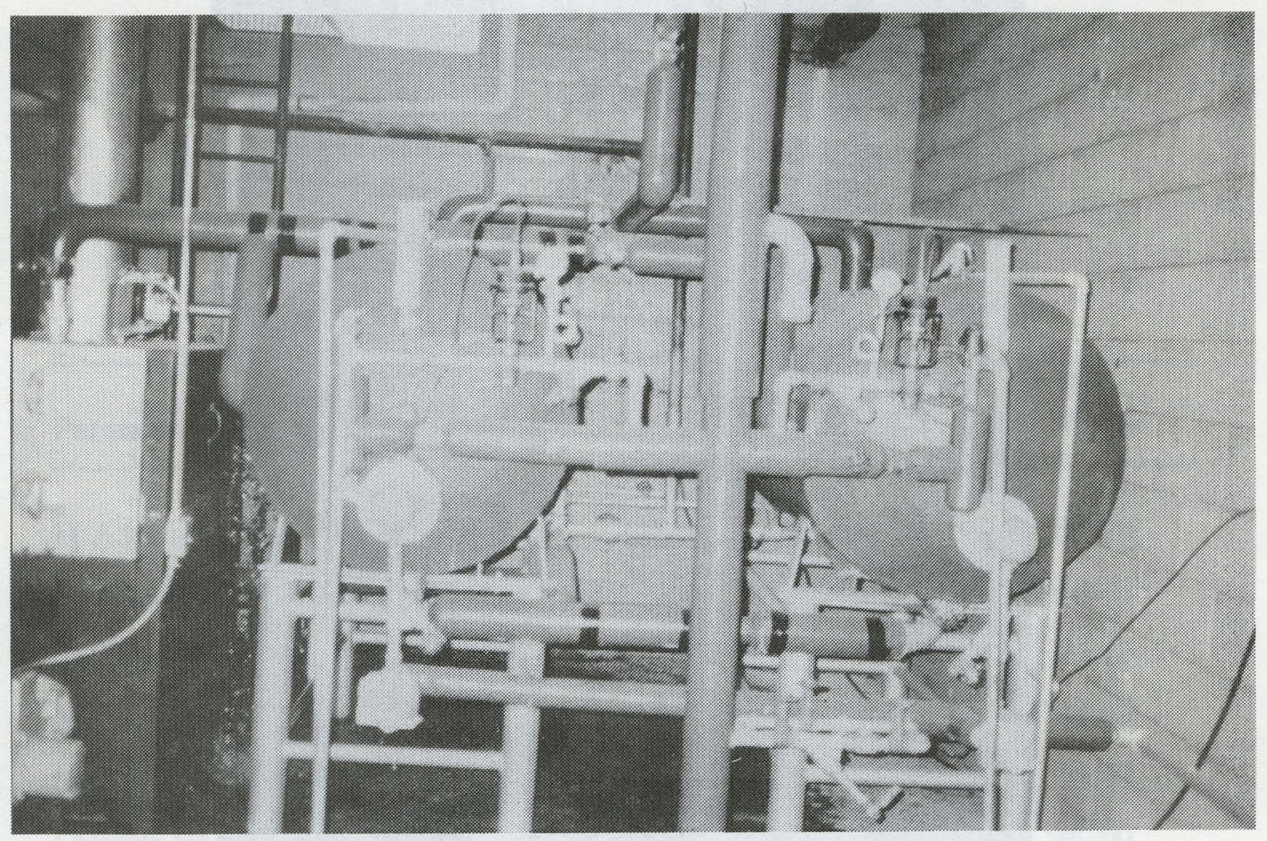

Figure 13. Hot water storage tanks at Dugway Proving Ground.

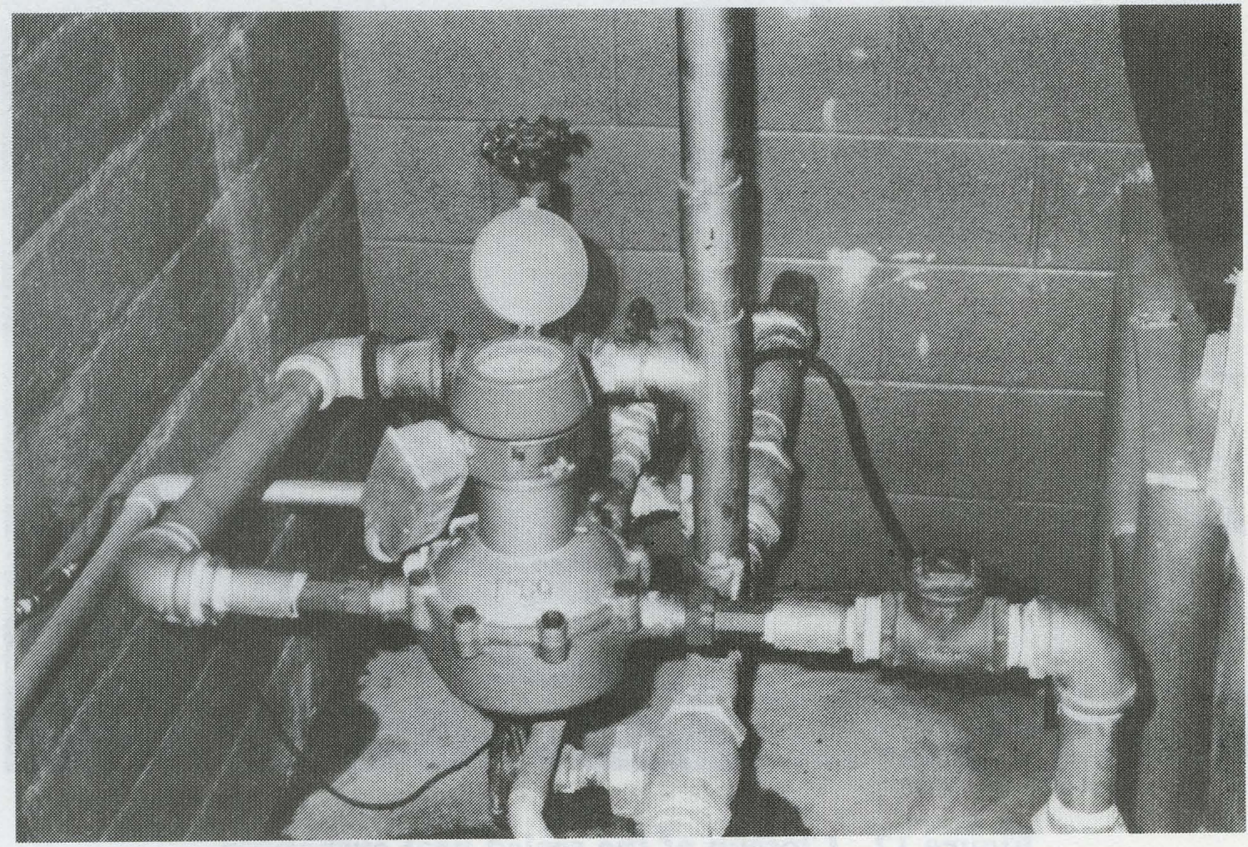

Figure 14. Electricontact water meter. 


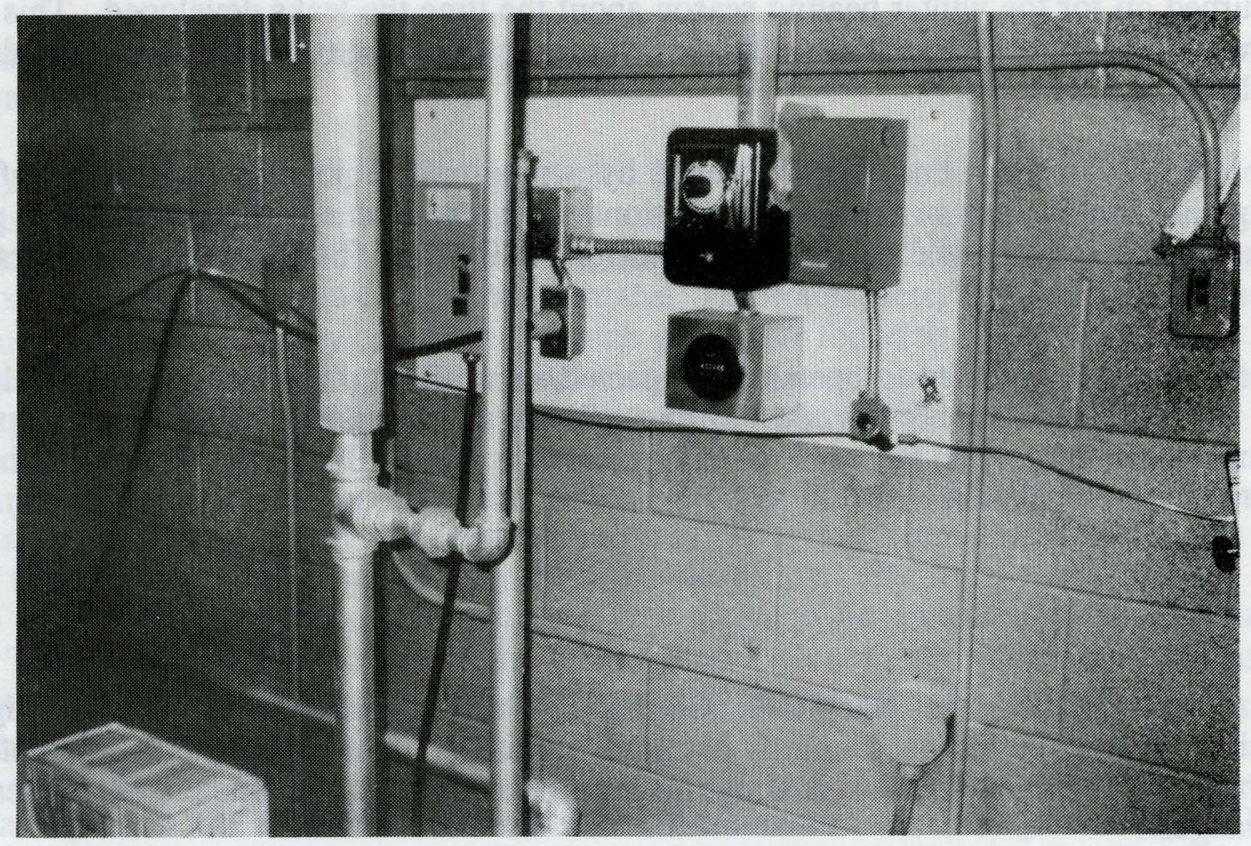

Figure 15. Carbon dioxide control panel.

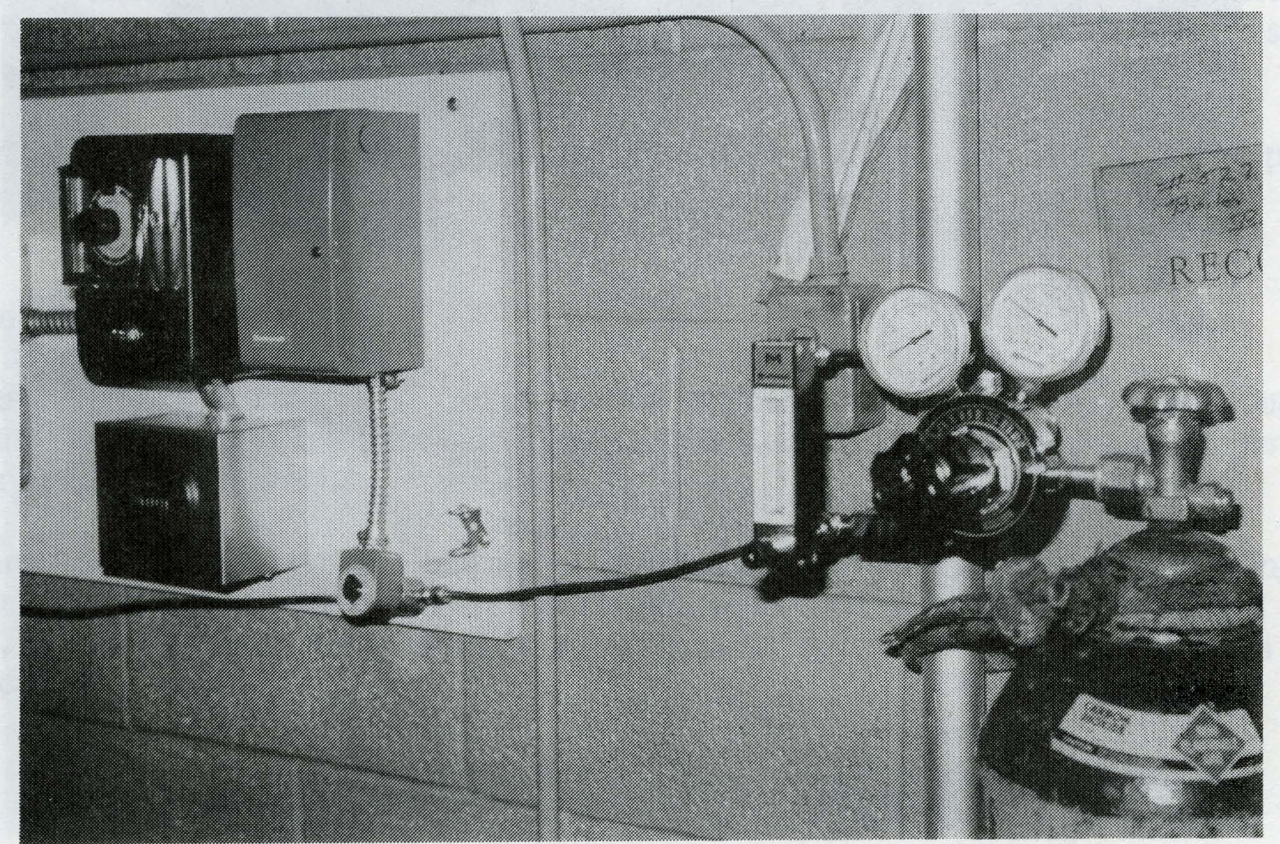

Figure 16. Carbon dioxide tank and regulator setup. 
Although the joints had been checked for leaks during initial installation, some leaks may have developed later, perhaps due to temperature changes inside the room. The furnace that generates steam had been turned on for the winter heating season about the time the leaks developed. This increased the temperature inside the room by 20 to $30^{\circ} \mathrm{F}$, which may have caused expansion in the joints where the leaks developed.

The leaks in the gas line were repaired by wrapping the joint threads with teflon tape and retightening the joints. All swagelock connections were checked again for leaks. A procedure for detecting and correcting gas leaks was established for the installation personnel who operate the carbon dioxide treatment system.

The system has continued to operate as expected, controlling the $\mathrm{pH}$ at approximately 7.3 (plus or minus 0.1 ) with carbon dioxide levels of 15 to $25 \mathrm{mg} / \mathrm{L}$ and metals undetected (monitoring performed two to three times per month). The new tank of carbon dioxide lasted 10 months. Figure 17 shows the DPG heat exchanger after treatment.

\section{Karlsruhe MCA}

Gerszewski Barracks in Karlsruhe, Germany, was the largest test site during the FEAP demonstration. Several buildings, primarily barracks, are linked together using the same hot water supply system. The water in the city system is a mixture from four sources. Parameters of interest showed the following ranges:

- $\mathrm{pH}-7.11$ to 7.35

- Hardness - 307 to $380 \mathrm{mg} / \mathrm{L}$

- Calcium - 108 to $130 \mathrm{mg} / \mathrm{L}$

- Iron - $<0.01$ to $0.05 \mathrm{mg} / \mathrm{L}$

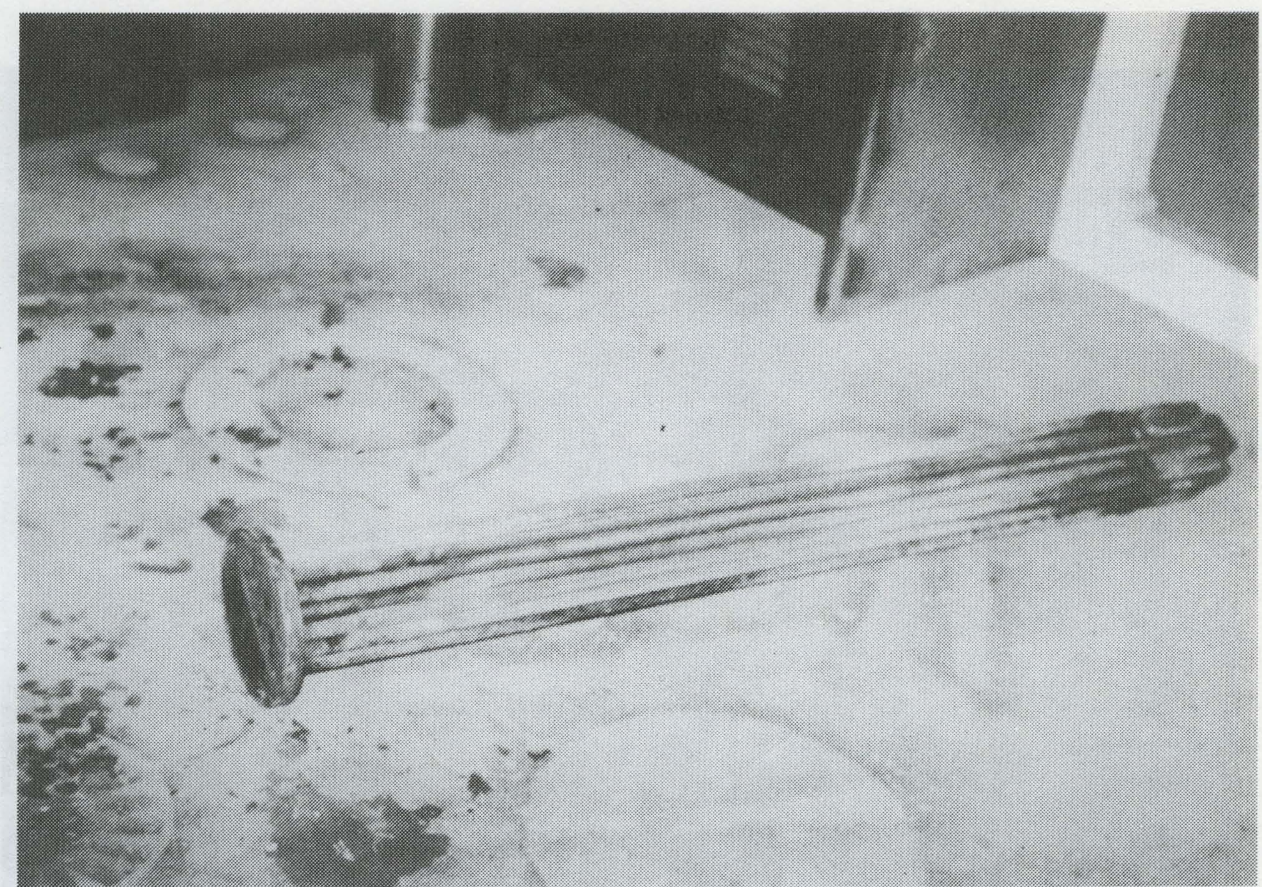

Figure 17. Heat exchanger after carbon dioxide treatment. 
- Copper - not quantified

- Total dissolved solids - not quantified; however, composed primarily of sulfate, chloride, calcium, and magnesium.

The system was installed in Summer 1988. Figure 18 is a schematic of the system. Several modifications are notable. The meter bypass had considerable flow reduction with the potential for a shortage of hot water to some buildings; however, that potential was never realized, although the system was turned off in mid-December for the winter months. The water meter was bypassed and gas injection turned off due to hot water supply complaints (which were later found to be unrelated to the supply-see below). The $2-1 / 2$ in. valve was opened to maximize water flow at peak use periods. The complaints about hot water supply were found to be a problem with the shower valves.

The injection system was operated for several months during 1988, discontinued as mentioned above, then restarted in April 1989. Other differences in the system were electrical and gas connections. Appropriate transformers were required to convert the electricity. Gas regulators had to be purchased in Germany to ensure proper connections and care was taken to be aware of differences when mixing equipment. The control panel was built in the United States. A correction factor of $6 / 5$ was required on the gas valve timer. This requirement was relatively unimportant as there is considerable flexibility in applied dosages of carbon dioxide.

The gas injection rate at this location was $0.5 \mathrm{cu} \mathrm{ft} / \mathrm{min}$ with $5 \mathrm{~min}$ of injection per 100 gal of water metered. The $\mathrm{pH}$ detected in the water was usually one-half unit below the city-supplied water, indicating proper functioning of the system. The hot water system consumed between 4500 and 11,000 gal/day, depending on the numbers of troops present. As elsewhere in the Army, troops would be gone periodically for training, leaving the barracks nearly deserted.

Figure 19 shows one of the twin hot water tanks servicing the buildings. Figure 20 presents the carbon dioxide injection system and water bypass at the test site. Figure 21 shows the test piece installation in the barracks.

This system was installed by the in-house workforce, primarily German nationals. Communication presented no obstacle once everything was explained, although it was necessary to have knowledgeable individuals involved. As at Fort Ord, obtaining carbon dioxide gas was a minor problem; the solution was to obtain it on the local market, a procurement action taking about 1 week.

The results of this application are improved conditions in the piping. The installing plumber has reported noticeable improvement.

\section{Summary of Field Tests}

For successful application of the carbon dioxide treatment system, responsible individuals must be charged with implementation and monitoring. With dedicated, interested individuals, proper execution and monitoring take minimal time.

Procurement of carbon dioxide tanks should be handled on a case-by-case basis using whatever procurement actions are necessary to ensure a consistent supply. Gas line connections should be checked periodically, especially if substantial temperature fluctuations occur. A slow leak can drain the carbon dioxide tank relatively quickly. 


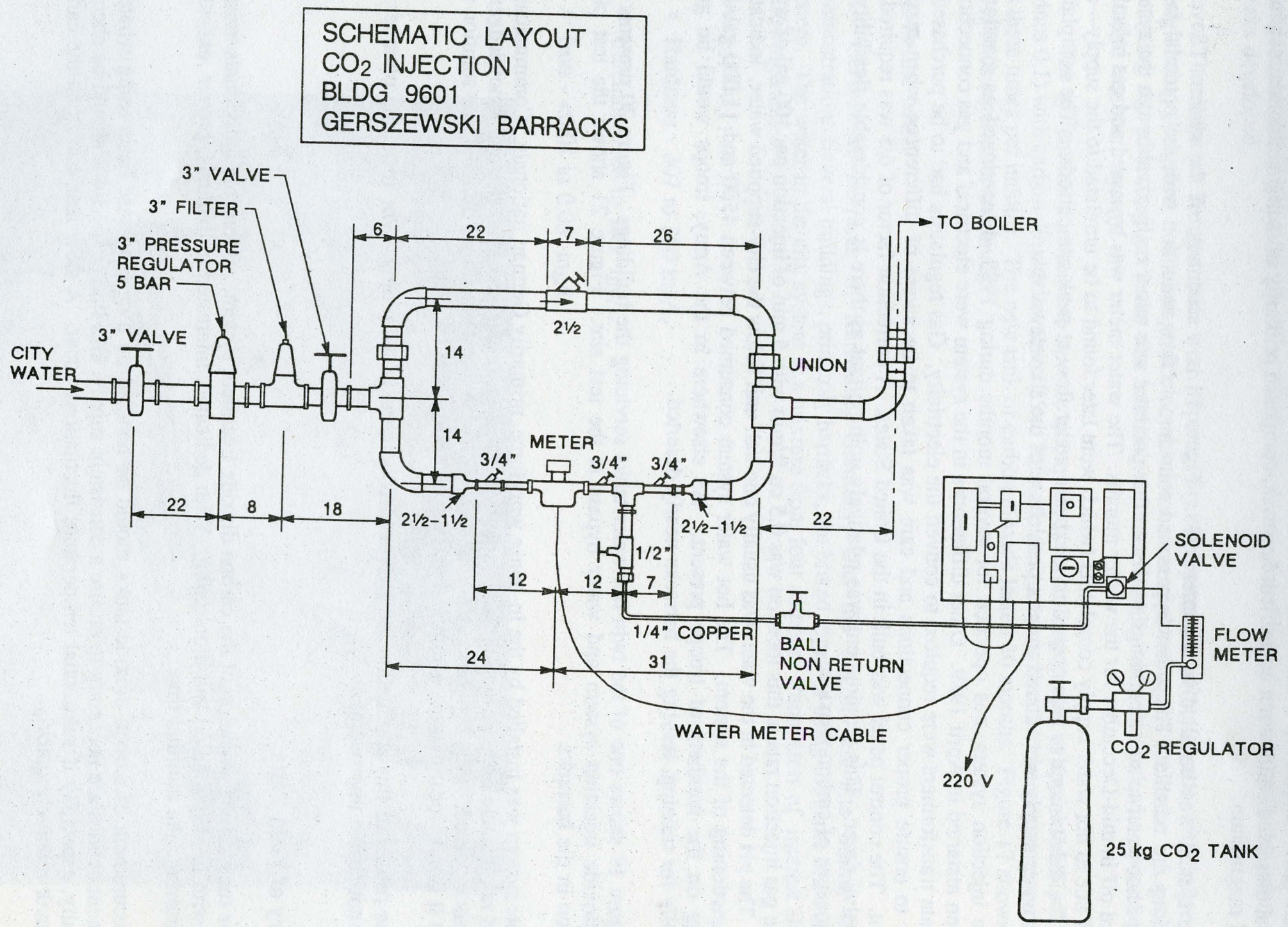

Figure 18. Schematic of Karlsruhe system. 


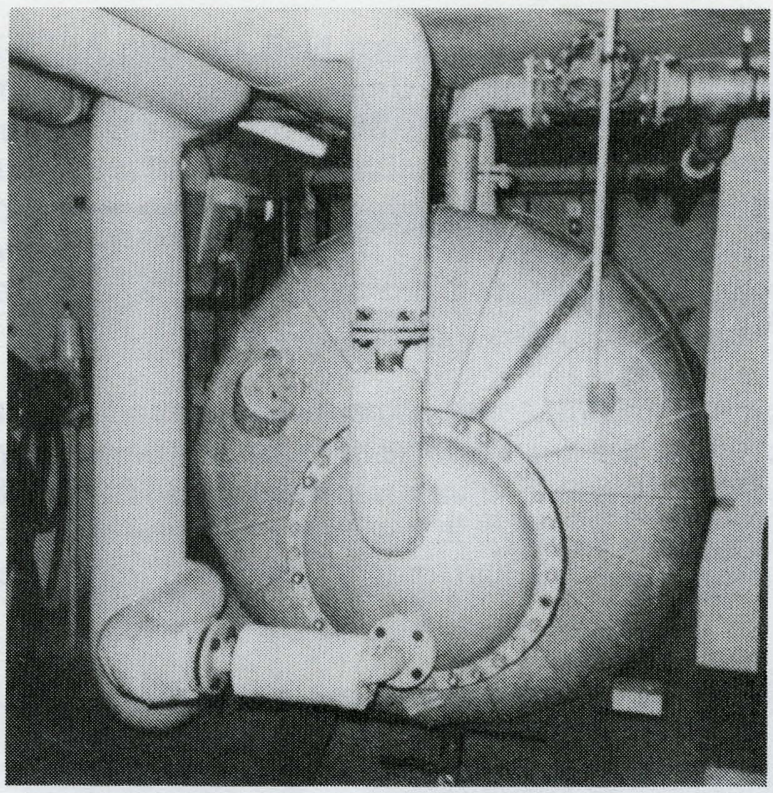

Figure 19. One of the hot water tanks at Karlsruhe.

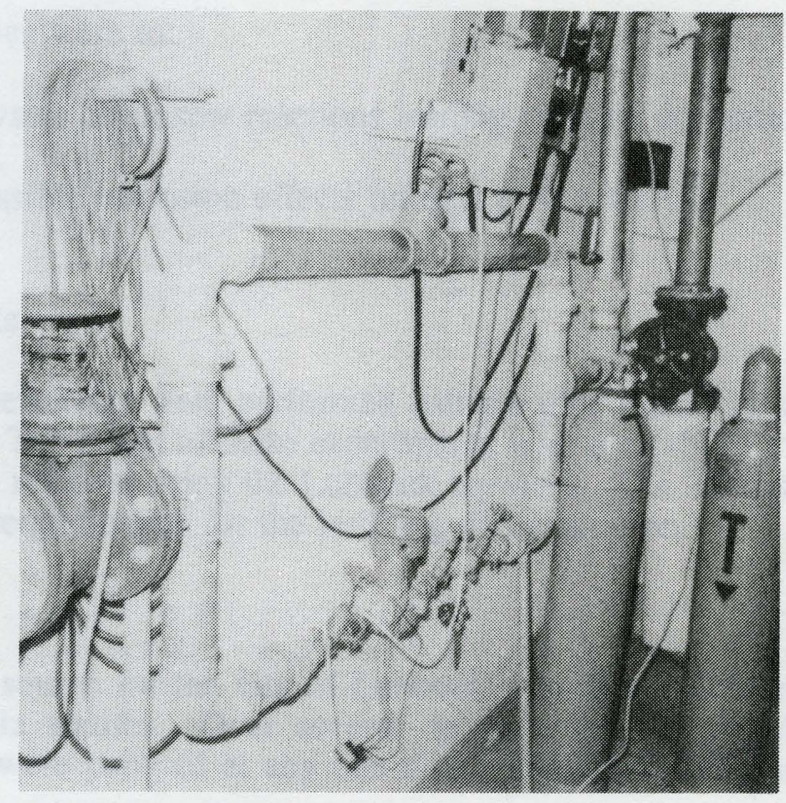

Figure 20. Carbon dioxide injection system and water bypass. 


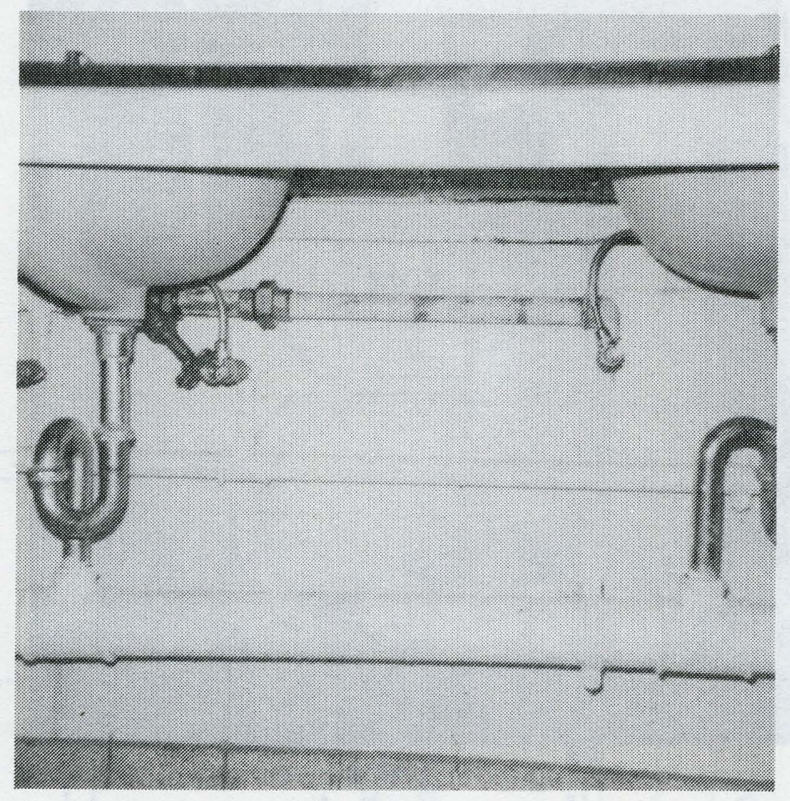

Figure 21. Test piece installation at Karlsruhe. 


\section{Overview}

Technical Report N-87/16 presents field results from Illinois. In four separate applications, the average water qualities varied from 182 to $336 \mathrm{mg} / \mathrm{L}$ hardness as $\mathrm{CaCO}_{3}$ and 150 to $360 \mathrm{mg} / \mathrm{L}$ TDS. The field demonstrations showed the technique to be effective in removing scale, but several factors prevented better agreement between the results. The chemical compositions of the scales were not completely calcium carbonate at any of the four sites. The carbon dioxide dosing systems were not able to adjust to variations in incoming water $\mathrm{pH}$ and hardness. Furthermore, erratic flow rates caused over- and under-dosing of carbon dioxide. Although the technique removed scale, monitoring and treatment control were insufficient to allow generalization of the results.

To specifically investigate the calcium carbonate dissolution kinetics and corrosion potential, Prakash et al. performed laboratory experiments using water with hardness of approximately $85 \mathrm{mg} / \mathrm{L}$ as $\mathrm{CaCO}_{3}$ and of $120 \mathrm{mg} / \mathrm{L}$ (TR N-87/16). The experimental results indicated that scale dissolution increased with increasing carbon dioxide addition and the associated decrease in $\mathrm{pH}$. The dissolution rate also appeared to be affected by water temperature, content (comparing the tapwater to deionized water), and water velocity.

Applications of the $\mathrm{CO}_{2}$ injection technique are being broadened through a demonstration using very hard water with high TDS. Experiments are being performed at Texas Tech University in Lubbock, where the water supply normally has above $1000 \mathrm{mg} / \mathrm{L}$ and hardness above $180 \mathrm{mg} / \mathrm{L}$. Major scale deposits have been found in campus buildings with heavy hot water use. High concentrations of sodium, sulfate, and chloride are present that could greatly affect the carbonate dissolution chemistry.

\section{Study Objectives}

The primary objective of controlled laboratory experiments was to observe the removal of calcium carbonate scale using carbon dioxide injection and local hot tapwater. A follow-up demonstration project began in FY90 on a campus building. The results will be incorporated in a USACERL report.

Secondary objectives were to:

- Model the water chemistry reactions leading to scale deposition and dissolution

- Quantify possible corrosion effects on new pipe material.

\section{Laboratory Experiments}

The laboratory experiments were performed using a pipe manifold system patterned after that of Prakash et al. (N-87/16). The intent of these experiments was to establish the effectiveness of the carbon dioxide injection on scale removal using the Lubbock tapwater. The laboratory results were then used to estimate carbon dioxide requirements for the building demonstration.

\section{Local Water Quality}

The original water source for the city of Lubbock was obtained from wells within the city limits which tapped the Ogallala aquifer. Over several decades, the city developed more than 100 wells, although not all of them were pumped at any one time. Table 4 summarizes the average water quality 
for: the 20 city wells in operation as of $1944 .^{8}$ These averages are typical of the water quality found in other wells in Lubbock. ${ }^{9}$ The small number of constituents listed in the 1944 data reflects the limitations of the time, but gives good representation of the major species.

Due to the high hardness and fluoride concentrations in the local groundwater, the City of Lubbock stopped using the local wells for water supply in the mid-1960s. Since then, the city has obtained its water supply from two sources. The primary source is Lake Meredith, located north of Amarillo, a relatively salty but safe reservoir on the Canadian River. The water undergoes turbidity removal by coagulation/flocculation, filtering, and disinfection with chloramines. During the summer, the water supply is supplemented by groundwater from a well field in Bailey County, northwest of Lubbock. The groundwater is disinfected only. Table 5 is a summary of the water quality reported recently by the city's water treatment plant laboratory. Seasonal variations of the water quality in Lake Meredith can be quite significant. The two waters are mixed in the distribution system, so it is difficult to estimate the fraction of each water received at any location.

It is apparent from Tables 4 and 5 that the quality of the Lubbock water supply changed markedly in the mid-1960s. Total hardness, bicarbonate, and fluoride concentrations decreased, while the sodium and chloride concentrations increased. Total phosphorus was not reported by Lang, but more recent data reported by Stecher ${ }^{10}$ showed values at or below $0.02 \mathrm{mg} / \mathrm{L}$ at selected city wells. The total phosphorus concentration in the current water sources may be high enough to inhibit scale formation. ${ }^{11}$ It is likely that the potential for accumulation of calcium carbonate scale was greater for buildings in operation before 1960. This observation will be discussed in detail later. Both waters have positive LI values, whether at ambient or heated temperatures. Using the calculation procedure given by Rossum and Merrill, ${ }^{12}$ the respective $\mathrm{LI}$ values at 20 and $65^{\circ} \mathrm{C}$ are 0.15 and 0.79 for the Lubbock groundwater, 0.16 and 0.80 for the Lake Meredith water, and 0.36 and 1.02 for the Bailey County groundwater. Further comparisons of the waters are presented later.

\section{Scaled Pipe Samples}

USACERL had intended to take samples of scaled pipes from a Texas Tech building with a welldefined scaling problem in a relatively simple system. Much like a typical military installation, the university campus includes buildings ranging in age from more than 60 years to less than 10 . Design and construction of plumbing systems vary among the buildings. Hot water pipe materials include copper, brass, galvanized steel, and stainless steel, depending on each building's age and function. Replacement piping has usually been chosen based on the relative cost of the pipe materials, so that piping of different age and composition often exist in the same system.

Most of the major scaling problems apparently had been corrected before this project began in Fall 1988. Since no scaled pipe samples could be found during the first several months of the project, the pipe scaling apparatus used by Prakash et al. (TR N-87/16) was assembled in an attempt to generate artificially scaled pipe samples. The apparatus was set up in the same way except that continuous makeup water was supplied from a water heater installed in the laboratory room. The makeup water flow was pumped through a second small pump which was controlled by a water level sensor in the heated water bath. The water was maintained at $65^{\circ} \mathrm{C}$, and the heating tapes on the copper tubes were kept at $75^{\circ} \mathrm{C}$. The 0.5 -in. diameter copper tubing samples were roughened before installation in the system.

8 J.W. Lang, Water Resources of the Lubbock District (Texas State Board of Water Engineers, 1945).

9 Y-C. Chen et al., Economic Potential for Development of Increasing Groundwater Storage Beneath a High Plains Municipality, Final Report (Texas Tech University Water Resources Center, 1988).

${ }^{10}$ L.R.S. Stecher, Groundwater Management Program for Texas Tech University, M.S. Thesis (University of Texas at Austin, 1985).

${ }^{11}$ J.C. Cowan and P.J. Weintritt, Water-Formed Scale Deposits (Gulf Publishing Co., 1976).

${ }^{12}$ J.R. Rossum and D.T. Merrill, "An Evaluation of the Calcium Carbonate Saturation Indexes," Journal of the American Water Works Association, Vol 75, No. 2 (1983). 
Table 4

Average Water Quality in Lubbock Wells, 1944*

\begin{tabular}{lc}
\hline Constituent & Concentration $(\mathrm{mg} / \mathbf{L})$ \\
\hline Calcium & 67 \\
Magnesium & 73 \\
Sodium + Potassium & 107 \\
Bicarbonate & 333 \\
Sulfate & 222 \\
Chloride & 121 \\
Fluoride & 3.5 \\
Nitrate as nitrogen & 4.3 \\
Total hardness as $\mathrm{CaCO}_{3}$ & 466 \\
Total dissolved solids & 838
\end{tabular}

* Source: J. W. Lang, Water Resources of the Lubbock District (Texas State Board of Water Engineers, 1945).

Table 5

Water Quality of Lubbock Water Supply, June 1989

\begin{tabular}{lrr}
\hline & \multicolumn{2}{c}{ Concentration $(\mathbf{m g} / \mathbf{L})$} \\
\cline { 2 - 3 } Constituent & Surface Water & Groundwater \\
\hline $\mathrm{pH}($ not $\mathrm{mg} / \mathrm{L})$ & 7.84 & 7.86 \\
Carbonate & 0.00 & 0.00 \\
Bicarbonate (as $\left.\mathrm{CaCO}_{3}\right)$ & 167.00 & 212.00 \\
Carbon dioxide & 5.00 & 26.00 \\
Lead & 0.01 & 0.01 \\
Selenium & 0.01 & 0.01 \\
Copper & 0.01 & 0.10 \\
Calcium & 59.00 & 52.00 \\
Magnesium & 27.00 & 18.00 \\
Sodium & 328.00 & 35.00 \\
Potassium & 8.00 & 7.00 \\
Iron & 0.10 & 0.12 \\
Aluminum & 0.39 & 0.01 \\
Manganese & 0.10 & 0.10 \\
Ammonia (as nitrogen) & 0.34 & 0.05 \\
Sulfate & 238.00 & 34.00 \\
Chloride & 362.00 & 1.00 \\
Nitrate (as nitrogen) & 0.35 & 1.96 \\
Total phosphorus & 0.51 & 0.35 \\
Fluoride & 0.68 & 1.55 \\
Silica & 8.00 & 49.00 \\
Total hardness as CaCO3 & 258.00 & 204.00 \\
Total dissolved solids & 1216.00 & 400.00
\end{tabular}


Prakash et al. were able to generate scale by oversaturating the water recirculating through the system with calcium and bicarbonate and by injection of sodium hydroxide to maintain the $\mathrm{pH}$ above the saturation level for calcium carbonate. The tubing samples were removed after 1 week and dried in an oven to encourage crystallization. The process was continued until a 0.25 -in. accumulation of scale was obtained.

It was hoped that the same procedure would work with the Lubbock water, but this was not successful. Several alternative conditions were used, with contact times of up to 3 weeks. First, since according to the LI, the Lubbock water was already oversaturated with calcium carbonate at $65^{\circ} \mathrm{C}$, simple addition of sodium hydroxide was used to elevate the $\mathrm{pH}$ of the water to approximately 10 , but no scale formed. In fact, the copper tubing turned black due to formation of copper oxide. Second, sodium carbonate and calcium chloride were added to the recirculating water to ensure significant oversaturation. This procedure resulted only in the attachment of a fine white powder-like material. Third, the solution was oversaturated by adding sodium bicarbonate and calcium chloride. Again, only the fine white powder resulted. Fourth, calcium carbonate was added with the sodium bicarbonate and calcium chloride in an attempt to catalyze the precipitation process. Ample precipitate was apparent in the water bath, but no additional scale resulted. Fifth, an agitator in the water bath was activated to circulate more of the precipitate through the heated tubing. This step also was unsuccessful. During several of these attempts, the copper tubes were removed and dried as often as every $48 \mathrm{hr}$.

The most likely factor preventing the formation of scale was the presence of phosphates in the Lubbock water. As shown in Table 5, the total phosphorus concentration is on the order of $0.5 \mathrm{mg} / \mathrm{L}$, and the phosphates contributing to that total could easily form scale inhibitors, such as sodium hexametaphosphate, with the ample sodium content in the water. In addition, magnesium and sulfate concentrations can disrupt the formation of calcium carbonate scale. Magnesium may take up part of the available carbonate to form $\mathrm{CaMg}\left(\mathrm{CO}_{3}\right)_{2}$ or $\mathrm{MgCO}_{3}$ - two compounds which are much less likely to precipitate than $\mathrm{CaCO}_{3}$. Finally, sulfate may interfere with the crystal surface formation process.

In spring 1989 , the plumbing staff discovered an unused, heavily scaled copper pipe in Drane Hall (Figure 22). This building had been constructed in 1940 as a dormitory and was later converted into an office. The scaled pipe probably had been installed during the original construction. It had been disconnected for an unknown period (probably since the building conversion), so its service life could not be determined.

The inside diameter of the pipe is $2.5 \mathrm{in}$., and approximately $0.5 \mathrm{in}$. of scale had accumulated around the circumference. A sample of the pipe was sent to USACERL for analysis. In a simple test to identify carbonate scale, a small piece of the scale was placed in $1 \mathrm{~N}$ hydrochloric acid. The scale effervesced due to carbon dioxide formation and eventually dissolved completely, indicating the scale was predominantly carbonate minerals. Since the artificial scaling process failed, the pipe from Drane Hall was cut into 3-in. sections for use in the pipe manifold experiments.

\section{Pipe Manifold Experiments}

The apparatus used in the scale removal experiments was again similar to that used by Prakash et al. (Figure 23). The carbon dioxide cylinder is not visible in the figure since it was behind the apparatus. The manifold was originally designed to hold scaled pipe samples of 1 - $\mathrm{ft}$ length and 0.5 -in. diameter, so modification was necessary to allow the 3-in.-long, 2.5-in.-diameter samples in the three vertical pipes to the right. The vertical pipe section on the left was used to hold a clean, new 9-in.-long by 0.5 -in.-diameter copper tube to monitor corrosive losses. The $\mathrm{pH}$ controller was set to the desired $\mathrm{pH}$ level with a tolerance of $0.1 \mathrm{pH}$ units, and the controller regulated the carbon dioxide injection to keep the system $\mathrm{pH}$ at the correct level. Flow rates were set to provide a flow velocity of $0.5 \mathrm{ft} / \mathrm{sec}$ in the scaled pipe samples, based on the actual open area. 


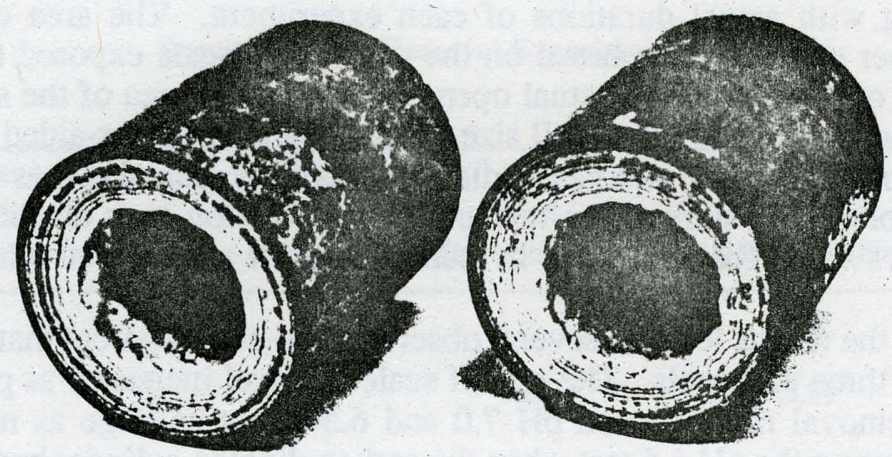

Figure 22. Scaled pipe samples from Drane Hall.

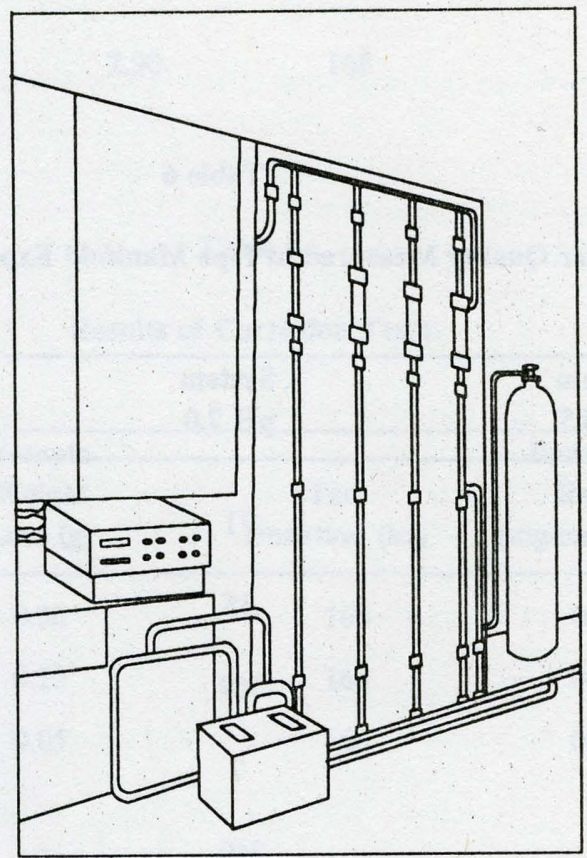

Figure 23. Pipe manifold apparatus used in laboratory experiments.

The three $\mathrm{pH}$ levels investigated were $6.5,7.0$, and 7.5 , all below the normal $\mathrm{pH}$ of the tapwater, which ranges from 7.8 to 8.1. In each experiment, three scaled pipe samples and one new copper tube were connected in the vertical risers on the manifold. Before installation, all four test sections were weighed to the nearest $0.01 \mathrm{~g}$. The time duration of each test was approximately 7 days. After each test was completed, the test sections were removed, dried overnight in an $104^{\circ} \mathrm{C}$ oven, and weighed to the nearest $0.01 \mathrm{~g}$. Samples of the water from the pipe manifold system were taken and analyzed for major ion concentrations. In addition, samples of the raw tapwater were collected twice during the experimental period. The bicarbonate concentrations were analyzed by titration, and the other ions were analyzed by ion chromatography. 
Table 6 lists the compositions of the different waters. Table 7 presents the results of the scale removal tests along with actual durations of each experiment. The area calculation to find the mass removed per area per unit time was based on the area of the scale exposed to the water, not necessarily the inside diameter of the pipe. The actual open cross sectional area of the scaled sample was measured by photocopying the end of the pipe at full size, then using a computer-aided drafting program to digitize and calculate the open area. The equivalent diameter was then calculated as the diameter of a circle with the same area. Table 8 summarizes the results of the corrosion tests on the new 0.5 -in. copper tubing. The values in Tables 7 and 8 are reported in metric units for comparison with the work of Prakash et al.

Inspection of the results leads to several observations. It is apparent that the scale removal technique was effective at all three $\mathrm{pH}$ levels. The rate of scale removal increased as $\mathrm{pH}$ decreased. However, the increase in scale removal rate between $\mathrm{pH} 7.0$ and 6.5 is not as large as might be expected. A small problem occurred during the $\mathrm{pH} 6.5$ test when the carbon dioxide cylinder became empty one night before the test was completed. A strip-chart recorder connected to the $\mathrm{pH}$ controller indicated that the carbon dioxide was off for just over $6 \mathrm{hr}$ while the system $\mathrm{pH}$ rose. A new cylinder of gas was obtained, and the test was continued from that point to a total experimental duration of $166 \mathrm{hr}$. This situation could not have caused any significant reduction in the total scale removal. This question is addressed further under Modeling Equilibrium Water Quality below.

Table 6

Water Quality Measured in Pipe Manifold Experiments (mg/L)

\begin{tabular}{lllll}
\hline Constituent & $\begin{array}{l}\text { System } \\
\mathbf{p H ~ 6 . 5}\end{array}$ & $\begin{array}{l}\text { System } \\
\mathbf{p H ~ 7 . 0}\end{array}$ & $\begin{array}{l}\text { System } \\
\mathbf{p H ~ 7 . 5}\end{array}$ & Tapwater \\
\hline $\mathrm{Ca}^{2+}$ & 51 & 71 & 3 & 42 \\
$\mathrm{Mg}^{2+}$ & 24 & 35 & 22 & 24 \\
$\mathrm{Na}^{+}$ & 405 & 369 & 371 & 380 \\
$\mathrm{~K}^{+}$ & 12 & 7 & 10 & 13 \\
$\mathrm{HCO}_{3}$ & 242 & 240 & 211 & 208 \\
$\mathrm{Cl}^{-}$ & 356 & 363 & 373 & 369 \\
$\mathrm{SO}_{2}{ }^{-}$ & 318 & 346 & 302 & 321
\end{tabular}


Table 7

Results of Scale Removal Experiments

\begin{tabular}{|c|c|c|c|c|c|}
\hline pH & $\begin{array}{l}\text { Sample } \\
\text { Weight } \\
\text { Loss (g) }\end{array}$ & $\begin{array}{l}\text { Average } \\
\text { Weight } \\
\text { Loss (g) }\end{array}$ & $\begin{array}{c}\text { Test } \\
\text { Duration (hr) }\end{array}$ & $\begin{array}{l}\text { Equivalent } \\
\text { Inside } \\
\text { Diameter (cm) }\end{array}$ & $\begin{array}{c}\text { Removal } \\
\text { Rate } \\
\text { (mg/cm²-day) }\end{array}$ \\
\hline & 10.35 & & & & \\
\hline \multirow[t]{3}{*}{6.5} & 10.90 & 10.78 & 166 & 3.89 & 16.7 \\
\hline & 11.10 & & & & \\
\hline & 8.45 & & & & \\
\hline \multirow[t]{3}{*}{7.0} & 10.10 & 9.68 & 168 & 3.96 & 14.6 \\
\hline & 10.50 & & & & \\
\hline & 2.20 & & & & \\
\hline \multirow[t]{2}{*}{7.5} & 3.50 & 2.90 & 168 & 3.84 & 4.5 \\
\hline & 3.00 & & & & \\
\hline
\end{tabular}

Table 8

Results of Corrosion Tests

\begin{tabular}{cccc}
\hline $\mathbf{p H}$ & $\begin{array}{c}\text { Sample } \\
\text { Weight } \\
\text { Loss (g) }\end{array}$ & $\begin{array}{c}\text { Test } \\
\text { Duration (hr) }\end{array}$ & $\begin{array}{c}\text { Removal } \\
\text { Rate } \\
\left(\mathbf{m g} / \mathbf{c m}^{2} \text {-day) }\right.\end{array}$ \\
\hline 6.5 & 0.30 & 166 & 0.48 \\
7.0 & 0.20 & 168 & 0.31 \\
7.5 & 0.05 & 168 & 0.08
\end{tabular}

It is interesting that the greatest increase in calcium concentration occurred in the $\mathrm{pH} 7.0$ test, while the bicarbonate concentrations increased similarly in both the $\mathrm{pH} 6.5$ and 7.0 tests. In a simple batch dissolution experiment, the concentrations of the components affected by dissolution of the solid would have to increase as the $\mathrm{pH}$ decreased. However, these experiments were not batch, but recirculating flow, with approximately 20 percent of the flow wasted and makeup water provided as regulated by the water level controller. The composition of the water in the system was not likely uniform over time and was affected by the incoming water quality and the dissolution process in the system. The composition of any water sample could then be dependent on the timing of the sample collection relative to makeup water addition.

The sample collection times were not controlled closely in these experiments, but three samples were taken during each test, with the average values reported in Table 6 . In addition, the magnesium concentration was elevated only in the $\mathrm{pH} 7.0$ test samples. Since all scaled pipe samples were from the same pipe, the composition of the scale should be the same in each sample. The scale would have to contain a significant amount of magnesium for dissolution to increase the magnesium concentration in solution. No significant added magnesium concentration was noted in the $\mathrm{pH} 6.5$ test, which resulted in 
the greatest dissolution. The most reasonable explanation for the $\mathrm{pH} 7.0$ results may be that the calcium and magnesium concentrations in the water supply must have been elevated through much of the duration of that test.

The corrosion rates for the different $\mathrm{pH}$ levels follow the expected trend, increasing with decreasing $\mathrm{pH}$. Each copper tube weighed approximately $88 \mathrm{~g}$, giving a weight of copper per unit area of about 1090 $\mathrm{mg} / \mathrm{cm}^{2}$. If corrosion were uniform, the copper would be completely removed after $6.2,9.6$, and 37 years at continuous exposure to these waters with $\mathrm{pH} 6.5,7.0$, and 7.5, respectively. Of course, corrosion is rarely uniform, and pipe failure could occur more quickly. Still, the corrosion rates are low enough to allow exposure of new pipe to the lower $\mathrm{pH}$ waters for shorter periods sufficient to remove scale from older pipe. Other corrosion mechanisms such as galvanic corrosion could complicate this situation.

\section{Modeling Equilibrium Water Quality}

In the laboratory experiments, carbon dioxide was added as needed to maintain a desired $\mathrm{pH}$ level in the water recirculating through the system. Since the gas was added by bubbling into an open water bath, much of it was lost, so that actual carbon dioxide concentrations in the water could not be calculated from the gas flow to the diffuser.

Gravimetric analysis was used to determine scale removal, and the water quality was characterized by its major ion concentrations. These data were sufficient to demonstrate the effectiveness of the technique but not to fully explain the scale removal process in this water. For this reason, a computer model for equilibrium water chemical analyses was used to interpret the experimental results.

Parkhurst et al. developed the model known as PHREEQE to analyze equilibrium and oxidation-reduction reactions of special interest to geochemists. ${ }^{13}$ The model allows the user to specify the elemental composition of the water solution and then performs several types of analyses. It includes a data base of thermodynamic coefficients and temperature correction parameters for many ionic species and minerals, and the user can modify or expand it as desired. The program can calculate theoretical combinations of the various water constituents, taking into account temperature and ionic strength effects on the reactions. Saturation indices for various minerals are derived. The water can be placed in equilibrium with various mineral solids and gases at specified saturation levels. Reactions can be added to the original solution in stepwise fashion and at various temperatures. A second program, PHRQINPT, was written to facilitate the assembly of input data required to run PHREEQE. Both programs are available from the International Ground Water Modeling Center at Butler University (telephone 317-2839458). It should be noted that this model, and others like it, consider only stoichiometric reactions and determine only when precipitation and dissolution of minerals are likely. They do not determine the amount of scale that may form in a given water system. Still, PHREEQE is useful in understanding the complicated chemical interactions that lead to scale deposits.

In this project, PHREEQE was used in three different ways. First, the raw water supplies were analyzed to determine the saturation indices of minerals that might form in the water. Second, by placing the water in equilibrium with the minerals with which the water was oversaturated, the model calculated the possible concentration change due to precipitation for each mineral. When referring to calcium carbonate, this quantity, called DELTA PHASE in the model output, corresponds to the CCPP value. Third, the model was used to estimate the carbon dioxide concentrations necessary to obtain the pH levels in the laboratory experiments.

To model conditions for the Texas Tech demonstration, the water quality data shown in Table 4 were used to represent the old Lubbock groundwater supply. The "tapwater" data in Table 6 were used

${ }^{13}$ D.L. Parkhurst, D.C. Thorstenson, and L.N. Plummer, PHREEQE - A Computer Program for Geochemical Calculations, Water Resources Investigations Report 80-96 (U.S. Geological Survey, (1980). 
to represent the current, possibly blended, water supply. In both cases, the solutions were charge-balanced by adding the required amount of chloride for electrical neutrality. This correction, which does not affect the carbonate chemistry, allowed the program to calculate the $\mathrm{pH}$ of the water. Results of the run for 65 ${ }^{\circ} \mathrm{C}$ are shown in Table 9. The base 10 logarithms of the saturation indices are listed as $\log$ (IAP/KT). At $25^{\circ} \mathrm{C}$ and $65^{\circ} \mathrm{C}$, both waters are oversaturated with respect to calcite, aragonite, and dolomite. Since it is usually accepted that aragonite is the dominant calcium carbonate formed at temperatures above 30 ${ }^{0} \mathrm{C}$, the information for calcite is not presented here. In addition, dolomite precipitates only under pressures much higher than those in normal pipe systems and may exist in water at concentrations very much above saturation. ${ }^{14}$ The precipitation potential for dolomite is therefore not shown in the table. The CCPP value was found by specifying the waters in equilibrium with aragonite.

It should be recognized that the calculation of saturation indices considers only individual minerals. The common ion effect may interfere in the formation of aragonite, $\mathrm{CaCO}_{3}$, if dolomite, $\mathrm{CaMg}\left(\mathrm{CO}_{3}\right)_{2}$, is also using carbonate in the solution. The formation of dolomite is not well understood, ${ }^{15}$ and its interaction in the scale formation in this water may not be quantified exactly. Since dolomite may exist in solution at a very oversaturated concentration, the CCPP may significantly overestimate the aragonite available for scale formation.

Next, PHREEQE was used to estimate the carbon dioxide concentration required to maintain the $\mathrm{pH}$ levels in the laboratory experiments. This step was completed for each test by specifying the water composition shown in Table 6 , adding chloride to achieve electroneutrality, selecting equilibrium with aragonite, and varying the carbon dioxide concentration, expressed in the model input as a partial pressure, from 2.6 to $520 \mathrm{mg} / \mathrm{L}$ in different simulations. For each carbon dioxide concentration, the model calculated the $\mathrm{pH}$ and the CCPP. If none of the discrete runs resulted in a pH exactly equal to that in the test, the carbon dioxide dose and CCPP were calculated by interpolation. Table 10 shows the results of this effort.

The results in Table 10 are interesting. The carbon dioxide doses are reasonable compared with Prakash et al. ${ }^{16}$ The CCPP value for $\mathrm{pH} 7.5$ indicates aragonite precipitation, although the test showed dissolution was occurring. It is possible that a certain level of oversaturation may be needed to achieve actual scale precipitation, so that dissolution may proceed past the theoretical equilibrium. It is also possible that dolomite was complicating this system. Other model simulations that include equilibrium with dolomite showed that the CCPP results become larger negative values than those in Table 10 . The difficulty is knowing what oversaturation level to assign to the dolomite in the simulation. In any case, the idealized modeling alone is not adequate to determine carbon dioxide dosage. Empirical laboratory experiments and close monitoring in the field are still necessary to determine optimal conditions.

Another interesting application of PHREEQE was to examine current Lubbock tapwater, as shown in Table 6, and show the effects of carbon dioxide injection on the water composition and aragonite scale removal. The unsuccessful scale generation experiments demonstrated that the current water supply does not generate scale (however, the current water must be used in the scale removal). This set of simulations showed how the calcium, bicarbonate (corresponding to alkalinity), and calcium carbonate dissolution all varied with $\mathrm{pH}$ changes caused by carbon dioxide injection. Figure 24 shows the results of these simulations. Note again that, when only aragonite is set in equilibrium with the solution, the aragonite precipitates at $\mathrm{pH}$ greater than 7.3. Figure 25 shows similar simulations with equilibrium when dolomite is added. The aragonite dissolves in the $\mathrm{pH}$ range 6 to 8, whereas dolomite precipitates at $\mathrm{pH}$ above 6.5.

\footnotetext{
${ }^{14}$ J.C. Cowan and D.J. Weintritt.

${ }^{15}$ W. Stumm and J.J. Morgan, Aquatic Chemistry, 2nd ed. (John Wiley \& Sons, 1981).

${ }^{16} \mathrm{~T}$. Prakash et al.
} 
Table 9

Mineral Equilibrium Analyses for Old (1944) and New (1989) Lubbock

Water Supplies at $68^{\circ} \mathrm{C}$

\begin{tabular}{lllc}
\hline Water & Mineral & $\log (\mathrm{IAP} / \mathrm{KT})$ & $\operatorname{CCPP}(\mathrm{mg} / \mathrm{L})$ \\
\hline \multirow{2}{*}{1944} & Aragonite & 0.49 & 33.8 \\
& Dolomite & 1.71 & \\
1989 & & & \\
& Aragonite & 0.49 & 13.0 \\
& Dolomite & 1.25 &
\end{tabular}

Table 10

Estimated Carbon Dioxide Concentration and

CCPP Values for the Laboratory Experiments

\begin{tabular}{ccc}
\hline $\mathbf{p H}$ & $\begin{array}{c}\text { Carbon } \\
\text { Dioxide }(\mathrm{mg} / \mathrm{L})\end{array}$ & $\mathbf{C C P P}(\mathrm{mg} / \mathrm{L})$ \\
\hline 6.5 & 176 & -235 \\
7.0 & 30 & -28 \\
7.5 & 15 & 8
\end{tabular}

\section{Installation in Doak Hall}

The carbon dioxide treatment system will be installed at Doak Hall on the Texas Tech campus. Details of the installation are currently being negotiated. While this application is for a university environment, the approach would be similar for any facility. Thus, the DEH can use this chapter as guidance for implementing a carbon dioxide treatment system on Army installations. Chapter 7 contains additional guidance.

Doak Hall was built in 1934 as a three-story dormitory with about 50 rooms per floor and a cafeteria/kitchen. The first floor has since been remodeled to serve as office space and the kitchen was removed. Today, about 200 students live on the upper two floors. A pipe sample removed from the attic showed evidence of scale in the copper plumbing system (Figure 26). In addition to its three aboveground floors, Doak Hall has a basement which is used for mechanical facilities. A 750-gal (estimated) water heater is included. Hot water flows from the heater through approximately $2000 \mathrm{ft}$ of 0.75 -in. copper pipe for connection to 500.5 -in. copper riser pipes that extend through the vertical walls to connect to sinks in each room on the second and third floors.

In addition, two community bath/shower rooms are supplied on each of the top two floors. Figure 27 shows the floor plans of the second and third floors. The first floor offices have negligible hot water demand. With an average vertical length of $60 \mathrm{ft}$, the riser pipes total approximately $3000 \mathrm{ft}$. These riser 


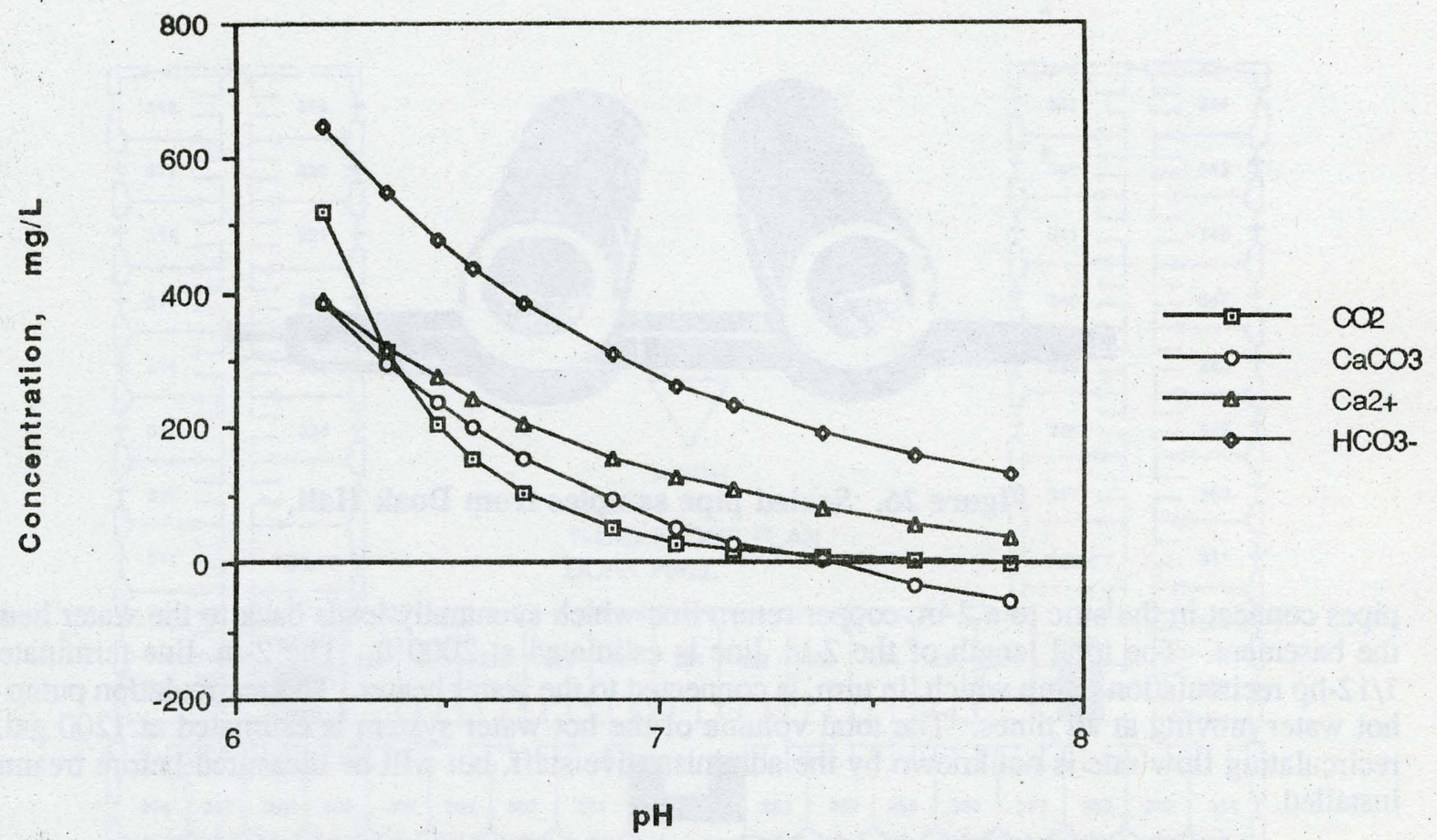

Figure 24. Effect of carbon dioxide addition on aragonite dissolution.

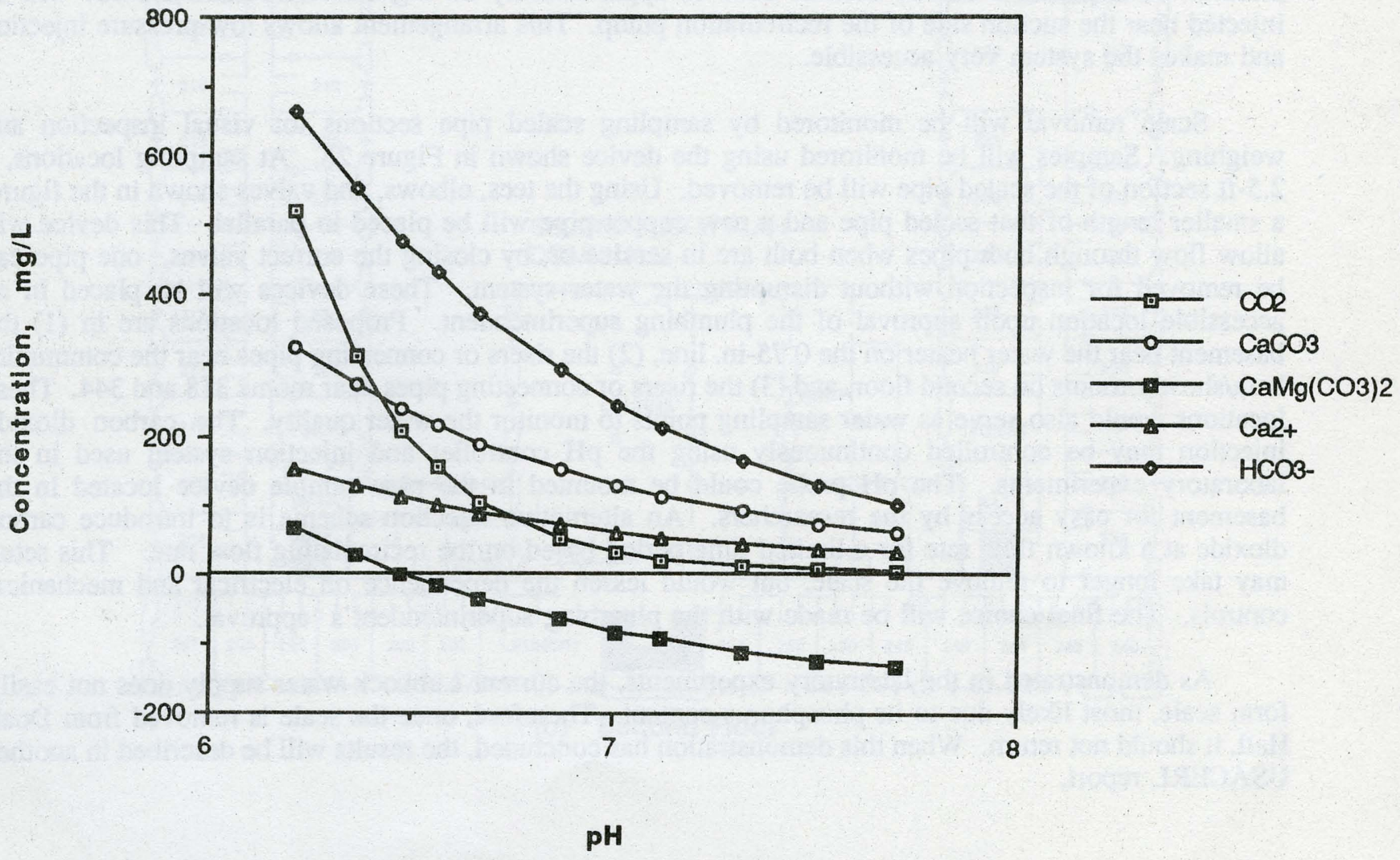

Figure 25. Effect of carbon dioxide addition on aragonite and dolomite dissolution. 


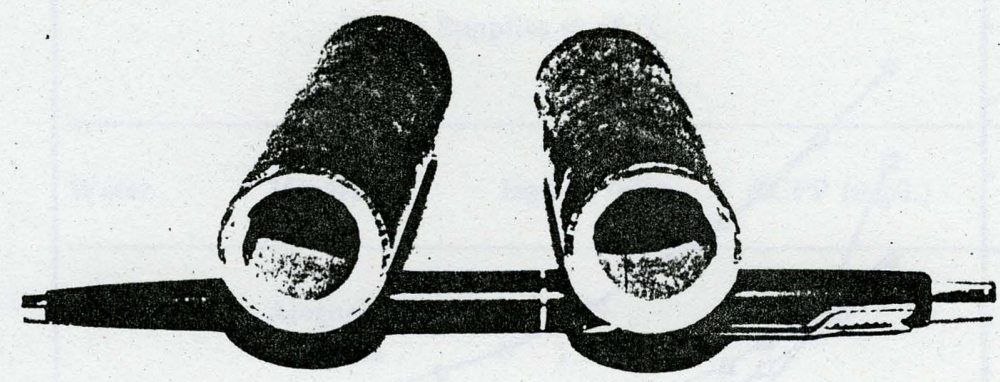

Figure 26. Scaled pipe samples from Doak Hall.

pipes connect in the attic to a 2 -in. copper return line which eventually leads back to the water heater in the basement. The total length of the 2 -in. line is estimated at $2000 \mathrm{ft}$. The 2-in. line terminates at a $1 / 12$-hp recirculation pump which, in turn, is connected to the water heater. The recirculation pump keeps hot water moving at all times. The total volume of the hot water system is estimated at 1200 gal. The recirculating flow rate is not known by the administrative staff, but will be measured before treatment is installed.

It appears from the laboratory experiments that a $\mathrm{pH}$ level between 7.0 and 7.5 will be sufficient to dissolve the scale. Since the system is old, a pH of 7.4 will be used as the target to cause slow dissolution, requiring a carbon dioxide dose of approximately $20 \mathrm{mg} / \mathrm{L}$. The carbon dioxide will be injected near the suction side of the recirculation pump. This arrangement allows low-pressure injection and makes the system very accessible.

Scale removal will be monitored by sampling scaled pipe sections for visual inspection and weighing. Samples will be monitored using the device shown in Figure 28. At sampling locations, a 2.5 - $\mathrm{ft}$ section of the scaled pipe will be removed. Using the tees, elbows, and valves shown in the figure, a smaller length of that scaled pipe and a new copper pipe will be placed in parallel. This device will allow flow through both pipes when both are in service or, by closing the correct valves, one pipe can be removed for inspection without disrupting the water system. These devices will be placed in an accessible location upon approval of the plumbing superintendent. Proposed locations are in (1) the basement near the water heater on the 0.75 -in. line, (2) the risers or connecting pipes near the community bath/shower rooms on second floor, and (3) the risers or connecting pipes near rooms 318 and 344 . These locations would also serve as water sampling points to monitor the water quality. The carbon dioxide injection may be controlled continuously using the $\mathrm{pH}$ controller and injection system used in the laboratory experiments. The $\mathrm{pH}$ probe could be mounted in the pipe sample device located in the basement for easy access by the researchers. An alternative injection scheme is to introduce carbon dioxide at a known flow rate for a limited time period based on the recirculating flow rate. This setup may take longer to remove the scale, but would lessen the dependence on electrical and mechanical controls. The final choice will be made with the plumbing superintendent's approval.

As demonstrated in the laboratory experiments, the current Lubbock water supply does not easily form scale, most likely due to its phosphorus content. Therefore, once the scale is removed from Doak Hall, it should not return. When this demonstration has concluded, the results will be described in another USACERL report. 


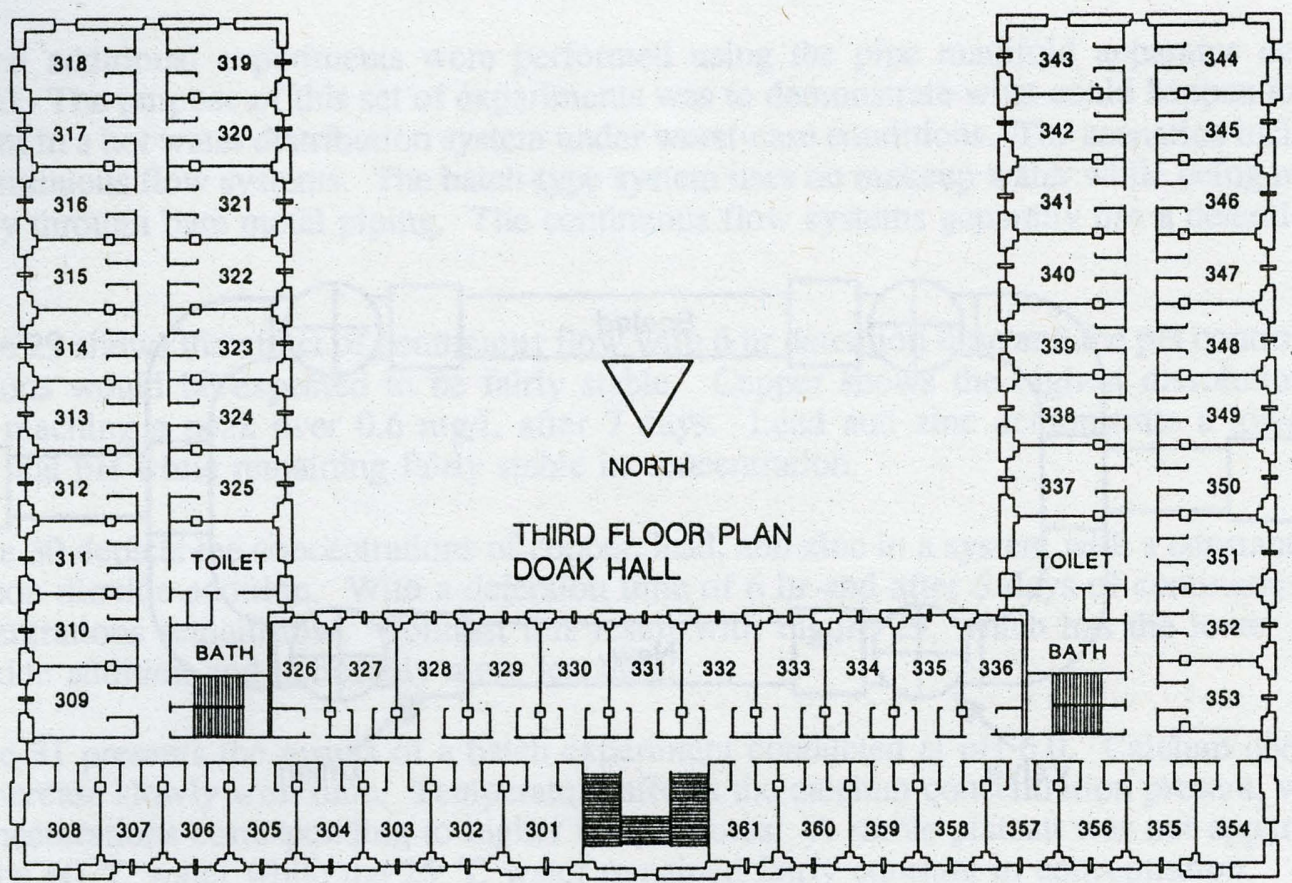

(a) Third Floor

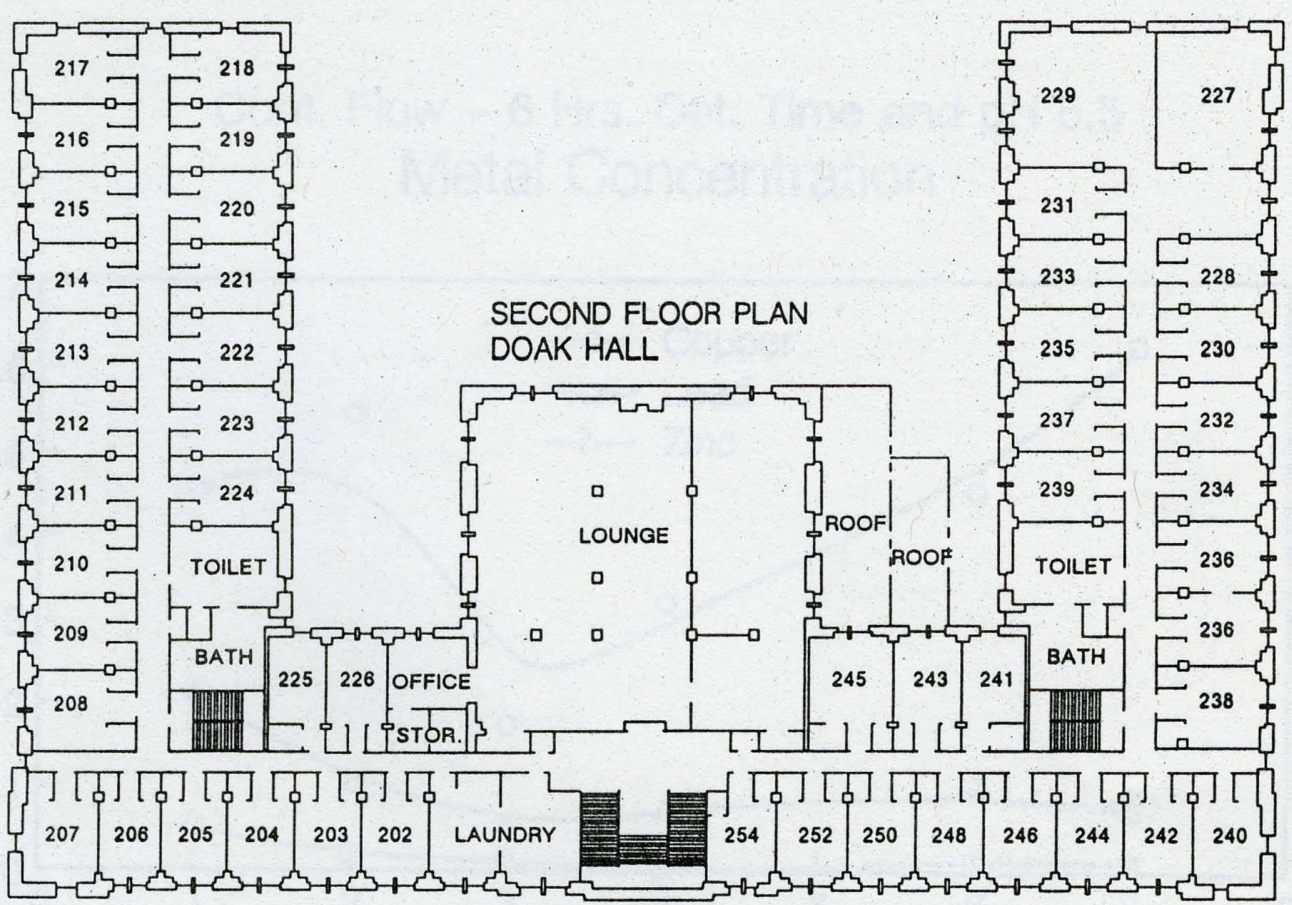

(b) Second Floor

Figure 27. Floor plans of the upper residential floors in Doak Hall. 


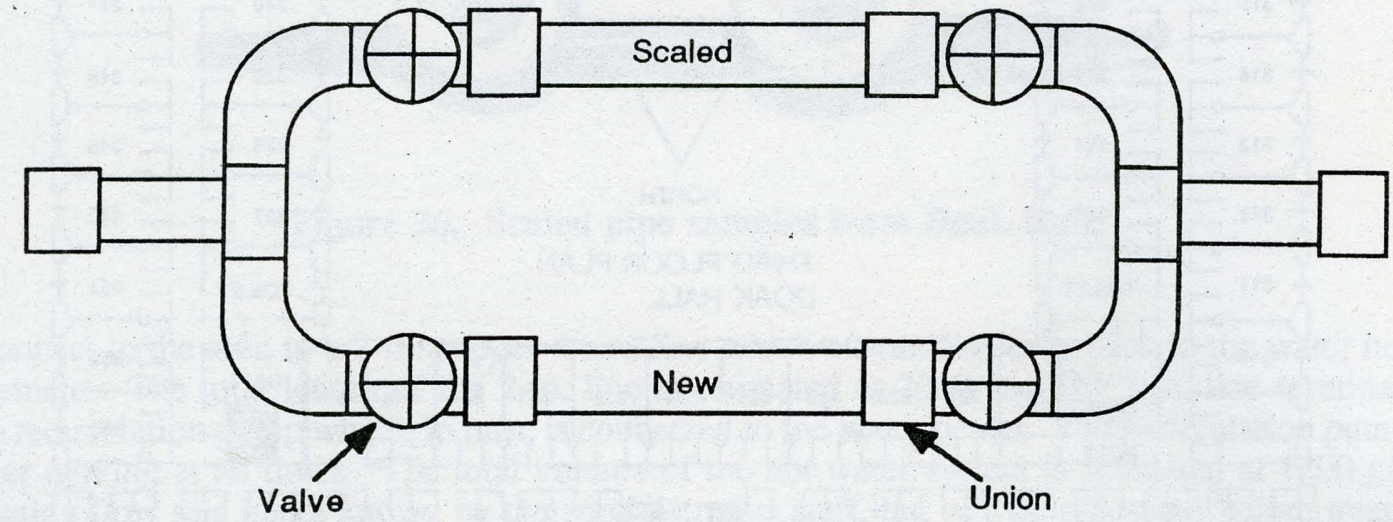

Figure 28. Device for monitoring scale removal and corrosion. 
Several additional experiments were performed using the pipe manifold apparatus described in Prakash et al. The purpose of this set of experiments was to demonstrate what could happen to dissolved metal content in a hot water distribution system under worst-case conditions. The scenarios include batchtype and continuous flow systems. The batch-type system uses no makeup water while being recirculated continuously through bare metal piping. The continuous flow systems generally use a detention time of $6 \mathrm{hr}$.

Figure 29 shows the effect of continuous flow with $6 \mathrm{hr}$ detention time and the pH controlled at 5.5. Concentrations would be expected to be fairly stable. Copper shows the highest dissolution rate and variability, reaching a peak over $0.6 \mathrm{mg} / \mathrm{L}$ after 7 days. Lead and zinc demonstrate a lower level of leaching at that $\mathrm{pH}$ while remaining fairly stable in concentration.

Figure 30 depicts the concentrations of copper, lead, and zinc in a system with a constant $\mathrm{pH}$ of 8.5 and no carbon dioxide addition. With a detention time of $6 \mathrm{hr}$ and after 5 days of continuous flow, the metal concentrations remain low. Contrast this result with Figure 29, which has the lower pH due to carbon dioxide addition and noticeably more leaching.

Figure 31 presents the results of a batch experiment conducted at $\mathrm{pH} 6.0$. Calcium concentration is seen to increase slowly with time. Temperature affects the calcium concentration present, with higher calcium concentrations corresponding to higher temperatures. A stable plateau was not apparent after 4 days with the $60^{\circ} \mathrm{C}$ water while the $25^{\circ} \mathrm{C}$ water remained fairly constant in concentration.

\section{Cont. Flow -6 Hrs. Det. Time and pH 5.5 Metal Concentration}

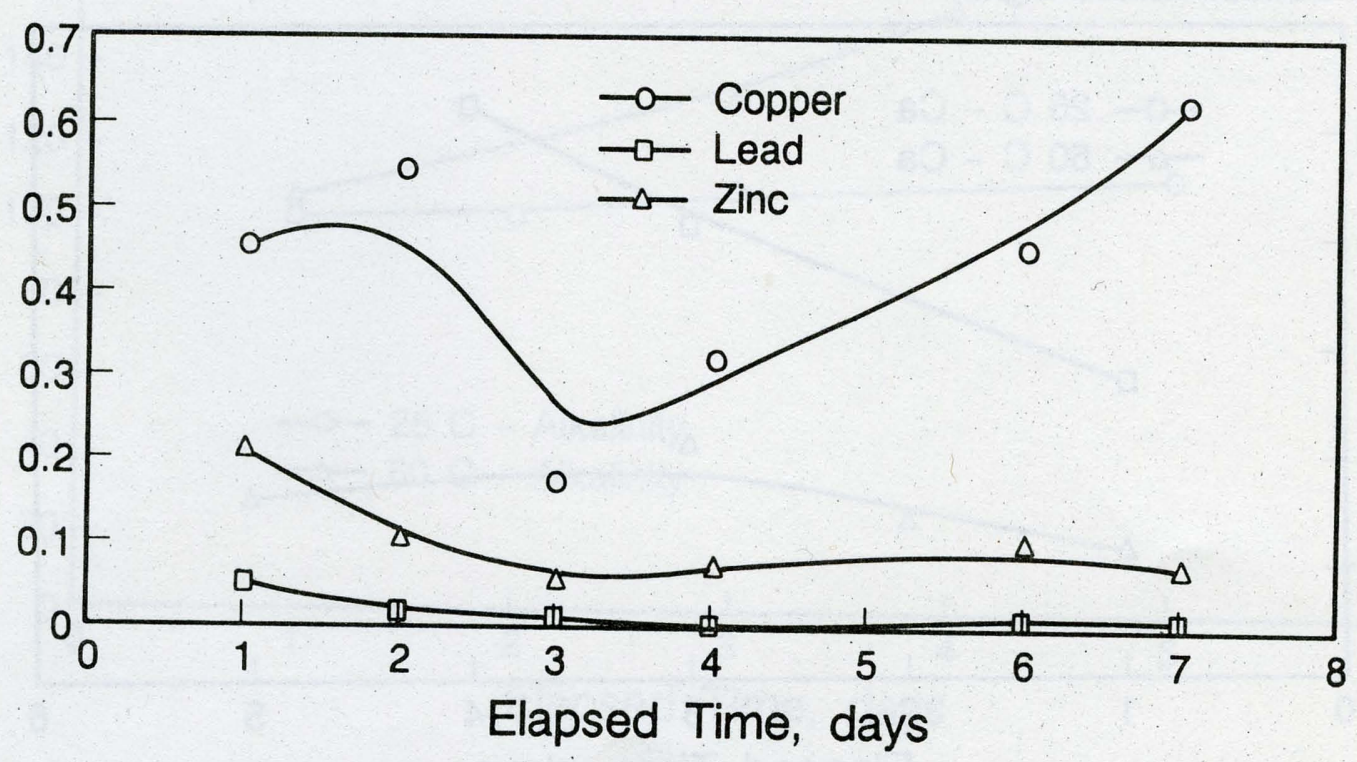

Figure 29. Effect of pH 5.5 on metal concentrations. 
Cont. Flow - $6 \mathrm{Hrs}$. Det. Time and pH 8.5

Metal Concentration

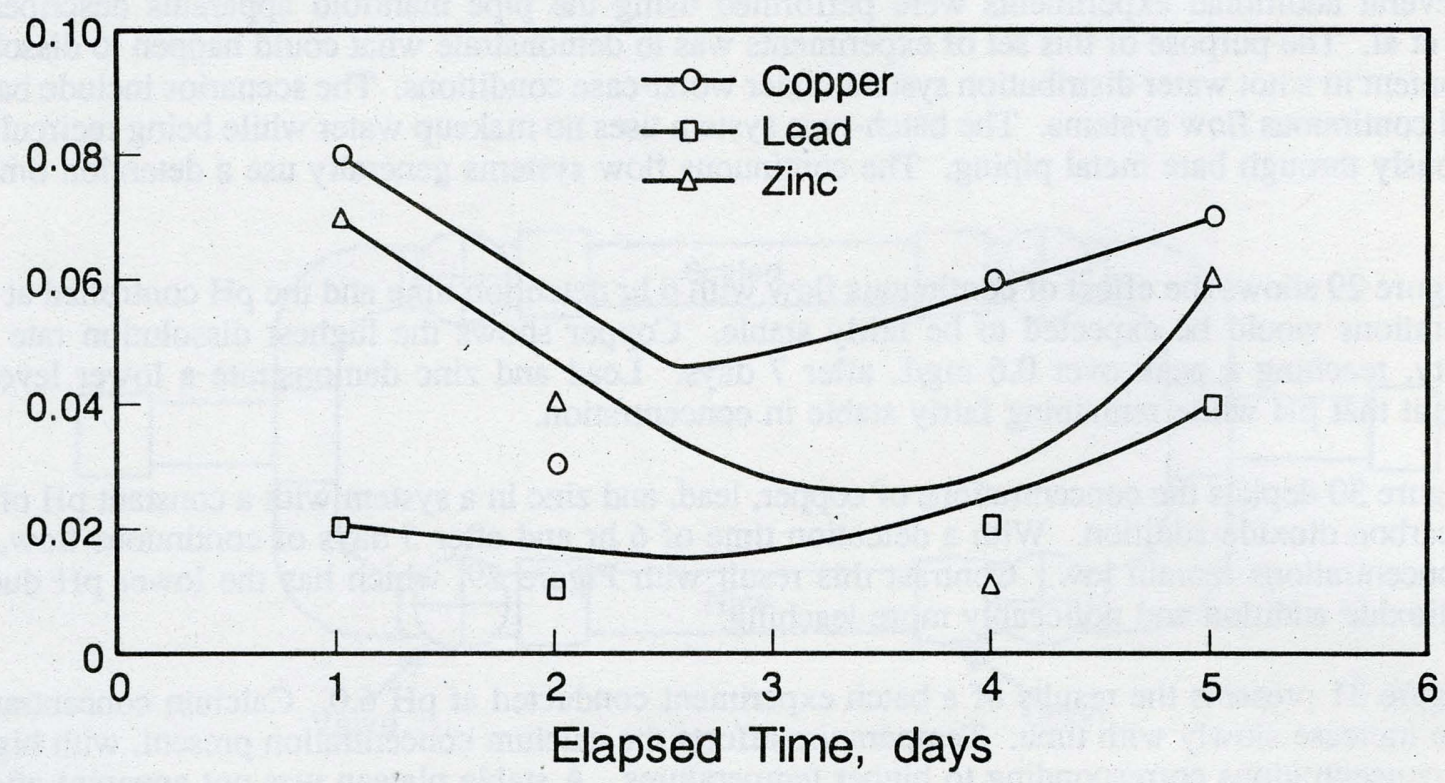

Figure 30. Effect of $\mathrm{pH} 8.5$ on metal concentrations.

Batch Expt. at pH6.0 - Temp. Effect

- Calcium Concentration

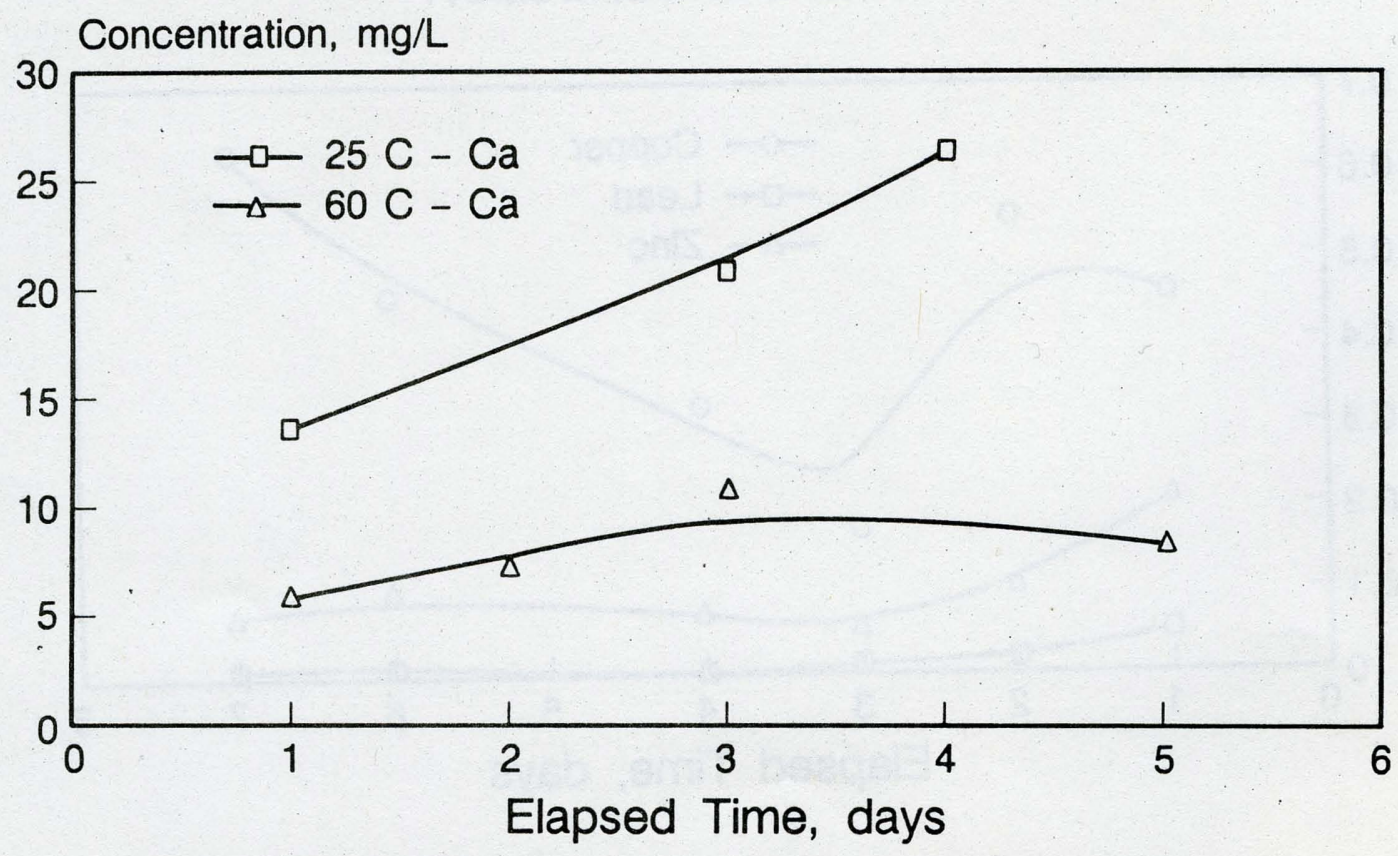

Figure 31. Effect of temperature on calcium concentration. 
Figure 32 shows the changes in alkalinity over time between temperatures with constant pH 6.0. Alkalinity. slowly increases at the $25^{\circ} \mathrm{C}$ level while a more rapid increase is apparent with a $60{ }^{\circ} \mathrm{C}$ temperature.

Figure 33 shows the increase in copper concentration with time at 25 and $60^{\circ} \mathrm{C}$ temperatures with a recirculating batch system and the $\mathrm{pH}$ controlled at 6.0. Copper is seen to constantly increase in concentration at both temperatures, with a more pronounced effect at the lower temperature.

Figure 34 depicts a batch experiment conducted at $25^{\circ} \mathrm{C}$, demonstrating the difference between carbon dioxide treatment and no treatment on copper concentration. The carbon dioxide treatment has a much more pronounced effect than when it is absent, with copper concentration climbing to higher than $5 \mathrm{mg} / \mathrm{L}$ over 4 days versus stable conditions.

Figure 35 compares the effects of presence and absence of carbon dioxide on copper concentration at $60{ }^{\circ} \mathrm{C}$. A slight increase in copper concentration is detectable during the batch experiment with the absence of carbon dioxide, whereas in the presence of carbon dioxide, it shows a rapid increase. Comparing this figure with the previous graph for $25^{\circ} \mathrm{C}$, copper concentration increases rapidly at either temperature.

\section{Batch Expt. at pH6.0 - Temp. Effect Alkalinity Concentration}

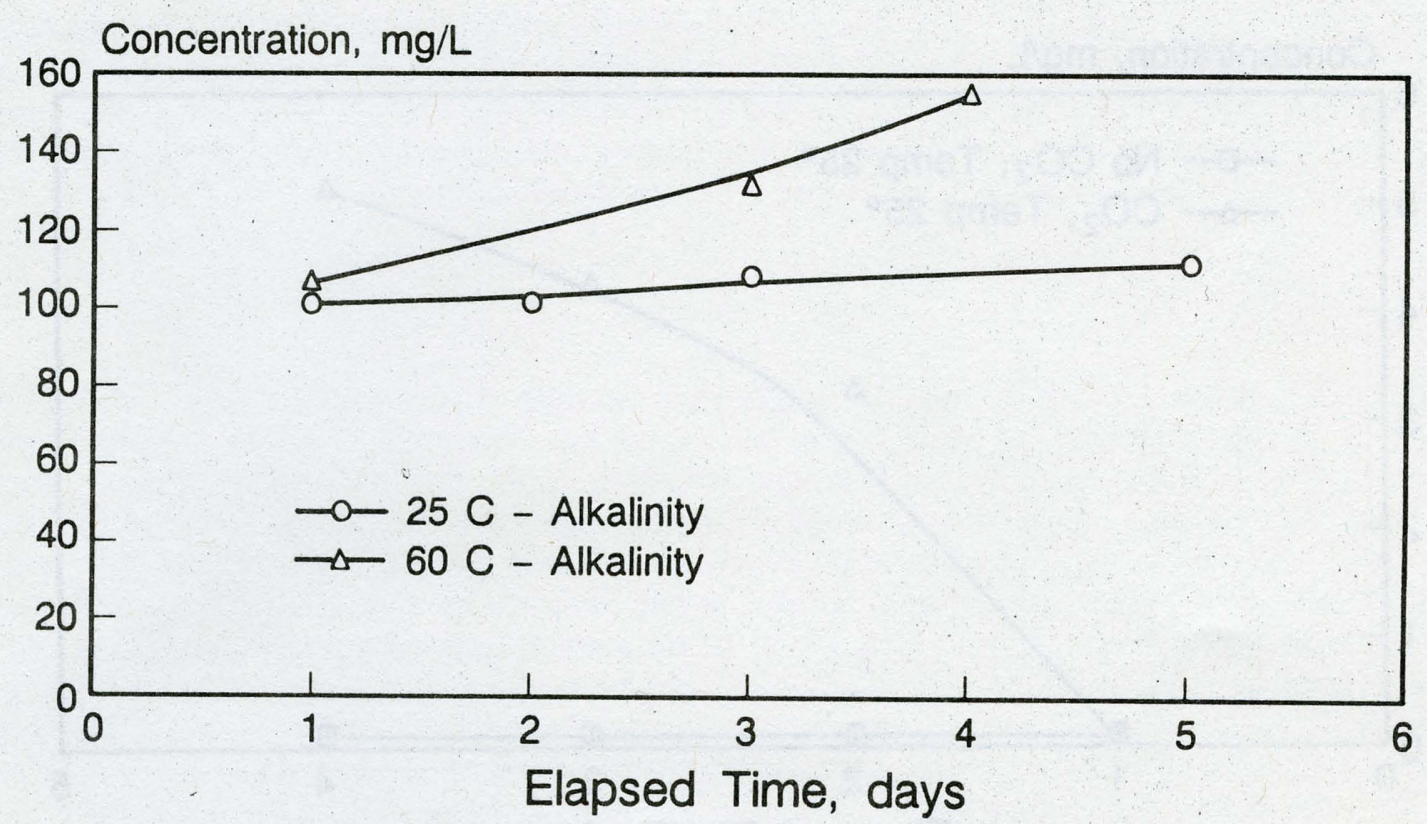

Figure 32. Effect of temperature on alkalinity concentration. 


\section{Batch Expt. at pH6.0 - Temp. Effect \\ Copper Concentration}

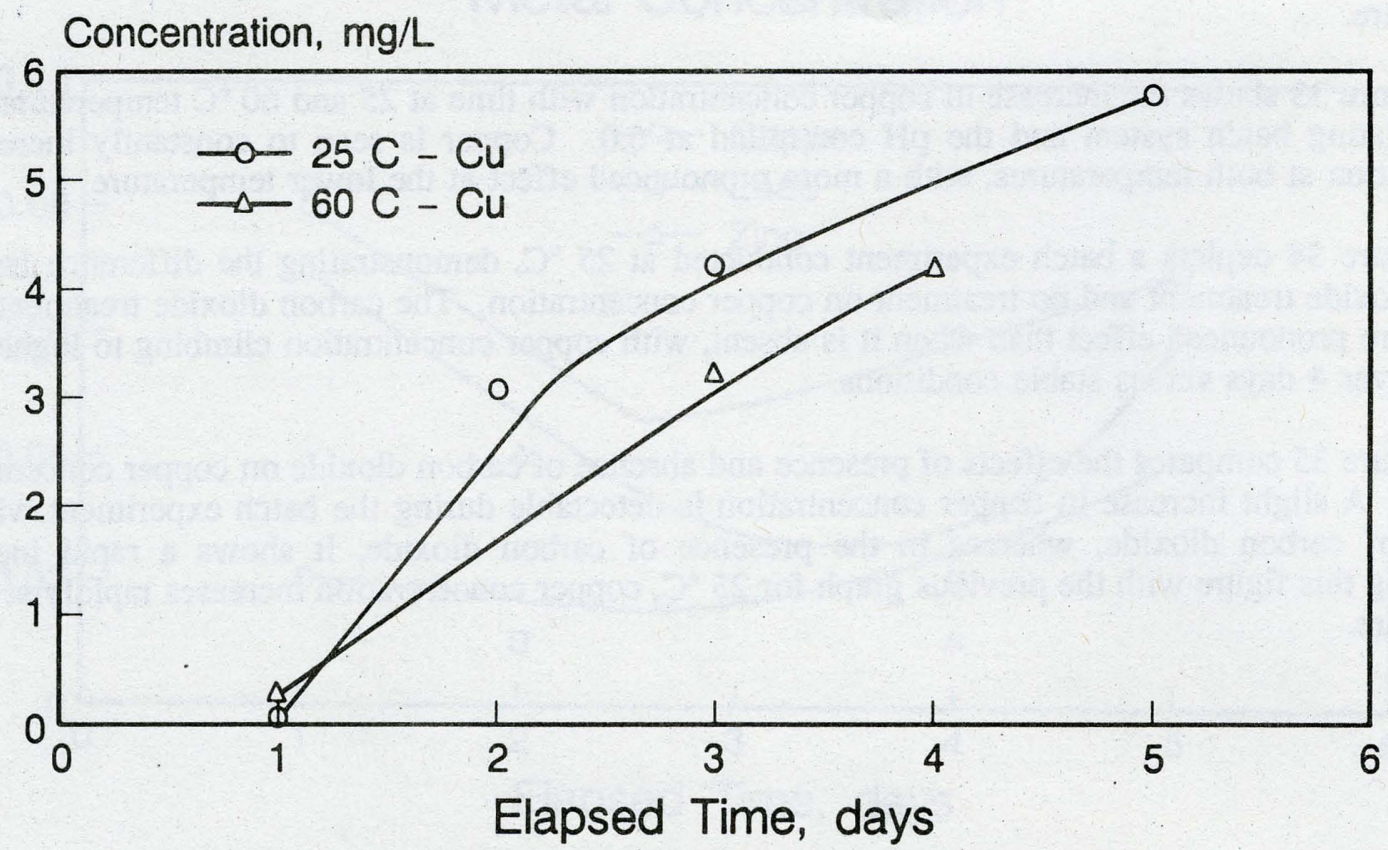

Figure 33. Effect of temperature on copper concentration.

Batch Expts. $-\mathrm{CO}_{2}$ Effect at $25^{\circ} \mathrm{C}$ Copper Concentration

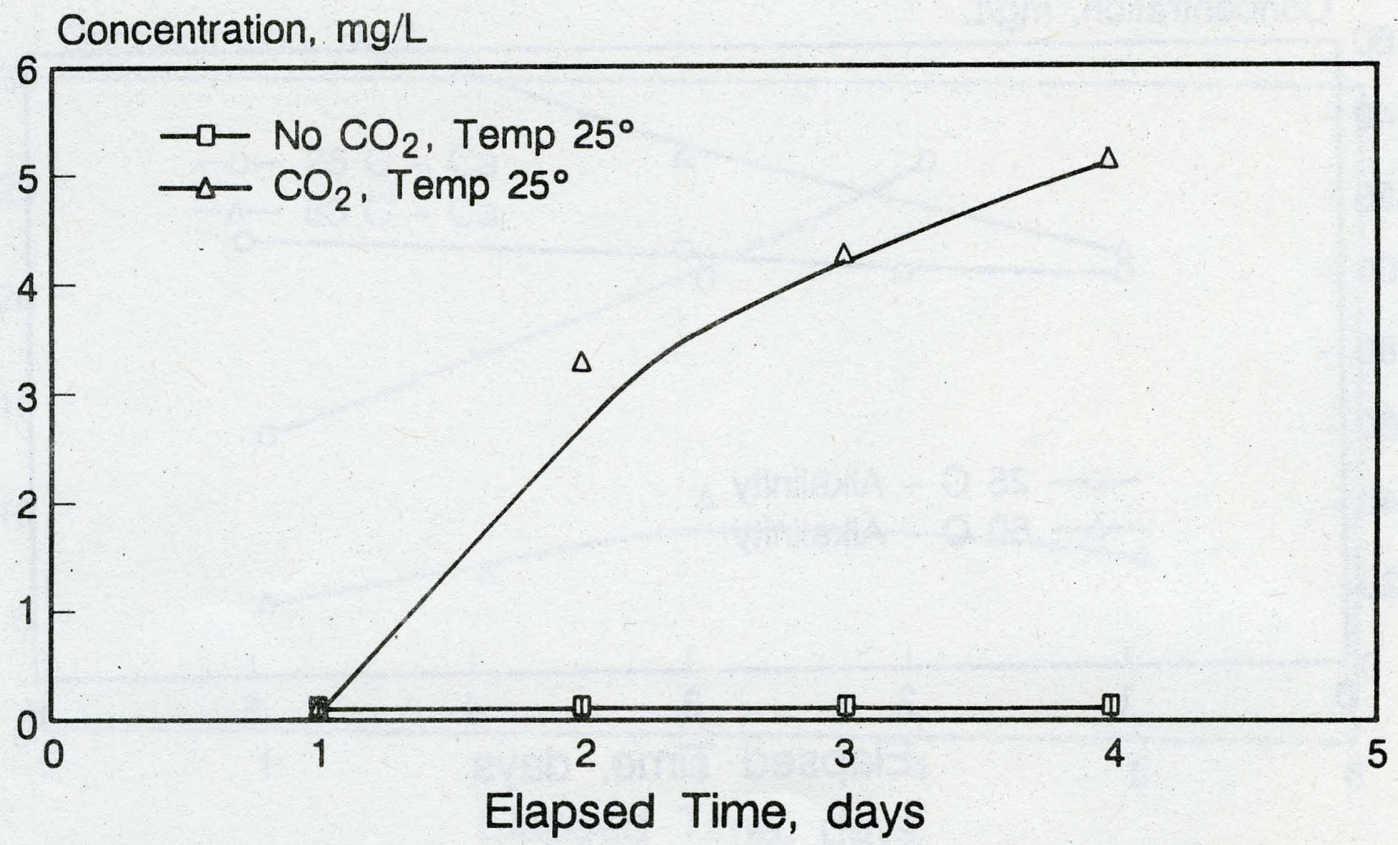

Figure 34. Effect of $\mathrm{CO}_{2}$ on copper concentration, $25^{\circ} \mathrm{C}$. 


\section{Batch Expts. $-\mathrm{CO}_{2}$ Effect at $60^{\circ} \mathrm{C}$ Copper Concentration}

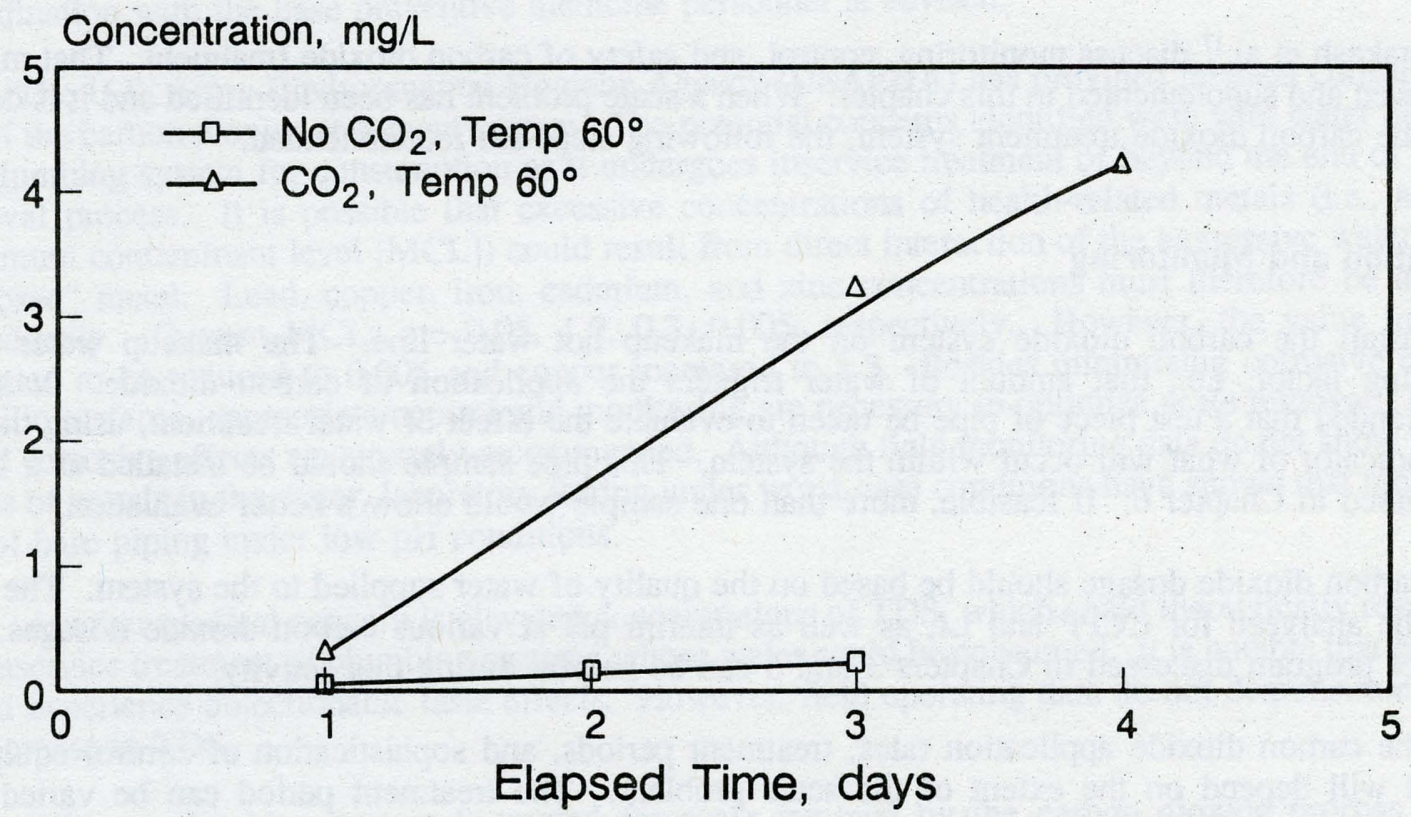

Figure 35. Effect of $\mathrm{CO}_{2}$ on copper concentration, $60^{\circ} \mathrm{C}$. 
Prakash et al. ${ }^{17}$ discuss monitoring, control, and safety of carbon dioxide treatment. That material is reviewed and supplemented in this chapter. When a scale problem has been identified and it is decided to use the carbon dioxide treatment system, the following steps are recommended.

\section{Installation and Monitoring}

Install the carbon dioxide system on the makeup hot water line. The makeup water is the controlling factor, i.e., that amount of water triggers the application of carbon dioxide. It is also recommended that a test piece of pipe be taken to evaluate the effect of water treatment, using the pipe as an indicator of what will occur within the system. This pipe sample should be installed as a bypass as discussed in Chapter 6. If feasible, more than one sample would allow a better evaluation.

Carbon dioxide dosage should be based on the quality of water supplied to the system. The water should be analyzed for CCPP and LI, as well as interim $\mathrm{pH}$ at various carbon dioxide dosages. The computer program discussed in Chapters 3 and 6 can be helpful during this activity.

The carbon dioxide application rates, treatment periods, and sophistication of control equipment required will depend on the extent of the scale problem. The treatment period can be varied from continuous to periodic (e.g., once a day or once a week), depending on the degree of scale present within the system.

Initial experimental results (Temkar et al., 1987) suggested that interim water $\mathrm{pH}$ in the system be maintained initially at about $2 \mathrm{pH}$ units below saturation $\mathrm{pH}$ (i.e., $\mathrm{pH}$ at which the CCPP is zero). As carbon dioxide application proceeds, the $\mathrm{pH}$ should be gradually increased to the saturation $\mathrm{pH}$ as the scale thickness reduces due to dissolution.

It has been suggested that the ideal equipment for controlling carbon dioxide injection into a potable water system would be automatic and respond directly to the level of carbon dioxide needed to maintain the desired $\mathrm{pH}$. Carbon dioxide injection would be controlled by the $\mathrm{pH}$ of water in the system as monitored by a pH meter/controller. However, in a typical building water system, it would be difficult to locate a $\mathrm{pH}$ sensor in a position that provides representative information.

\section{Safety}

Scale dissolution by carbon dioxide treatment in potable water systems is the reverse of the precipitation process by which the scale was deposited earlier. The most immediate effect of applying carbon dioxide to a potable water system is a rapid reduction in $\mathrm{pH}$. Using carbon dioxide to control $\mathrm{pH}$ is inherently safe compared with mineral acids, which are expensive in addition to being hazardous to handle. Also, any overdosage of carbon dioxide into an operating potable water system (e.g., due to an equipment malfunction) is considered least harmful among the scale removal alternatives. In the extreme case, soda water would be produced which would be no more harmful for consumption than any other carbonated beverage. However, in such cases, it should be noted that exposure of low pH carbonated water to piping materials could increase metal concentrations above acceptable limits for consumption. Thus, some type of automatic control system should be employed to offset the corrosive effects of carbon dioxide in water on the piping material.

${ }^{17}$ T. Prakash et al. 
Water samples should be taken while the carbon dioxide system is operating and evaluated for indicator parameters such as carbon dioxide, $\mathrm{pH}$, hardness, and metals representing the piping materials. Coordination with the base preventive medicine personnel is advised.

The U.S. Army Environmental Hygiene Agency (USAEHA) has provided medical consultation on use of the carbon dioxide treatment system. The potential concerns identified were with water taken from the plumbing system for consumption as it undergoes inservice treatment or beyond the end of the scale removal process. It is possible that excessive concentrations of health-related metals (i.e., above the maximum contaminant level [MCL]) could result from direct interaction of the aggressive water with the "exposed" metal. Lead, copper, iron, cadmium, and zinc concentrations must therefore be monitored periodically. Current MCLs are 0.05, 1.0, 0.3, 0.005, respectively. However, the value for lead is expected to be reduced to 0.005 and copper increased to 1.3 . Besides minimizing corrosive effects on metallic surfaces, appropriate control and monitoring are necessary to optimize scale removal. Efforts to avoid corrosive effects are strongly recommended. Although field monitoring data do not show increased levels of metals in the water, laboratory testing under worst-case conditions have shown that metals leach out of bare piping under low pH conditions.

Another medical concern is elevated concentrations of TDS, which could theoretically result during the inservice treatment of plumbing systems whose water could be consumed. It is notable that consumers could experience objectionable taste effects. However, field operating data do not demonstrate this type of increase in TDS.

When a plumbing system is treated for scale removal by the carbon dioxide process and it is possible that the water will be consumed, appropriate notification to indicate a lesser water quality may need to be provided to potential consumers. This notice should be coordinated with the local medical authority.

Local and state regulatory authorities should be consulted to determine what, if any, requirements would be imposed before startup of the carbon dioxide scale removal process. Although carbon dioxide is considered the least innocuous chemical that can be used for scale removal, local and state regulations pertaining to treatment of water supplies should be reviewed before beginning any such treatment. In some cases, the treatment program may need to be monitored by a licensed water treatment plant operator. 


\section{9 : CONCLUSIONS AND RECOMMENDATIONS}

This report has summarized the carbon dioxide treatment system, presented new laboratory research results, and described the lessons-learned from FEAP demonstrations. The previous research summarized here examined the precipitation/dissolution phenomena of calcium carbonate and carbon dioxide. Scaling indexes were analyzed and a computer program was developed (available from USACERL) to optimize application of the carbon dioxide treatment system.

Analytical modeling techniques for predicting scale dissolution characteristics were described. Details on these models also are available from USACERL.

Procedures were described to help installations monitor their water supplies and determine the potential for scaling.

Operation of the carbon dioxide system was evaluated under conditions of very hard water. The system was shown to be successful for all types of water tested.

The carbon dioxide treatment technology will be demonstrated at Texas Tech in a dormitory. Laboratory tests were completed to determine optimal treatment parameters, and the planned application is described. The approach to be used at Texas Tech can be generalized for any facility, so that installations can use this information as guidance in installing, operating, and monitoring their own system.

As part of the laboratory experiments on the Texas water samples, a computer modeling program called PHREEQE was investigated. This program was useful in describing the equilibrium water chemistry. Its predictions are based on theoretical idealization; however, the processes leading to scale formation are not understood well enough to make the model's predictions perfectly accurate. Relationships between oversaturation, actual precipitation, and scale adhesion limit modeling efforts.

The carbon dioxide treatment system has been demonstrated under FEAP at three sites having especially hard waters: Fort Ord, CA, Dugway Proving Ground, UT, and Karlsruhe MCA, Germany. The results showed that the treatment system was successful at all three sites; however, it was found that much of the system's success depends on having responsible operators to monitor the water and adjust the treatment as necessary.

It is recommended that the carbon dioxide treatment system be refined for universal application at Army facilities with scale problems.

\section{METRIC CONVERSION TABLE}

$$
\begin{aligned}
1 \mathrm{in} . & =2.54 \mathrm{~cm} \\
1 \mathrm{lb} & =0.305 \mathrm{~kg} \\
1 \mathrm{cu} \mathrm{ft} & =0.028 \mathrm{~m}^{2} \\
1 \mathrm{psi} & =6.895 \mathrm{kPa} \\
1 \mathrm{gal} & =3.785 \mathrm{~L} \\
1 \mathrm{hp} & =0.75 \mathrm{~kW} \\
{ }^{\circ} \mathrm{F} & =\left({ }^{\circ} \mathrm{C} \times 1.8\right)+32
\end{aligned}
$$




\section{REFERENCES}

Chen, Y-C., K.A. Rainwater, R.H. Ramsey, and M.J. Dvoracek, Economic Potential for Development of Increasing Groundwater Storage Beneath a High Plains Municipality, Final Report (Texas Tech University Water Resources Center, 1988).

Corrosion Control by Deposition of $\mathrm{CaCO}_{3}$, Films--A Handbook of Practical Application and Instruction (American Water Works Association, 1978).

Cowan, J.C., and D.J. Weintritt, Water-Formed Scale Deposits (Gulf Publishing Co., 1976).

Lang, J.W., Water Resources of the Lubbock District (Texas State Board of Water Engineers, 1945).

Merrill, D.T., and R.L. Sanks, "Corrosion Control by Deposition of Calcium Carbonate Films: A Practical Approach to Plant Operators," Journal of the American Water Works Association (JAWWA), Vol 69, No. 1 (1978).

Parkhurst, D.L., D.C. Thorstenson, and L.N. Plummer, PHREEQE - A Computer Program for Geochemical Calculations, Water Resources Investigations Report 80-96 (U.S. Geological Survey, 1980).

Prakash, T.M., C.H. Neff, R.J. Scholze, J.T. Bandy, and E.D. Smith, Carbon Dioxide Treatment for Scale Removal and Control in Potable Water Systems, Technical Report N-87/16/ADA184346 USACERL, 1987).

Rossum, J.R., and D.T. Merrill, "An Evaluation of the Calcium Carbonate Saturation Indexes," Journal of the American Water Works Association, Vol 75, No. 2 (1983).

Stecher, L.R.S., Groundwater Management Program for Texas Tech University, M.S. Thesis (University of Texas at Austin, 1985).

Stumm, W., and J.J. Morgan, Aquatic Chemistry, 2nd ed. (John Wiley \& Sons, 1981).

Temkar, P.M., J. Harwood, and R.J. Scholze, Calcium Carbonate Scale Dissolution in Water Stabilized by Carbon Dioxide Treatment, Technical Report N-90/01/ADA218502 (USACERL, August 1989). 


\section{APPENDIX:}

\section{PARTS USED IN THE DOSAGE CONTROL PANEL}

1. Breaker Box: Cutler-Hammer 2-pole box with 15-amp single-pole breaker

2. Main Switch: Bryant part \#4902-I double-pole, single-throw switch; 15 or $20 \mathrm{amp}$

3. Reset Timer: Eagle Signal Controls Cat. \#HP-518A6 C2587

4. Momentary Switch: McGill 0093-3001

5. Minute Meter: Cramer part \#10188, type 635, rating 115/60; time range 99999.9 min

6. Minute Meter Box: Bod Radio, Inc., part \#CU-3007-A, Combination Shaper Screw Minibox

7. Contactor: Honeywell part \#R4243B 1038 120-volt coil, 30-amp contacts; switching deposit

8. Contactor Box: Honeywell part \#129703A--Enclosure for Contactors

9. Solenoid Valve: ASCO Cat. \#8262D22 1/4-in. NPT

10. Outlet: Hart-Lock, 15-amp, 125-volt, grounding 